\title{
Bottom-up drivers of global patterns of demersal, forage, and pelagic fishes
}

Petrik, Colleen M. ; Stock, Charles A.; Andersen, Ken Haste; van Denderen, P. Daniël; Watson, James

Published in:

Progress in Oceanography

Link to article, DOI:

10.1016/j.pocean.2019.102124

Publication date:

2019

Document Version

Peer reviewed version

Link back to DTU Orbit

Citation (APA):

Petrik, C. M., Stock, C. A., Andersen, K. H., van Denderen, P. D., \& Watson, J. (2019). Bottom-up drivers of global patterns of demersal, forage, and pelagic fishes. Progress in Oceanography, 176, [102124].

https://doi.org/10.1016/j.pocean.2019.102124

\section{General rights}

Copyright and moral rights for the publications made accessible in the public portal are retained by the authors and/or other copyright owners and it is a condition of accessing publications that users recognise and abide by the legal requirements associated with these rights.

- Users may download and print one copy of any publication from the public portal for the purpose of private study or research.

- You may not further distribute the material or use it for any profit-making activity or commercial gain

- You may freely distribute the URL identifying the publication in the public portal 


\section{Accepted Manuscript}

Bottom-up drivers of global patterns of demersal, forage, and pelagic fishes

Colleen M. Petrik, Charles A. Stock, Ken H. Andersen, P. Daniël van Denderen, James R. Watson

PII: S0079-6611(18)30195-2

DOI: https://doi.org/10.1016/j.pocean.2019.102124

Article Number: $\quad 102124$

Reference:

PROOCE 102124

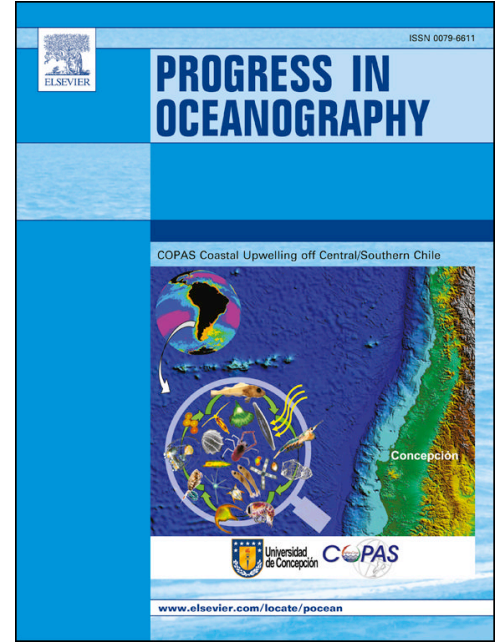

To appear in:

Progress in Oceanography

Received Date:

26 June 2018

Revised Date:

31 May 2019

Accepted Date:

14 June 2019

Please cite this article as: Petrik, C.M., Stock, C.A., Andersen, K.H., Daniël van Denderen, P., Watson, J.R., Bottomup drivers of global patterns of demersal, forage, and pelagic fishes, Progress in Oceanography (2019), doi: https:// doi.org/10.1016/j.pocean.2019.102124

This is a PDF file of an unedited manuscript that has been accepted for publication. As a service to our customers we are providing this early version of the manuscript. The manuscript will undergo copyediting, typesetting, and review of the resulting proof before it is published in its final form. Please note that during the production process errors may be discovered which could affect the content, and all legal disclaimers that apply to the journal pertain. 


\section{Bottom-up drivers of global patterns of demersal, forage, and pelagic fishes}

\section{Colleen M. Petrik ${ }^{1,{ }^{*}, \dagger}$, Charles A. Stock ${ }^{2}$, Ken H. Andersen ${ }^{3}$, P. Daniël van Denderen ${ }^{3}$, James R.} Watson 4

${ }^{1}$ Program in Atmospheric and Oceanic Sciences, Princeton University, Princeton, NJ 08540

${ }^{2}$ NOAA, Geophysical Fluid Dynamics Laboratory, Princeton, NJ 08540

${ }^{3}$ Centre for Ocean Life, DTU Aqua, Technical University of Denmark, Lyngby, Denmark

${ }^{4}$ College of Earth, Ocean and Atmospheric Sciences, Oregon State University, Corvallis, OR 97331

*contact email: cpetrik@tamu.edu

†Present address: Department of Oceanography, Texas A\&M University, MS 3146, College Station, TX 77840

KEYWORDS: allometry; ecosystem; fisheries oceanography; mechanistic model; trophodynamics

\section{ABSTRACT}

Large-scale spatial heterogeneity in fisheries production is predominantly controlled by the availability of zooplankton and benthic organisms, which have a complex relationship with primary production. To investigate how cross-ecosystem differences in these drivers determine fish assemblages and productivity, we constructed a spatially explicit mechanistic model of three fish functional types: forage, large pelagic, and demersal fishes. The model is based on allometric scaling principles, includes basic life cycle transitions, and has trophic interactions between the fishes and with their pelagic and benthic food resources. The model was applied to the global ocean, with plankton food web estimates and ocean conditions from a high-resolution earth system model. Further, a simple representation of fishing was included, and led to moderate matches with total, large pelagic, and demersal catches, including re-creation of observed variations in fish catch spanning two orders of magnitude. Our results highlight several ecologically meaningful model sensitivities. First, coexistence between forage and large pelagic fish in productive regions occurred when forage fish survival is promoted via both favorable metabolic allometry and enhanced predator avoidance in adult forage fish. Second, the prominence of demersal fish is highly sensitive to the efficiency of energy transfer to benthic invertebrates. Third, the latitudinal distribution of the total catch is modulated by the temperature dependence of metabolic rates, with increased sensitivity pushing fish biomass toward the poles. Fourth, forage fish biomass is suppressed by strong top-down controls on temperate and subpolar shelves, where mixed assemblages of large pelagic and large demersals exerted high predation rates. Last, spatial differences in the dominance of large pelagics vs. demersals is strongly related to the ratio of pelagic zooplankton production to benthic production. We discuss the potential linkages between model misfits and unresolved processes including movement, spawning phenology, seabird and marine mammal predators, and socioeconomically driven fishing pressure, which are identified as priorities for future model development. Ultimately, the model and analyses herein are intended as a baseline for a robust, mechanistic tool to understand, quantify, and predict global fish biomass and yield, now and in a future dominated by climate change and improved fishing technology.

\section{INTRODUCTION}


Fishes are an important resource economically, socially, and nutritionally (FAO 2016). For this reason, fisheries oceanographers and managers have long sought to forecast fisheries yields, often on a species- and regional stock-specific basis (Christensen et al. 2015). These efforts have received mounting attention as the growing human population increases demands on seafood and jobs (Barange et al. 2014) while climate change is projected to alter ocean productivity (Bopp et al. 2013, Laufkötter et al. 2015) and subsequent fisheries yields (e.g. Cheung et al. 2010, Blanchard et al. 2012, Lefort et al. 2015). However, the connections between ocean productivity and fisheries yields is not straightforward (Ryther 1969, Friedland et al. 2012, Stock et al. 2017) and the need to understand global fisheries extends beyond total yields. Fishes come in many shapes and sizes, with differences related to habitat, feeding preferences, and life history characteristics. These various functional types serve different roles in their ecosystems and have disparate socioeconomic value. They also rely on different energy flow pathways from phytoplankton (van Denderen et al. 2018) and are subject to varying degrees of predatory and fisheries control (Frank et al. 2005, Andersen \& Pedersen 2010).

Most of the commercially important fish species fall into three functional types: small pelagic fish (termed forage fish), large pelagic fish, and demersal fish. Forage fish live in the upper water column where they feed on plankton (Blaxter \& Hunter 1982, Cury et al. 2000, van der Lingen et al. 2006). They tend to have smaller maximum sizes and serve as prey to numerous marine predators (Blaxter \& Hunter 1982, Cury et al. 2000, Pikitch et al. 2014). Representative species include sardines and anchovies. Large pelagic fish also live in the upper water column, as well as greater depths, where they act as top predators, only feeding on plankton during their larval stages (Lehodey et al. 2008). Notable examples include tunas and billfishes. Thusly, forage fish and large pelagics are different trophic levels in the classic size-structured pelagic food chain that extends from phytoplankton to zooplankton to fish. In contrast to these pelagic fishes, demersal fishes live near the seafloor and consume benthic fauna that derive their energy from export production (Blanchard et al. 2009, Rowe \& Demming 2011). Demersal fish are generalist predators capable of feeding on pelagic animals in addition to benthic resources (Garrison \& Link 2000, Bulman et al. 2001). This functional group is exemplified by gadids and flatfishes, such as Atlantic cod and Greenland halibut.

These three fish functional types have been studied extensively and represented in numerous models from the regional to global scale with detail that ranges from species-specific behavior and life histories to maximum size as the only trait. Such models have been used to predict distributions (Lehodey et al. 2008, Maury 2010, Harfoot et al. 2014, Watson et al. 2015), estimate potential yield (Andersen \& Beyer 2015, Carozza et al. 2017), examine the effect of different fishing strategies (Andersen \& Pedersen 2010, Jennings \& Collingridge 2015, Galbraith et al. 2017), and project the impacts of climate change on fish and fisheries (Cheung et al. 2010, Blanchard et al. 2012, Barange et al. 2014, Lefort et al. 2015). There remains a need, however, to understand the dominant factors determining the global distribution and productivity of these functional types in order to predict the changing structure of fish communities and their productive capacity under global change and continued exploitation.

It was our objective to elucidate the bottom-up drivers of the global patterns of forage, large pelagic, and demersal fish production and catches. To do so, we constructed a mechanistic model based on allometric rate scaling principles that resolves trade-offs and interactions between these three key functional types. Specifically, it simulates the competitive and predatory trophic interactions between the fishes and with their pelagic and benthic food resources and replicates fundamental aspects of fish life cycles. The model builds off of size spectrum models 
(e.g. Benoit \& Rochet 2004, Andersen \& Pedersen 2010, Blanchard et al. 2009, 2012, Hartvig et al. 2011, Jennings \& Collingridge 2015), and uses allometric relationships to describe physiological rates. It differs by distinctly representing functional groups through variations in habitat, maximum size, and feeding preferences. Also, in contrast to many size spectrum models, our model is spatially explicit, and mechanistically connected to lower trophic levels without relying on assumptions about trophic transfer efficiency. We coupled this model to a highresolution global earth system model that resolves plankton trophodynamics (Stock et al. 2014, 2017) to mechanistically explore drivers underlying the coexistence, distribution, and biomass productivity of these critical fish functional types across ecosystems in the contemporary ocean.

\section{METHODS}

To aid recognizability, we have named this new model the FishErIes Size and functional TYpe model (FEISTY). FEISTY is a size- and trait-based model of higher trophic level dynamics. For the analysis herein, FEISTY was forced with physical and plankton food web dynamics provided by GFDL's ESM2.6 high-resolution earth system model (Delworth et al. 2012, Dunne et al. 2012, 2013, Stock et al. 2017). In the methods below, we first briefly describe the physical and plankton forcing, followed by a detailed description of FEISTY and its integration with ESM2.6.

\subsection{Physical and Plankton Food Web Drivers}

Outputs from GFDL's ESM2.6 high-resolution Earth System Model were used to provide physical and plankton food web forcing for FEISTY. ESM2.6 was constructed by integrating carbon and plankton food web dynamics from GFDL's Carbon, Ocean Biogeochemistry and Lower Trophics (COBALT) ecosystem model (Stock et al. 2014) with a high resolution physical climate simulation (Delworth et al. 2012). The horizontal resolution is $10-\mathrm{km}$ in the ocean submodel and $50-\mathrm{km}$ in the atmospheric submodel. The ocean has 50 vertical layers, with $10-\mathrm{m}$ vertical resolution over the top $200 \mathrm{~m}$ and a minimum depth of $40 \mathrm{~m}$ (i.e., all locations $<40 \mathrm{~m}$ are treated as if they are $40 \mathrm{~m}$ deep).

COBALT uses 33 state variables to resolve global-scale cycles of nitrogen, carbon, phosphate, silicate, iron, calcium carbonate, oxygen, and lithogenic material (Stock et al. 2014). The representation of planktonic food web dynamics within COBALT includes bacteria, diazotrophs, small and large phytoplankton, and three zooplankton groups that feed on phytoplankton, bacteria, and each other according to mean predator to prey size ratios (Hansen et al. 1994). The small zooplankton group represents microzooplankton that are $<200 \mu \mathrm{m}$ in equivalent spherical diameter (ESD). The medium zooplankton are parameterized as small- to medium-bodied copepods (0.2-2.0 mm ESD), and the large zooplankton are parameterized as large copepods/krill (2.0-20 mm ESD). The combined pool of medium and large zooplankton comprise what are commonly referred to as "mesozooplankton" (Sieburth et al. 1978). The parameterization of trophic interactions relies primarily on allometric and bioenergetic relationships, and the model was calibrated to ensure quantitative consistency with large-scale planktonic food web dynamics, including patterns in primary and zooplankton production (Stock et al. 2014). Within ESM2.6, COBALT was furthermore able to robustly capture differences in chlorophyll, primary production, medium and large zooplankton biomass, and export fluxes across globally-distributed, mostly coastal "large marine ecosystems" (LMEs), with the exception of inland seas (Stock et al. 2017). The primary shortcomings of ESM2.6-COBALT are (i) it under-predicts very high chlorophyll $\left(>5 \mathrm{mg} \mathrm{m}^{-3}\right)$ inferred from satellites in nearshore 
regions $(<25 \mathrm{~m})$ and (ii) the fully coupled atmosphere-ocean configuration is more susceptible to regional biases and drifts in biome boundaries relative to ocean simulations forced by atmospheric reanalysis. Chlorophyll mismatches in nearshore regions may arise partially from satellite estimate errors linked to the complex optical properties of these waters (Schofield et al. 2004, Dierssen 2010), but likely also reflect ESM2.6 limitations in nearshore regions such as the $40 \mathrm{~m}$ minimum depth.

The fully coupled ESM2.6-COBALT was run with 1990 greenhouse gas conditions and the relatively coarse representation of the plankton food web (van Oostende et al., 2018) for 55 years to reach equilibrium conditions for the upper ocean processes that exert dominant controls on ocean productivity (Stock et al. 2017). The run was initialized with hydrography from year 141 of a 1990 control with the CM2.6 physical climate model and nutrients from the World Ocean Atlas (Garcia et al. 2006), dissolved organic carbon from GLODAP (Key et al. 2004), and other fields from a coarse-resolution COBALT simulation (Stock et al. 2014). We use a monthly climatology formed from the last 5 years of the coupled ESM2.6-COBALT run as an estimate of contemporary cross-ecosystem energy flows from plankton to fish, noting that these estimates were highly similar across differing 5, 10, and 20 year segments (Stock et al. 2017). This climatology was interpolated to a daily timescale and a coarser horizontal resolution grid of $1^{\circ}$ latitude/longitude to force FEISTY. For all FEISTY simulations, the monthly climatology was repeated for a total of 150 years to ensure equilibrium conditions were met. After reaching equilibrium, there is little interannual variability due to the repeated forcing of a 5-year climatology and the large differences between the ecosystems analyzed herein are generally much greater than interannual differences between those systems. Our results present the final year of this simulation, though any year or set of years from the last 20 would produce similar results.

COBALT is linked to FEISTY in an "offline" fashion. That is, COBALT outputs drive the fish model, but there are no feedbacks of the fish on the plankton. All COBALT biomasses and fluxes were converted from moles of nitrogen (molN) to grams wet weight ( $\mathrm{gWW}$ ) assuming Redfield (1934) stoichiometry and the constant wet weight to carbon ratio of 9:1 (Pauly \& Christensen 1995). From here on, all biomasses will be expressed as wet weight (i.e. g signifies $\mathrm{gWW}$ ). The specific COBALT outputs that drive the fish model are: medium and large zooplankton biomass integrated over the top $100 \mathrm{~m}, m d z$ and $\lg z\left(\mathrm{~g} \mathrm{~m}^{-2}\right)$, the mortality rate of medium and large zooplankton, which sets an upper bound for material consumed by fish, also integrated over the top $100 \mathrm{~m}$, loss_mdz and loss_lgz $\left(\mathrm{g} \mathrm{m}_{-}-2 \mathrm{~d}^{-1}\right)$, the flux of detrital matter to the ocean bottom, det_btm $\left(\mathrm{g} \mathrm{m}^{-2} \mathrm{~d}^{-1}\right)$, the mean temperature in the upper $100 \mathrm{~m}, T_{p}\left({ }^{\circ} \mathrm{C}\right)$, and the bottom temperature, $T_{b}\left({ }^{\circ} \mathrm{C}\right)$. The annual mean values of these forcings are provided in the Supplementary material (Supp. Table S1) for reference. A detailed assessment of ESM2.6 skill at the ocean-biome and across Large Marine Ecosystem (LME) is provided by Stock et al. (2017).

\subsection{FEISTY - A Global Fisheries Model}

\subsubsection{Fishes}

Fishes in FEISTY are defined by their functional type, size, and maturity stage (Figure 1). There are three fish functional types represented in the model: forage fish (F), large pelagic fish (P), and demersal fish (D). Forage fish are planktivores and have a smaller maximum size compared to the large pelagic and demersal types. Adult large pelagics and demersals are piscivores, but prey depends on life stage and habitat. Both the forage fish and large pelagics are 
fully pelagic, living their entire lives in the upper $100 \mathrm{~m}$ represented by the model. The demersal fish begin their lives as pelagic larvae, then transition to the benthic habitat as juveniles. The adults are fully benthic in areas where the water column is $>200 \mathrm{~m}$, while in shallower areas they may feed both on the benthos and in the pelagic water column. Our representation of demersals is largely based on the life history strategies of gadids and pleuronectids where early life stages are pelagic, the late juvenile stage is the most bottom-oriented, often relying on specific benthic habitat for shelter or food, and adults of increasing maturity inhabit more of the water column and their feeding becomes opportunistic.

The biological rates in the model are based on allometry using the mass, $w(\mathrm{~g})$, of each size class. Fish size classes are defined using logarithmic size bins appropriate for the life history stage it represents by holding $Z$, the ratio of initial and final body sizes of each size-class, constant across all stages. The small fish size class (S) is $1-500 \mathrm{mg}$ (geometric mean $20 \mathrm{mg}$ ), which is equivalent to $4.6-36.8 \mathrm{~mm}$ in length (geometric mean $13 \mathrm{~mm}$ ) and encompasses the large zooplankton size range. The medium fish size class (M) represents fishes $0.5-250 \mathrm{~g}$ (geometric mean $11.2 \mathrm{~g}, 10.4 \mathrm{~cm}$ ) and the large fish size class (L) represents $0.25-125 \mathrm{~kg}$ (geometric mean $5.6 \mathrm{~kg}, 0.82 \mathrm{~m}$ ). These lengths were calculated from the weights using the length-weight relationship of Andersen and Beyer (2015). The small size class of the forage fish (SF) is an immature stage of both larvae and juveniles, and the medium size class is the mature adult stage (MF). For large pelagic and demersal fish, the small size class is representative of the larvae (SP, SD), the medium the juveniles (MP, MD), and the large the adults (LP, LD). The number of groups ( 2 for small, early maturing fish and 3 for large, late maturing fishes) was chosen a priori. FishBase was consulted via the R package "rfishbase" (Boettiger et al. 2012) to determine the mean lengths ("TL") and weights ("Weight") of fishes by the "Order" and "DemersPelag" categories to ensure that the geometric mean sizes represented typical forage and large pelagic fishes. While these size bins and functional types are coarse, they allow us to capture the basic contrasts and life cycle stages for the functional types of interest herein in a numerically efficient way tractable for long, global simulations. The structure is also intended as a framework that can be expanded to other functional types or refined for a specific species as needed.

The general form of the mass-conserving model is derived from the stage-structured formulation of De Roos et al. (2008), which approximates a continuously size-based formulation into a few stages. The central assumption is that the ratio of mortality to growth rate is independent of body size within a life stage, such as is when both growth and mortality scale with mass, e.g., as mass raised to the power 0.75 and -0.25 respectively. This assumption is inspired by a full size-structured model where growth and mortality does indeed scale allometrically at steady state (Andersen \& Beyer 2006). In FEISTY, and other dynamic sizestructured models (Hartvig et al. 2011), growth and mortality will vary between life stages because they are emergent results of both metabolic factors and dynamic changes in prey and predators. In this case the formulation is not exact, but a useful numerical approximation that has been used successfully for similar applications (e.g. Van Leeuwen et al. 2008).

Each functional type is modeled as a collection of size-classes, with smaller classes growing into larger size classes. The fish biomass density in size and stage class $i\left(B_{i}, \mathrm{~g} \mathrm{~m}^{-2}\right)$ evolves with time $(t, \mathrm{~d})$ as:

$$
\frac{d B_{i}}{d t}=B_{i} \cdot\left(v_{i}-\rho_{i}-\gamma_{i}-\mu_{n a t}\right)+R_{i}-\psi_{i}-H_{i}
$$

where ?? $\left(\mathrm{d}^{-1}\right)$ is the biomass-specific rate of energy assimilation available for growth and reproduction (i.e., total assimilation minus catabolic respiration), ?? $\left(\mathrm{d}^{-1}\right)$ is the biomass-specific 
rate of energy used for reproduction, ?? $\left(\mathrm{d}^{-1}\right)$ is the biomass-specific rate of energy used for somatic growth to the next size class, and $\mu_{\text {nat }}\left(\mathrm{d}^{-1}\right)$ is the biomass-specific natural mortality rate (Table 1). The biomass recruiting from the size class below or, in the case of the larvae, via reproduction, is given by $R_{i}$. The biomass lost to predation by larger size classes $\left(\psi, \mathrm{g} \mathrm{m}^{-2} \mathrm{~d}^{-1}\right)$ arises through the modeled consumption, and $H\left(\mathrm{~g} \mathrm{~m}^{-2} \mathrm{~d}^{-1}\right)$ is the biomass lost to fishing harvest. The parameterization of each of these terms is described in the subsections that follow.

Benthic invertebrates, which consist of a pool with no explicit size that derives energy from the detrital flux to the sea floor, are modeled separately from the fish functional types. The invertebrate biomass density $\left(B_{I} ; \mathrm{g} \mathrm{m}^{-2}\right)$ over time is

$$
\frac{d B_{I}}{d t}=\beta \cdot d e t_{-} b t m-\psi_{I},
$$

where $\beta$ represents the transfer efficiency from detritus to benthic invertebrates and $\psi_{I}$ is the predation losses $\left(\mathrm{g} \mathrm{m}^{-2} \mathrm{~d}^{-1}\right)$ via consumption by the demersal medium and large size classes. The parameter $\beta$ reflects both the respiration costs of the benthic invertebrates and the fraction of the detrital flux that is buried or remineralized directly by bacteria. The value of $\beta$ was parameterized such that the global distribution of benthic invertebrates closely resembled the megafauna estimates of Wei et al. (2010) and the trophic level of large demersal fish was $>3$ in coastal regions.

Spatially, FEISTY is comprised of a set of discretized ordinary differential equations representing a demographic system at each spatial grid cell, being forced offline by vertically integrated temperature, vertically integrated zooplankton biomass concentrations and mortality losses, and bottom temperature and detrital fluxes. To step the model forward in time we used a simple forward-Euler scheme, integrated with a daily time step. Without the inclusion of fish movement, the forward-Euler scheme is stable at these temporal scales and the spatial scales of the global model grid.

\subsubsection{Consumption and Predation}

Predation is the consequence of consumption following encounter. The biomass-specific encounter rate, $E_{i, j}\left(\mathrm{~d}^{-1}\right)$, between predator $i$ and prey type $j$ is a temperature-dependent function of prey biomass, $Y_{j}\left(\mathrm{~g} \mathrm{~m}^{-2}\right)$, prey preference, $\theta_{j}$, and fish weight,

$$
E_{i, j}=\theta_{j} \cdot Y_{j} \cdot A_{i}
$$

where $A_{i}$ is the mass-specific search rate $\left(\mathrm{m}^{2} \mathrm{~g}^{-1} \mathrm{~d}^{-1}\right)$ :

$$
A_{i}=\exp \left(k \cdot\left(T-T_{0}\right)\right) \cdot a_{E} \cdot w_{i}^{b_{E}}
$$

where $T_{0}$ is $10^{\circ} \mathrm{C}$ (See section 2.2.5 on temperature-dependence). Mass-specific consumption of prey biomass, $I\left(\mathrm{~d}^{-1}\right)$, is calculated using a multi-prey Type II feeding function:

$$
I_{i}=\sum_{j \in J} \frac{C_{i} \cdot E_{i, j}}{C_{i}+\sum_{j}^{J} E_{i, j}},
$$

where we use the index $j$ for prey in the diet set $J$, which depends on the predator (see below). The mass-specific maximum consumption rate, $C\left(\mathrm{~d}^{-1}\right)$, is:

$$
C_{i}=\exp \left(k \cdot\left(T-T_{0}\right)\right) \cdot a_{C} \cdot w_{i}^{b_{C}},
$$

where $k$ governs temperature sensitivity and $b_{C}$ is an allometric scaling constant determining body-size dependence. Following this, the predation rate of a given functional type in size class $i$, $\psi_{i}\left(\mathrm{~g} \mathrm{~m}^{-2} \mathrm{~d}^{-1}\right)$,

$$
\psi_{i}=\sum_{n \in i+1} I_{i, n} \cdot B_{n},
$$

is the sum of consumption by the predators of the next size class up $(n \in i+1)$. 
The diet set $J$ varies amongst the groups as previously described and shown in Figure 1, with a full prey preference matrix given in Table 2 . In the basic model formulation, all of the linkages between fish in Figure 1 are assumed to have equal preferences/prey availability $(\theta=1)$. We explore the necessity of additional prey avoidance and predator specialization for coexistence of fish functional types in a series of experiments (Section 2.3). To support this, we allow the medium-size fish to consume the medium zooplankton, though two size classes removed from them, at a lesser preference, $\theta_{S}$. We explore the implication of enhanced predator avoidance by adult forage fish relative to the juvenile stages of larger fish by reducing their availability to large predators, $\theta_{A}$. Lastly, $\theta_{D}$ diminishes the feeding effectiveness of demersal generalists feeding on pelagic prey relative to pelagic specialists.

FEISTY is coupled with the zooplankton fields from COBALT in a manner that ensures fish cannot consume more energy than zooplankton can provide. COBALT creates large-scale patterns in medium and large zooplankton productivity that are consistent with observed patterns (Stock et al. 2014). This sets an upper bound for fish consumption, but zooplankton production can also be lost to natural mortality, unresolved cannibalism within zooplankton groups, or predators not resolved by our model (e.g., gelatinous zooplankton, marine mammals). If the consumption calculated by FEISTY is less than available zooplankton production from COBALT, the excess energy is presumed lost to these other pathways. If the calculated fish model feeding rates are greater than available zooplankton production, we reduce feeding rates proportionally so that energy is conserved.

\subsubsection{Growth and Reproduction}

The total biomass-specific energy available for growth or reproduction (production rate) for a given size-class $i$ is:

$$
v_{i}=\alpha \cdot I_{i}-M_{i}
$$

where ?? is the food assimilation efficiency and $M$ is biomass-specific basal metabolic costs $\left(\mathrm{d}^{-}\right.$ 1). Basal metabolic costs are

$$
M_{i}=\exp \left(k_{M} \cdot\left(T-T_{0}\right)\right) \cdot a_{M} \cdot w_{i}^{b_{M}},
$$

where $k_{M}$ governs temperature sensitivity and $b_{M}$ dictates size-dependence. Following De Roos et al. (2008), the growth to the next size class (maturation rate) is:

$$
\gamma_{i}=\frac{\kappa_{i} \cdot v_{i}-\mu_{\text {toti }}}{1-z^{\left(1-\mu_{\text {toti }} /\left(\kappa_{i} \cdot v_{i}\right)\right)}}
$$

where $\mu_{\text {toti }}$ is the total mortality rate of fish class $i\left(\mathrm{~d}^{-1}\right)$, which is the sum of the natural mortality rate, the predation rate, and the fishing mortality rate, all expressed as biomass-specific rates:

$$
u_{\text {toti }}=u_{n a t}+\frac{\psi_{i}}{B_{i}}+f_{i}
$$

and where $z_{i}$ is the ratio of the initial to the final body size that a particular life stage encompasses. Thus, $z_{i}$ reflects the size range that an individual has to grow through before maturing to the next size class. ?? ${ }_{i}$ is a unit-less parameter that controls the fraction of ?? ${ }_{i}$ used for somatic growth, hence $1-? ?_{i}$ is the energy invested in the production of eggs for each sizeclass $i$. Each functional type only has one size class with mature individuals. In the immature size classes $100 \%$ of energy is allocated to growth $(? ?=1)$. Since the mature size class spans a range of sizes, we assume that it represents both adults that have reached their maximum size and those that are still growing. For this mature group, energy is split 50\% towards reproduction and $50 \%$ towards growth $(? ?=0.5)$. The energy available for reproduction is:

$$
\rho_{i}=v_{i} \cdot\left(1-\kappa_{i}\right) \text {. }
$$


Since there is no larger size class for the adults to mature to, the available energy, ??, determining the flux out of the size class is instead available for reproduction. Biomass in the smallest size classes is produced from reproduction with an efficiency, $\varepsilon$, that accounts for egg mortality and other processes that reduce the number of larvae from the mass-specific fecundity of mature females (e.g. sex ratios). The biomass recruiting to the smallest size class $(i=1)$ or the next size class up $(i>1)$ is

$$
R_{i}= \begin{cases}\varepsilon \cdot\left(\rho_{A}+\gamma_{A}\right) \cdot B_{A}, & i=1 \\ \gamma_{i} B_{i-1}, & i>1\end{cases}
$$

where the subscript $A$ denotes an adult stage (MF, LP, or LD).

\subsubsection{Non-predation Mortality}

Natural mortality, ?? nat $\left(\mathrm{d}^{-1}\right)$, from sources other than piscivory (e.g. disease, zooplankton, birds, marine mammals) is treated as a constant equivalent to $0.1 \mathrm{y}^{-1}$. In addition, mortality from fishing harvest is simulated by applying a constant fishing mortality rate, $f\left(\mathrm{~d}^{-1}\right)$,

$$
H_{i}=f_{i} \cdot B_{i} \text {. }
$$

\subsubsection{Temperature-dependence of model rates}

A broad range of temperature relationships have been reported for marine teleost fishes, but most estimates cluster around a doubling in biological rates for each $10^{\circ} \mathrm{C}$ temperature increase $\left(\mathrm{Q}_{10}\right)$. A meta-analysis of resting metabolism by Clarke and Johnston (1999) found within-species $\mathrm{Q}_{10}$ values that ranged from 0.45 to 3.41, with a median of 2.40, whereas their cross-species analysis resulted in a $\mathrm{Q}_{10}$ of 1.83. As a starting point, a $\mathrm{Q}_{10}$ of 1.88 from Eppley (1972) and the COBALT plankton biological rates (Stock et al. 2014) was adopted. We assumed that encounter and consumption rates followed the lower temperature-sensitivity of anabolism (Perrin 1995), here represented with a $Q_{10}$ of 1.88 .

The temperature, $T$, used to calculate rates varies by fish functional type and feeding behavior. For pelagic stages $T=T_{p}$ and for benthic stages $T=T_{b}$. For demersal adults in coastal areas, the temperature depends on the estimated fraction of time spent in the pelagic, $\lambda$, and demersal zones $(1-\lambda)$. While the adult demersals do not explicitly split their time between environments, the temperature weighting is proportional to the biomass of prey (medium size fish and benthos) in both areas,

$$
\lambda=\frac{B_{M F}+B_{M P}}{B_{M F}+B_{M P}+B_{M D}+B_{\text {Bent }}} .
$$

The effective temperature for adult demersals in then calculated as

$$
T=T_{p} \cdot \lambda+T_{b}(1-\lambda) \text {. }
$$

\subsection{Parameter sensitivity and conditions for the coexistence of functional types}

Our initial simulations used uniform prey availability/preference for all the predator-prey linkages shown in Figure $1(\theta=1)$ and the most commonly employed biological rate allometric relationships $\left(b_{C}, b_{E}, b_{M}\right)$. We use a perturbation analysis to understand the basic sensitivities in the patterns of fish biomass distributions and to devise a pragmatic strategy for tuning at the global scale (Appendix), leading to the parameter values in Table 1. The sensitivity analysis perturbed parameters by $\pm 10 \%$ from those most commonly employed in the literature (Table A1). Parameter sensitivity was calculated as the difference in $\log _{10}$-transformed mean biomass of the perturbation, Pert, from the base level, Base, 


$$
S_{n}=\log _{10}\left(\overline{\text { Pert }_{n}}\right)-\log _{10}\left(\overline{\text { Base }_{n}}\right) \text {, }
$$

where $n$ denotes the response variable. The logarithmic transformation was used to ensure similar weighting of changes across orders of magnitude. Five different perturbation response metrics were chosen: forage fish biomass, large pelagic fish biomass, demersal fish biomass, low latitude biomass (latitudes $<30^{\circ} \mathrm{N}$ or S), and high latitude biomass $\left(>30^{\circ} \mathrm{N}\right.$ or S). The total magnitude of all response metrics (Mag) was calculated as the square root of the sum of all five squared (i.e., the L2 norm of the response vector). Responses of parameter changes were clustered using the "hclust" routine in RStudio v1.0.143.

Considered together, these response metrics provide a broad yet concise perspective on how perturbations to each parameter can affect the global distribution and prominence of each functional type, as well as the total biomass. This perspective is central to the objective of understanding the dominant factors determining the global distribution and productivity of these functional types. While a complete optimization across all parameters is not possible in a 3D global context, the perturbation analysis provides a transparent means of optimizing over a limited number of key controls to obtain reasonable agreement with observations. The details of this calibration are discussed in Section 3.2 and further details are provided in the Appendix. We acknowledge that there may be other pathways to similar skill, but a complete exploration of these pathways falls outside the scope of paper.

\subsection{Generalized additive model of functional type dominance}

Generalized additive modeling (GAM) of fisheries landings data (Watson 2017) binned by ecoregion found that the fraction of large pelagic fish out of total large pelagic and demersal fishes could best be estimated by the ratio of pelagic resources to benthic resources (van Denderen et al. 2018). We similarly estimated GAMs to compare the results of FEISTY to these findings, and to isolate the dominant environmental drivers of functional type dominance. Three different response variables were estimated: (i) the fraction of large pelagics out of all fishes with large adults $(\mathrm{P} /(\mathrm{P}+\mathrm{D}))$, (ii) the fraction of large pelagics out of all pelagic-inhabiting fishes $(\mathrm{P} /(\mathrm{P}+\mathrm{F}))$, and (iii) the fraction of large fishes out of all large and medium fishes ((LP+LD)/ $(\mathrm{LP}+\mathrm{LD}+\mathrm{MP}+\mathrm{MD}+\mathrm{MF}))$. For each of these fractions, the same four regressors were examined in isolation as drivers: $\log _{10}$-transformed net primary production (NPP, $\left.\mathrm{mg} \mathrm{C} \mathrm{m}^{-2} \mathrm{~d}^{-1}\right), \log _{10^{-}}$ transformed ratio of zooplankton production lost to higher predation to detritus flux to the seafloor (Zloss:Det), upper water column $(0-100 \mathrm{~m})$ temperature $\left(\mathrm{PelT},{ }^{\circ} \mathrm{C}\right)$, and the proportion of the LME that was continental shelf, as expressed as the fraction of the area $<200 \mathrm{~m}$ (Frac $<200 \mathrm{~m})$. GAM is a nonlinear extension of multiple linear regression that represents the dependence of a single response variable on a set of regressors, each through a smooth function, that interact additively with the response (Hastie \& Tibshirani 1990). Our analysis was completed with the "betareg" package (Cribari-Neto \& Zeileis 2010) in RStudio v1.0.143 using a beta distribution (suitable for proportional data) with a probit link function and splines with a maximum of 3 knots as the smoothing function.

\subsection{Comparison with historical fish catches}

The assessment of the realism of the simulated global distribution of fish functional types in FEISTY is based, by necessity, on reconstructed fish catch (Pauly \& Zeller 2015). With our objective of understanding the bottom-drivers of spatial catch patterns that often vary by orders 
of magnitude, the fishing parameterization in FEISTY was kept as simple as possible. Fishing was implemented with a constant fishing mortality rate in space and time. Fisheries mainly targeted adult fishes (MF, LP, and LD) under the implicit assumption that fisheries adjust their gear to target those fishes. Juvenile fishes in the medium size class (MP and MD) experienced a fishing mortality of $10 \%$ of the fishing rate to represent bycatch and reduced selection by fishing gear. We used a fishing mortality rate that would result in approximately maximum sustainable yield across all three functional types, $0.3 \mathrm{yr}^{-1}$ (Andersen \& Beyer 2015).

Fishery-independent observations and estimates of fish abundance are very sparse. Though our analysis focuses on bottom-up effects, we must rely on fisheries catch data for model validation because they have the most global coverage. We use a global catch reconstruction from the Sea Around Us (SAU) project that incorporates estimates of industrial fisheries, smallscale fisheries, and discards (Pauly \& Zeller 2015). We compared SAU catches to those simulated by the model at the spatial level of large marine ecosystems (LMEs). LMEs are "relatively large regions on the order of $200,000 \mathrm{~km}^{2}$ or greater, characterized by distinct: (1) bathymetry, (2) hydrography, (3) productivity, and (4) trophically dependent populations" (www.lme.noaa.gov/Portal/). These LMEs primarily cover coastal ecosystems and inland seas ( $22 \%$ of the ocean area), but account for $>95 \%$ of fish catch in the SAU reconstruction. Following the results of Stock et al. (2017), we removed 21 of the 66 LMEs that were identified as low-effort, low-catch (LELC) outliers. These included the oligotrophic insular Pacific/Hawaiian LME, most polar LMEs where ice and severe weather tend to restrict effort, and Australian LMEs where conservative regulations limit catch (Flood et al. 2014, AFMA 2015, Mcowen et al. 2015). The remaining 45 LMEs accounted for $93.4 \%$ of the total catch in all 66 LMEs.

For each of these 45 LMEs, we compared total catch and catch by functional type. There are 24 groups of fishes in the SAU database, defined by size and functional type (Table 3; Palomares et al. 2015). We mapped these onto the two sizes and three functional types that were harvested in the model: F (MF), P (MP and LP), and D (MD and LD; Table 3). In most instances, a SAU category was $100 \%$ representative of a FEISTY fish type. The two exceptions were sharks, which can be either pelagic or demersal. Similar to the weighting scheme of Friedland et al. (2012), we split these two groups, Small to Medium Sharks $(<90 \mathrm{~cm})$ and Large Sharks $(\geq 90 \mathrm{~cm})$, evenly into $50 \%$ pelagic and $50 \%$ demersal.

Catches by LME and fish group were obtained for the years 1950-2010. For each LME, we reduced the catch dataset to the years with the top 10 annual total catches (c.f. Cheung et al. 2008, Stock et al. 2017). These 10 years were used to calculate the mean catch of all fishes and by type for comparing to model results. The top 10 years are assumed to approximate maximum fish catch potential in heavily fished LMEs, and hence likely reflect constraints from bottom-up ocean productivity. Further, 10 years was chosen so that the time period short enough to exclude long time periods before industrialized fishing. Two different metrics were used for comparing the $\log _{10}$-transformed annual catches $\left(\mathrm{MT} \mathrm{km}^{-2} \mathrm{y}^{-1}\right)$ by LME: the correlation coefficient (r) and root mean square error (RMSE).

\section{RESULTS}

\subsection{Controls on the distribution and coexistence of fish functional types}


Predator-prey and metabolic relationships based on standard weight and temperature scaling relationships did not allow for coexistence of forage fish and large pelagic fish, with large pelagics easily outpacing forage fish (Figure 2A). The parameter perturbation analysis revealed diverse ways of modulating the relative abundance of different functional types and their latitudinal distribution (Figure 3). Since the primary bias of model simulations with literature parameter values was too few forage fish, Figure 3 shows the responses associated with parameter shift directions that result in a positive change in forage fish biomass (noting that the opposite change is generally anticorrelated and thus not shown). Furthermore, to focus analysis on those parameters exerting significant controls on the fisheries patterns the model is intended to simulate, we have limited the parameters shown in Figure 3 to those producing a total response magnitude (Mag) beyond the first quartile of the distribution of total response magnitudes of all parameters. The primary subdivisions occur between those parameters exerting large control on the forage fish biomass (top cluster in Figure 3 with blue and purple lines of the dendrogram), moderate control (bottom cluster in Figure 3 with red and brown lines of the dendrogram), and those that do not (middle cluster in Figure 3 with greens lines of the dendrogram). Within the top "large forage fish control" and bottom "moderate forage fish control" clusters, there are smaller subdivisions by the effects on other groups.

The top cluster suggests several options to address the extreme scarcity of forage fish in our initial simulation. Two of the 3 parameters producing the largest forage fish increases controlled the size-dependence of biological rates (Figure 3). Either i) decreasing the weight sensitivity of metabolism (less negative $b_{M}$ ) such that the metabolic penalty for being smaller was not as great; or ii) increasing the weight sensitivity of the encounter rate (more negative $b_{E}$ ) such that the biomass-specific encounter rate advantage of being small was greater, led to marked increases in forage fish biomass. This sensitivity of forage versus large-pelagic dominance to metabolic scalings with size is consistent with the findings of De Roos et al. (2003). However, shifting $b_{M}$ within the observed range while maintaining other constraints failed to upend the dominance of large pelagic fish in all but a few oligotrophic systems (Figure 2B). Forage fish only became prevalent when more advantageous metabolic scalings were combined with the parameter exhibiting the greatest single impact on forage fish abundance: enhanced predator avoidance by adult forage fish relative to juvenile large fishes sharing the same medium size class (Figure $3 ; \theta_{A}$ ). Changing $\theta_{A}$ from 1 to 0.5 produced robust coexistence in highly productive regions, with truncated food webs dominated by forage fish in lower productivity subtropical gyres (Figure $2 \mathrm{C}$ ). While the perturbation analysis suggests that the additive effects of many perturbation across other parameters may be able to produce similar modulations in prominence, it is notable that this would require numerous shifts of parameters to the extreme ends of their uncertainty ranges.

Several perturbations in the top "large forage fish control" cluster also exhibit secondary demersal responses. In contrast, the benthic efficiency $(\beta)$ exerts a relatively strong and targeted effect on demersal biomass. Assuming a low benthic efficiency $(\beta=0.025)$ produced benthic invertebrate biomasses (Supp Figure S1) much lower than the empirical estimates of Wei et al. (2010) at high latitudes and generally resulted in the dominance of large pelagic fish over demersals in most non-polar latitudes (Figure 4A). This imbalance, particularly in the North Pacific, could be remedied with a moderate increase in $\beta$ (e.g., Figure 4C). Greater increases in $\beta$ could produce demersal-dominant catches in many ecosystems (e.g., Figure 4E) and start to approach the high latitude benthic biomass estimates of Wei et al. (2010), but create values far above these estimates in subtropical gyres (Supp Figure S1). 
The capacity to modulate the relative prominence of low versus high latitude fish biomass is generally limited relative to the capacity to modulate functional types (Figure 3). When focusing on those parameters producing the largest relative change between low and high latitude systems (e.g., increase low latitude biomass and decrease high latitude biomass), the most effective parameters are the assimilation efficiency $(\alpha)$ and the intercepts of the maximum consumption and metabolism allometric relationships $\left(a_{C}\right.$ and $\left.a_{M}\right)$. In all these cases, parameter perturbations that decrease the energy available for growth (decreasing assimilation or maximum consumption by $10 \%$, increasing metabolic costs by $10 \%$ ) have a disproportionately negative impact in lower latitudes where energetic constraints are generally tighter. This response, however, is often secondary to others for these variables.

The next three most effective parameters at modulating the latitudinal distribution of fish are the temperature dependence coefficients of the metabolic, maximum consumption, and encounter rates, respectively $\left(k_{M}, k_{C}\right.$, and $\left.k_{E}\right)$. While their effect may seem subtle in Figure 3, modulation of these temperature sensitivities over the full range of uncertainty can lead to marked changes in the global fish distribution. For example, increasing the temperaturedependence of $k_{M}$ to the high end of its uncertainty leads to a marked reduction in low latitude fish biomass (Figure 5) because of warm water respiration increases. This effect is particularly strong in oligotrophic subtropical gyres where energy surpluses are particularly small. In contrast, the biomass in cooler, high latitude systems is enhanced. It is also notable that, unlike $\alpha, a_{C}$, and $a_{M}$, the temperature coefficients have relatively small responses of the functional type biomasses, thus providing a relatively efficient way to modulate the latitudinal distribution without strongly impacting other quantities.

\subsection{Comparison against global catch patterns}

We used the sensitivities described in Section 3.1 to calibrate the model to best match observed total catch and catch by functional type (see Appendix). As described above in Section 3.1, there are undoubtedly multiple parameterization that lead to fish functional type and latitudinal distributions that are consistent with catch data. The sensitivities highlighted suggest several common characteristics: i) favorable metabolic allometry for forage fish and an enhanced capacity to avoid predation relative to the juvenile stages of larger fish (Figure 2C), ii) a relatively high benthic transfer efficiency to favor demersals in LMEs with high benthic fluxes (Figure 4C), and iii) a relatively strong temperature dependence of metabolic costs to shift the highest catches toward high latitudes (Figure 5B). As discussed in Section 2, a full optimization over all parameters is computationally infeasible for global simulations. The parameter combination is thus not expected to be a global optima, nor does it preclude other simulations producing similar fits. Rather, it is a pragmatic, transparent tuning of dominant constraints on the key quantities the model is attempting to match.

On the LME scale, the resulting agreement between annual catches in the model simulation and the Sea Around Us Project catch reconstructions was generally moderate, with Pearson $r$ values $\geq 0.54$ when comparing large pelagic fish, demersals, and all fishes combined (Figure 6B,C,D, Table 4). With its globally uniform fishing rate, FEISTY tended to capture the highest forage fish catch systems, but systematically overestimated forage fish catches in a number of LMEs with very low catches (Figure 6A). There were no large outliers when comparing the demersal catches, but model underestimates occurred in colder LMEs (Figure 6C). In addition to examining catches of each functional type, we also compared the fraction of 
the simulated catch that was large pelagic fish rather than demersal fish. The model's skill in recreating variations in this fraction was statistically significant, but ultimately limited $(\mathrm{r}=0.33$; Table 4; Supp Figure S2).

While there are clearly discrepancies between modeled and reconstructed catch, the model's skill in matching observed catch levels is generally moderate and all skill metrics should be viewed with the knowledge that catch is an imperfect measure of species distribution (see Sections 2.4 and 4.1) and the simulated catch arises from a very simple fishing model. We thus continue in Section 3.3 with an analysis of the drivers of the modeled distribution. Extensive evaluation of the discrepancies will be provided in the Discussion (Section 4).

\subsection{Global distribution of fish functional types}

The biomass distribution of both types of fishes inhabiting the pelagic environment are similar in that they are greatest in the tropics and temperate regions, with lows in the subtropical gyres and lowest values in polar areas (Figure 7A,B). The large pelagic fish differ from the forage fish in the tropics and subtropics where they are mostly restricted to the eastern side of ocean basins, near areas of upwelling (Figure 7B). These regions of upwelling, in addition to subpolar areas, are associated with high large pelagic fish biomasses and reduced forage fish populations (Figure 7A,B). A latitudinal gradient in demersal fish biomass is not well defined, instead demersal fish are more abundant in coastal areas than the deep basins (Figure 7C). When combined, the total fish biomass is equally high in offshore tropical and temperate regions and coastal areas, with intermediate levels in polar oceans, and the lowest levels in the subtropics (Figure 7D). Global mean fish biomass excluding that harvested was $1.54 \times 10^{9} \mathrm{MT}$, of which $1.50 \times 10^{9} \mathrm{MT}$ was in the medium and large size classes.

The global distribution of the fraction of large pelagic fish to the other two types broadly mimics that of the large pelagic fish on their own. There are very few areas with equivalent abundances; usually one type dominates. A pattern emerges when this fraction is defined on an LME scale and compared to the production of pelagic (zooplankton) and benthic (benthic invertebrate) resources (Figure 8A,B). Large pelagic fish proliferate over demersals when the ratio of zooplankton production (available to higher predators) to benthic detritus flux is elevated (Figure 8A).

When used in a generalized additive model, this ratio of zooplankton to detritus was able to explain $68 \%$ of the deviance in the fractions of pelagic fish over demersals (Table 5; Supp. Table S2). The relationship between the ratio of zooplankton to detritus for the fractions of pelagic fish over forage fish $(\mathrm{P} /(\mathrm{P}+\mathrm{F}))$ and the fraction of large fishes compared to medium fishes $(\mathrm{L} /(\mathrm{L}+\mathrm{M})$, where $\mathrm{L}=(\mathrm{LP}+\mathrm{LD})$ and $\mathrm{M}=(\mathrm{MP}+\mathrm{MD}+\mathrm{MF}))$ were weaker, only explaining $26 \%$ and $24 \%$ of the deviance, respectively (Figure 8B,C, Table 5; Supp. Tables S3, S4). The fraction of large fishes compared to medium fishes was strongly correlated to temperature, with lower fractions of all large fishes in warm LMEs (Figure 8C, Table 5, Supp Figure S3J, Supp. Table S4). Temperature was also associated with the fraction of large pelagic fish compared to demersals and forage fish (Table 5; Supp. Tables S2, S3), with extreme warm and cold environments decreasing the fraction (Supp Figure S3B,F). Only a small amount of the deviance of all three fractions was explained by the proportion of the LME that was continental shelf, as expressed as the fraction of the area $<200 \mathrm{~m}$ (Table 5; Supp. Tables S2-4). The dominance by large pelagic fish decreased as this shelf area increased, while the percentage of large fishes compared to medium fishes increased as this area increased (Supp Figure S3C,G,K). In all cases, 
NPP was a worse predictor than the ratio of zooplankton to detritus and worse or equivalent to temperature (Table 5; Supp. Tables S2-4). These relationships were driven by low fractions of large pelagics (or high fractions of large fishes) at low NPP values, while there was a large spread in fractions in LMEs with high NPP values (Supp Figure S3D,H,L).

\subsection{Fish dynamics in major ecosystem domains}

A more detailed perspective on the drivers of the prevalence of functional types is provided through inspection of several locations representative of more general ocean domains. Domain 1 is the Eastern Bering Sea (Table 6) as representative of a "Shelf Sea," an area over the continental shelf $(<200 \mathrm{~m})$ that has high amounts of both pelagic and benthic production. Shelf seas tend to be located in temperate and subpolar environments with seasonal variability of the physical and biological conditions. Other classic examples include the North Sea and the Scotian Shelf. Domain 2, the Peruvian Upwelling System (Table 6), is an example of an "Upwelling" region with high pelagic production and little to no benthic production. These habitats occur in areas with coastal upwelling such as the western margin of continents (e.g. off Peru and California) and with equatorial upwelling such as in the eastern Pacific. Domain 3 is an "Oligotrophic Gyre", with the example being the location of the Hawaii Ocean Timeseries (commonly referred to as "HOT"; Table 6). Such nutrient-poor areas occur in the subtropics where there is a permanent thermocline and shallow mixed layer depth, resulting in low primary production yielding low pelagic and benthic prey.

In each of these domains we compared the mean biomass of the resources (medium and large zooplankton, benthos) and the fishes, the consumption fluxes between groups, and the effective transfer efficiencies. We defined 3 estimates of transfer efficiency. TEeff $f_{\mathrm{LTL}}$ : the ratio of secondary production of the lowest consumer trophic levels (Lower Trophic Levels (LTL); medium zooplankton, large zooplankton, benthos) to net primary production (NPP). TEeff $\mathrm{HTL}_{\text {: }}$ : the ratio of highest trophic level (Higher Trophic Levels (HTL); pelagics and demersals in the large size class) fish production to secondary production. TEeff $\mathrm{ATL}_{\mathrm{AT}}$ : the ratio of HTL production to NPP, which encompasses All Trophic Levels.

In the Shelf Sea with the Eastern Bering Sea as an example (Table 6), the demersal abundance was greater than large pelagic abundance (Figure 9). This was related to the amount of benthic resources, demonstrated with the Z:D ratio (Figure 8A), that serve as an additional resource that is not shared with the large pelagic fish. Strong top-down control by large pelagic fish and demersals limited the relative prominence of forage fish biomass in these areas compared to regions $>200 \mathrm{~m}$ such as the Oligotrophic Gyres and Upwelling regions (Figure 9). Eastern Bering Sea effective transfer efficiency from NPP to the large size class $\left(\right.$ TEeff $\left._{\text {ATL }}\right)$ was $3.80 \times 10^{-3}$, which separated into an effective transfer efficiency of LTL as 0.14 and of HTL as $2.72 \times 10^{-2}$ (Table 7).

The forage fish and large pelagic fish coexisted at high abundances in the Upwelling

Domain, but there were fewer forage fish than expected (Figure 9). These regions hosted little to no demersal population. The large pelagic abundance in this Upwelling region was greater than the demersal abundance in the Shelf Sea. The Peruvian Upwelling effective transfer efficiencies were similar to those of the Shelf Sea locations, with $\mathrm{TEeff}_{\mathrm{ATL}}=2.93 \times 10^{-3}, \mathrm{TEeff}_{\mathrm{LTL}}=0.10$, TEeff $_{\mathrm{HTL}}=3.04 \times 10^{-2}$ (Table 7).

In the Oligotrophic Gyre domain, food webs were truncated with little to no biomass of the highest trophic levels, large pelagic fish and demersals (Figure 9). Large demersals exceeded 
large pelagic fish because of sparse benthic resources (Figure 9). The effective transfer efficiencies in the Oligotrophic Gyres were the lowest by 1-2 orders of magnitude. HOT effective transfer efficiencies were $\mathrm{TEeff}_{\mathrm{ATL}}=2.27 \times 10^{-5}$, TEeff $_{\mathrm{LTL}}=0.03$, and $\mathrm{TEeff}_{\mathrm{HTL}}=6.71 \times 10^{-4}$ (Table 7).

\section{DISCUSSION}

\subsection{Reconciling simulated and observed catches}

The time-average catches simulated by FEISTY showed moderate agreement with total, demersal, and large pelagic catches from empirical reconstructions across globally distributed LMEs (Figure 6). This suggests that FEISTY's description of bottom-up forcing and interactions between functional types captures significant drivers and processes structuring fish communities at global scales. However, while peak forage fish catch was captured, the model markedly overestimated forage catch in some systems. In contrast, the agreement with large pelagic and demersal catches were more balanced in terms of over- and under-estimation, though some systematic biases remained. All misfits are likely linked to a combination of limited resolution of both fish and fisheries dynamics within FEISTY, in addition to shortcomings in the model forcing (Stock et al. 2017). The model predicts potential catches if the entire globe is fished with one strategy, which is clearly a simplification of a far more complex reality. Fishing patterns and intensity vary greatly between systems due to cultural, management, and technology differences (Watson et al. 2013, Kroodsma et al. 2018) that are not covered by our simulations. Further, fisheries catch is an imperfect test of the model performance, as it is not necessarily proportional to biomass abundance (Branch et al. 2010), which is the primary variable of interest modeled by FEISTY. However, due to the limited records on biomass abundance at global scales, fisheries catches are a reasonable substitute for measuring whether FEISTY captures broad-scale biological patterns. The model objectives to recreate catch patterns across globally-distributed heavily fished ocean and coastal biomes where the catch per unit area varies by over two orders of magnitude also lessens concerns over the simplicity of the fishing model. While the simplicity of the fishing model undoubtedly contributes to the misfit between the model and catch reconstruction, the extremely large oceanographic contrasts maximize the "bottom-up" signal.

The correspondence between empirical catch reconstructions and simulated catches of forage fish was poor. While FEISTY captured peak catches associated with large forage fisheries, it greatly overestimated forage fish catches in a number of LMEs with very low catches despite seemingly favorable energetics. The biggest over-estimates were restricted to two regions with neighboring LMEs: The North Pacific LMEs of the Eastern Bering Sea, Gulf of Alaska, Aleutian Islands, West Bering Sea, and Chukchi Sea; and nine LMEs along the eastern coasts of North and South America. Interestingly, there is large variation $( \pm 5 \mathrm{x})$ between the SAU catch reconstruction and that of Watson (2017) for forage fish in many of these LMEs. This suggests that the original landings data are not straightforward and that the SAU project (Pauly \& Zeller 2015) and Watson (2017) have made different choices in their methods of estimation for these regions.

A second explanation for the misfits could be that forage fish are present, but not targeted in those LMEs where the model over-estimates forage catch. Compilation of effort hours associated with purse seine vessel tracks analyzed by the Global Fishing Watch (Kroodsma et al. 2018) demonstrates that 2012-2016 effort for schooling pelagic fish targeted by purse seines is 
lower than the median in half of these over-estimated LMEs, with the exception of the Aleutian Islands, Eastern Bering Sea, Gulf of Alaska, California Current, Northeast U.S. Shelf, Scotian Shelf, and Patagonian Shelf (Supp Figure S4). The purse seine vessels in these median or above effort LMEs may be targeting large pelagic fish rather than forage fish, which cannot be distinguished by this gear type. These data demonstrate where forage fish harvesting is not occurring rather than where it definitively is. Apart from these seven LMEs, the over-estimation of forage fish catches in FEISTY can likely be explained by modeled fishing rates that were higher than the suggested historic rates of the past 50 years.

Additional misfit in the simulated forage fish catch could be the result of top-down factors. Synthesis of 72 Ecopath food web models revealed that forage fish catch exceeded that of their predators in all ecosystems (Pikitch et al. 2014), though this excluded non-harvested predators such as seabirds and marine mammals. In contrast, simulated forage fish catch does not exceed that of large pelagic fish in many regions where both groups overlap, suggesting strong top-down control of forage fish by their predators in our model. While our model exhibits relatively few over-estimations of forage catch, we expect that simulated overexploitation of the predators will reduce top-down control, allowing for greater forage fish populations in such systems (e.g. Andersen \& Pedersen 2010, Szuwalski et al. 2017).

While the fit to large pelagic fish catch is far better than the forage fish catch, there are some LMEs where simulated catches differ from those observed by a factor of 5 (Figure 6B). Most of the under-estimated LMEs are around northern Europe, a region where the fishing mortality of large predatory fishes greatly exceeded $0.3 \mathrm{yr}^{-1}$ during the 1951-2006 reconstructed SAU time period (Christensen et al. 2003). One of the remaining lower simulated catch locations, the Indonesian Shelf, highlights the longitudinal disparity in the simulated biomass of large pelagic fish across the Pacific. This distribution agrees with the results of Watson et al. (2015) who found that large fish predators were absent from the subtropical western Pacific when fish migration and movement were not considered. However, much of this region became viable for large predators when they were allowed to swim in the direction that increased their per capita net growth rates (Watson et al. 2015). Thus, the large migratory abilities of this functional type appear to be necessary for their existence in the less productive regions of the ocean, namely the tropics and subtropics. As a next test of our model, we aim to add behavioral movement rules, as well as advection and diffusion, as appropriate for each functional type. This may rectify the distribution and catches of the large pelagic fish and improve the other functional types as well.

FEISTY large pelagic catches in the subpolar and upwelling LMEs and the Patagonian Shelf skew higher than SAU catch estimates. This is particularly apparent in the North Pacific, where the model predicts higher large pelagic biomass than suggested by catch. These regions have fewer large pelagic fish but are not devoid of large pelagic top predators. Instead, marine birds, pinnipeds, and cetaceans serve the same trophic role (Cury et al. 2000, Kaschner et al. 2011, Pikitch et al. 2014). Conversely, in the subpolar areas, the model underestimates catches of demersal fish. Again, this is most likely explained by the simplistic model fishing rate, which was lower than historic rates of the past 50 years in regions that experienced overexploitation of many demersal gadids and flatfishes, such as in the North Atlantic (Christensen et al. 2003).

Overall, a large amount of the discrepancy between modeled and observed catches can be explained by the simplistic representation of fishing in the model. We hypothesize that a better representation of the actual fishing patterns in the model would bring the simulated catches better in line with observations, while maintaining that existing model skill merits further discussion of 
results relative to alternative models (Section 4.2) and the sensitivity of the model to parameterization of fish ecology (Section 4.3).

\subsection{Comparisons with estimates from alternative models}

There have been numerous recent studies exploring drivers of fish biomass, catch, and catch by functional type. These offer alternative estimates of quantities arising from different models, often with more simplified dynamics. We contrast the results and underlying mechanisms herein, with emphasis on the most recent studies for each quantity.

\subsubsection{Biomass}

Jennings and Collingridge (2015; JC15 from here on) used a size-based macroecological model to estimate the total biomass of marine consumers in a pristine ocean without fishing. The general global patterns of their estimates of consumer biomass and our simulations of all fish biomass are similar, with lows in the middle of subtropical gyres and highs in upwelling regions and subpolar areas (Supp Figure S5; their Figure 6). The mean biomass is higher in JC15 than the FEISTY results, though they emphasize the large uncertainty in this value, and they simulate a larger size range of consumers $(1 \mathrm{~g}$ to $1000 \mathrm{~kg})$ than FEISTY $(0.02 \mathrm{~g}$ to $5.6 \mathrm{~kg})$. When comparing the modeled biomass of medium and large fishes to that of JC15 in the $100 \mathrm{~g}$ to $10 \mathrm{~kg}$ range, the FEISTY global biomass estimate of $1.50 \times 10^{9} \mathrm{MT}$ is near their median of $1.60 \times 10^{9} \mathrm{MT}$ and falls well within the $50 \%$ uncertainty bounds. There are, however, other dissimilarities suggesting more robust linkages to differences in model structure. There is less spatial variability in the JC15 distribution (their Figure 6) and their biomass is lower in temperate regions, higher in subpolar and polar areas, and does not extend as far westward of coastal upwelling areas. These discrepancies result in variations at the LME scale such that a comparison of LME rankings by biomass is not significant despite agreement on the ocean biome scale (Kendall ?? rank correlation, $\mathrm{p}=0.61)$. Even with higher mean biomass, their estimates of production $\left(\mathrm{g} \mathrm{m}^{-2}\right.$ $\mathrm{yr}^{-1}$ ) and the production to biomass ratio are lower than those of FEISTY (Supp Figure S5; their Figure 6). One of the differences in model structures is that the JC15 model does not include functional types that differ by traits other than maximum size. When their biological rate parameters (encounter, maximum consumption, and basal metabolism) were used within the FEISTY framework, they caused the loss of the forage fish group.

It is important to note that the biomass estimates of JC15 compared here are from a median simulation $\left(4.9 \times 10^{9} \mathrm{MT}\right)$ with $90 \%$ uncertainty intervals that ranged from 0.3 to 26.1 $\mathrm{x} 10^{9} \mathrm{MT}$ that were primarily driven by uncertainty in trophic transfer efficiency and its relationship with predator-prey body mass ratios. The predator-prey body mass ratio was constrained by the simple trophodynamics of the three size classes in FEISTY. The trophic transfer efficiency (TE) assumptions are yet another difference between FEISTY and JC15. The TE was a constant prescribed by JC15 while in FEISTY it emerged as a function of the underlying interactions between fish functional types and plankton food web dynamics, and hence varied in space and time. A median of $2.82 \times 10^{-3}$ fraction of the lowest consumer trophic level production reached the highest trophic level in FEISTY $\left(\right.$ TEeff $\left._{\mathrm{HTL}}\right)$. If we assume this large size class was 3 trophic levels above the lowest consumers, this effective transfer efficiency would reflect a mean highest trophic level transfer efficiency of $14.1 \%\left(\mathrm{TE}=\mathrm{TEeff}_{\mathrm{HTL}}{ }^{1 / 3}\right)$, with a $90 \%$ confidence interval of 5.6-35.0\% (Supp Figure S6). This is a wider range than that of JC15 who used TEs $7.8-17.1 \%$ with a mean of $11.6 \%$ in their sensitivity analysis. However, the 
fractions of the primary production that reached the lowest consumers $\left(\mathrm{TEeff}_{\mathrm{LTL}}\right)$ from the COBALT simulation, 0.05 [0.01, 0.11], were strikingly lower than those assumed by JC15, 0.22 $[0.12,0.26]$, which may account for why our median biomass is less than theirs but falls within their large confidence intervals. More importantly, the dynamic differences in trophic efficiency and consideration of pathways connecting plankton and fishes in FEISTY likely contributed to the accentuated gradients in fish biomass relative to forcing with NPP.

\subsubsection{Total catch}

The mechanistically-inspired, empirical work of Stock et al. (2017) was better able to reconcile fisheries catch at the LME scale as a function of both zooplankton production and the flux of detritus to the sediment rather than as a function of just net primary production. Refinement of the Stock et al. (2017) empirical model was also accomplished via similar mechanisms that improved FEISTY's fit to observed catch (Section 3.1). To best model SAU catches, they needed to apply a heavy penalty on the transfer efficiency of tropical systems, justified by higher metabolic demands and lower oxygen (Deutsch et al. 2015), and needed to boost the transfer efficiency associated with benthic fluxes, assuming lower foraging costs for benthic environments (Stock et al. 2017). Similarly, FEISTY benefited from a parameterization that increased the temperature sensitivity of the basal metabolic rate, which lowered large pelagic catches in the subtropics and increased those of demersals in subpolar regions. To increase the transfer efficiency of the benthic environment, we did not alter the foraging abilities of demersal fish, but instead allowed the benthic invertebrate production to temporally mimic the flux of detritus to the bottom. Our estimate of transfer efficiency from detritus to benthos of $7.5 \%$ can be thought of as an average transfer efficiency of $10 \%$ (Pauly \& Christensen 1995) applied to 75\% of the detrital flux, which agrees well with estimates of the amount of particulate organic carbon consumed by benthic metazoans that range from 60 to $90 \%$ (Rowe \& Demming 1985, Rowe \& Demming 2011).

Like Stock et al. (2017), the dynamic response of transfer efficiencies results in a dynamic range of catch (i.e., a factor of 100 across heavily fished systems). Stock et al. (2017) estimated total fisheries catch instead of separating it by functional type. Our total simulated catches by LME had greater agreement with their model $(r=0.79)$ than with the SAU catch reconstruction (Table 5). The skill is degraded relative to the simple trophodynamic approach because Stock et al. (2017) took the trophic level of the catch from observations rather than deriving it dynamically.

Our model supports the idea proposed by Ryther (1969) that trophic transfer efficiency varies by oceanographic province. Ryther (1969) assumed transfer efficiencies of 10, 15, and $20 \%$ for Oceanic, Coastal, and Upwelling provinces respectively. The transfer efficiencies produced by COBALT from NPP to secondary production at the test locations were less than their corresponding Ryther (1969) estimates, with the exception of our Shelf Sea that was equivalent to the Coastal province. The effective transfer efficiencies of NPP to the lowest trophic level (TEeff $\left.f_{\mathrm{LTL}}\right)$ and to the highest trophic level $\left(\mathrm{TEeff}_{\mathrm{ATL}}\right)$ were greater in the Shelf Sea than the Upwelling region, but the transfer from LTL to HTL $\left(\right.$ TEeff $_{\mathrm{HTL}}$ ) was greater in the Upwelling region. Meta-analysis of Ecopath models revealed that Upwelling Areas tend to have lower (LTL) or the lowest (HTL) transfer efficiencies compared to subpolar, temperate,

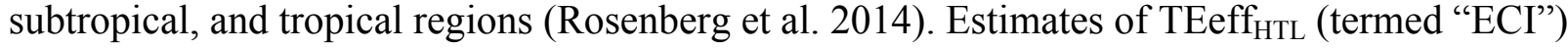
from the SAU catch data also showed this pattern (Maureaud et al. 2017). These studies diverge greatly on the regional rankings of transfer efficiency. For example, the tropics have the highest 
TE in Rosenberg et al. (2014) and the lowest in Maureaud et al. (2017). On the LME scale, our TEeff $_{\text {HTL }}$ values compare favorably $(\mathrm{r}=0.53)$ to the ECI scores of Maureaud et al. (2017), but skew higher with a mean of $0.0176 \pm 0.011$ compared to their $0.0096 \pm 0.006$ (Supp Figure S7). The effective transfer efficiencies of FEISTY also generally fall within the canonical value of 10\% (10.13\% \pm 5.81\%; Pauly \& Christensen 1995) but do show large regional differences (Supp Figure S6).

\subsubsection{Catch by functional type}

The pelagic and benthic pathways from NPP to fishes (zooplankton production and the flux of detritus to the sediment) can be used to understand catch composition in addition to the total amount of catch. Van Denderen et al. (2018) used a food web model to predict the biomass of large pelagic and demersal predators as functions of pelagic and benthic resources, estimated from the pe-ratio (the fraction of net primary production that sinks out of the photic zone), that was highly correlated to fisheries landings (Watson 2017) at the scale of ecoregions. At the LME scale (3-4x ecoregion size), the van Denderen et al. (2018) model fractions correlated moderately with FEISTY large pelagic catch fractions $(r=0.54$, Table 4$)$, but the FEISTY correlations with the SAU large pelagic catch fractions were low $(\mathrm{r}=0.33$, Table 4$)$. However, the van Denderen et al. (2018) model fractions also degrade at the LME scale (not shown). The fair correlation between FEISTY and the van Denderen et al. (2018) model results from the same mechanism operating in each to determine the fraction of large pelagic fish compared to demersals (Table 5, Figure 7A). In advance of creating the food web model, van Denderen et al. (2018) estimated the fraction of large pelagic fish in Watson's (2017) landings data using a generalized additive model (GAM). The ratio of pelagic resources to benthic resources explained the majority of the deviance in the relative biomass of large pelagic fish versus demersals in both the van Denderen et al. (2018) GAM and the GAM fit to the FEISTY output, with the fraction of large pelagic fish increasing as the ratio of pelagic to benthic resources increased.

As previously found by other studies (Friedland et al. 2012, Stock et al. 2017, van Denderen et al. 2018), our model suggests that the production of fish biomass is closely tied to the separation of net primary production into pelagic and benthic secondary production. The amount of each type of secondary production determines the total biomass of the system, while the ratio of the two influences which functional types dominate. These relationships were exemplified in our ocean domains. Both Shelf Seas and Upwelling areas have high primary and secondary production, resulting in large biomasses and catches of fishes. In contrast to the Shelf Seas, the deep Upwelling areas experience decay in the detrital flux such that very little reaches the bottom. This difference in the ratio of secondary production led to coexistence of forage fish and large pelagic fish at high abundances in Upwelling areas while the demersals were scarce. On the other hand, demersal abundance exceeded that of large pelagic fish in Shelf Seas as presumed. In contrast to our expectations, the large pelagic abundance in Upwelling areas was not less than the demersal abundance in the Shelf Sea. This was likely the result of the pelagic feeding penalty imposed on demersals and that the forage fish were not stronger competitors against the large pelagic fish. As anticipated, forage fish did dominate the Oligotrophic Gyres, where secondary production was too low to support the largest size classes, and their abundance was lowest in the Shelf Seas where they were vulnerable to two types of predators. The dominance of medium sized fishes like the forage fish was more predicated on the pelagic temperature rather than the zooplankton to benthos ratio. Higher temperatures were more 
metabolically costly to the largest size class and are indicative of regions with permanent thermoclines and oligotrophy.

\subsubsection{Summary}

To summarize, FEISTY provides similar estimates to the total fish biomass as a sizebased model without functional types (Jennings \& Collingridge 2015), represents observed trends in fisheries catches (SAU), reflects the environmental variability in trophodynamics related to LME scale differences in fisheries catch as explained by a less mechanistic model (Stock et al. 2017), and reproduces the underlying mechanism involved in structuring large pelagic vs. demersal dominant environments (van Denderen et al. 2018). The global patterns produced by FEISTY were fairly insensitive to the parameter exploration to maximize correspondence with empirical catch records, indicating that the model is robust. Overall, we believe that the skill achieved supports the utility of FEISTY as a tool for assessing global trends in forage, large pelagic, and demersal fish biomasses and exploring their mechanistic basis.

\subsection{Parameterizations and fish ecology}

Maximizing catch correlations was robust to parameter permutations, having the basic characteristics of our model calibration (i.e. favorable allometry and/or predator avoidance of forage fish, benthic energy transfer efficiency sufficient for large demersal fisheries, and temperature-dependent metabolic processes favoring elevated high latitude fish catch). There was, however, a somewhat delicate balance to first achieving coexistence of all three functional types under the same metabolic scaling principles. Using the parameterizations and associated mass-dependent functions for encounter/clearance rate, maximum consumption, and basal metabolism from established size-based models (e.g. Hartvig et al. 2011, Hartvig \& Andersen 2013, Jennings \& Collingridge 2015) often led to the local extinction of one or two groups. To prevent dominance of the large pelagic fish over the forage fish, the weight sensitivity of basal metabolism needed to exceed that of feeding rates. This results in a decreasing scope for growth with increasing size. We chose $b_{C}=-0.25$ and $b_{M}=-0.175$, a difference of -0.075 , which is similar to the difference in one of the first fish bioenergetics models, $b_{C}-b_{M}=-0.07$ (Kitchell et al. 1977), and the Jennings and Collingridge (2015) model, $b_{C}-b_{M}=-0.08$. These are exponents for weight-specific rates $\left(\mathrm{g} \mathrm{g}^{-1} \mathrm{~d}^{-1}\right)$ and are equivalent to non-weight specific rate $\left(\mathrm{g} \mathrm{d}^{-1}\right)$ exponents of $b^{*}{ }_{C}=0.75$ and $b^{*}{ }_{M}=0.825$, which fall within the ranges reported in the literature. von Bertalanffy (1960) argued that acquisition rates, such as consumption, scale with surface area $\left(b^{*}{ }_{C}=0.67\right)$, while metabolism scales as the organism's mass $\left(b^{*}{ }_{M}=1.0\right)$. Through a metaanalysis of fish studies, Clarke and Johnston (1999) found that $b^{*}{ }_{M}$ had a mean value of 0.79 . Reported mean or median scaling exponents ranged from 0.65 to 0.95 in the 110 studies, while individual values spanned a greater range, 0.40-1.29 (Clarke \& Johnston 1999). Analysis of variance indicated a statistically significant variation between different families and orders where the differences were caused mainly by high mean values for Myctophiformes and Salmoniformes at the level of order (Clarke \& Johnston 1999), fishes with life history traits very similar to our forage fish functional group. Furthermore, the mass-dependence of metabolism varies with ontogeny, being highest for larval stages, intermediate for juveniles, and lowest for adults (Fuiman \& Higgs 1997). Thus, a better parameterization of global fish distributions may exist with mass-dependent basal metabolic rates that vary by functional type (c.f. Killen et al. 2016) 
and life history stage. However, the robustness of such distinctions is still debated (Anderson \& Beyer 2015)

Previous studies have highlighted the critical role of temperature-dependent metabolic costs on the latitudinal distribution of fish catch (Libralato et al. 2008, Stock et al. 2017). FEISTY best approximated catch reconstructions of large pelagic fish and demersal fish when basal metabolism was more temperature sensitive than encounter and clearance rates. The $\mathrm{Q}_{10}$ of basal metabolism was 2.35, akin to the within-species mean of 2.40 found by Clarke and Johnston (1999), while encounter rates had $\mathrm{Q}_{10}=1.88$. This difference in temperature sensitivity for resting metabolism and other rates is also adopted by the global fish model of Cheung et al. (2010). There is ample support for the high temperature sensitivity of metabolic rates (e.g. von Bertalanffy 1960). The support for the temperature scaling of encounter rates is less solid, but there is both theoretical and empirical support for a smaller temperature sensitivity than metabolism. The encounter rates are a manifestation of increased activity. Arguably, if metabolic rates increase with temperature, so does activity. However, activity increases similarly for the prey, making them also more adept at avoiding predation (Rall et al. 2012). This would argue for a neutral or a weaker temperature response of encounter rates. Empirical studies also support a lower temperature sensitivity of consumption, with a $\mathrm{Q}_{10}$ around 1.6-1.8 (Perrin 1995).

Achieving robust coexistence between forage fish and large pelagic fish required giving forage fish a benefit relative to large pelagic fish. In the absence of the demersals, our forage fish and large pelagic fish represent an intraguild predation system where two species are engaged in both a predator-prey relationship (LP-MF, MP-SF) and a competitive relationship (MP-MF, SPSF) (Polis et al. 1989, Diehl \& Feißel 2000, Rosenheim 2007). Models of such systems predict extinction of the top predator (large pelagic fish) at low productivities (e.g. oligotrophic gyres) because of lack of food availability, while at high productivities (e.g. upwelling regions) the intermediate consumer (forage fish) is excluded by high predation by the top predator that can sustain itself solely on their shared resource (Holt \& Polis 1997, Mylius et al. 2001, Hartvig \& Andersen 2013). Coexistence occurs at intermediate productivities in this case. To ensure more robust coexistence we add the effect that adults of the smaller species are superior to juveniles of the same size but from a larger species. Specifically, we represented a predator avoidance advantage by the adult forage fish of the same size class as the juvenile large pelagics. Such an advantage may reflect schooling as a predator avoidance strategy (Blaxter \& Hunter 1982, Magurran 1990) or it could be the consequence of ontogenetic changes in sensory organs and propulsive muscle tissue (Fuiman \& Higgs 1997). The role of this difference in predation rate for coexistence is illustrated by theoretical models of intraguild predation where coexistence at higher productivities becomes possible with a decrease in the attack rate of the top predator on the intermediate consumer (van de Wolfshaar et al. 2006). These results are borne out in FEISTY, where only the predator avoidance effects of forage fish facilitated coexistence of forage fish and large pelagics (Figure 2B). Our parameterization required that adult forage fish was a factor of two less vulnerable to predation than juvenile large pelagic fish.

Despite the addition of predator avoidance, forage fish still struggle against large pelagics. A good example is eastern boundary currents where the biomass of large pelagics is larger than forage fish. An additional and ecologically plausible effect would be to also make adult forage fish competitively superior in feeding than juvenile large pelagics (Werner 1977). We found, however, that the predator avoidance effect produced a much larger response than reducing the feeding ability of the juvenile large pelagic fish (see Appendix). A deeper 
knowledge of the specific mechanisms leading to coexistence of small and large pelagic species in intraguild predation systems would make it possible to increase the realism of FEISTY.

We believe that some of these issues could be mitigated by including more of the defining characteristics of these two functional groups, namely swimming abilities (discussed in Section 4.1), spawning preferences, and additional prey resources. In our static version of the model, the large pelagic fish dominate in highly productive non-shelf systems such as areas of upwelling. Though large pelagics like tunas and billfishes are found in these regions, catches are lower than those in non-upwelling regions of the tropics (Le Manach et al. 2015). The temperature and eddy kinetic energy ranges of western boundary currents make them ideal spawning areas for tunas and billfishes, while many upwelling regions are inhabitable for their larvae (Schaefer 2001, Boyce et al. 2008, Reglero et al. 2014). Furthermore, many forage fish graze directly on phytoplankton and microzooplankton (van der Lingen et al.2006). These additional food sources may give forage fish the required edge over juvenile large pelagic fish, making the difference in predator vulnerability unnecessary. Additionally, many large pelagic fish shift to deeper feeding with ontogeny such that their diets include mesopelagic and bathypelagic prey (Lehodey et al. 2008). FEISTY only represents the top $100 \mathrm{~m}$ of the pelagic environment. Addition of a mesopelagic habitat, with mesopelagic zooplankton and a new mesopelagic fish functional type, may allow for niche separation that could further foster coexistence.

Exclusion of the demersal fish by the large pelagic fish was not as problematic compared to the forage fish. Demersal fish catches were sensitive to the parameterization of the benthic invertebrate resource pool. At first this pool was simulated with a carrying capacity. This formulation suffered because when the biomass approached the carrying capacity, none of the growth reflected in bottom detritus flux was realized. Instead it was dissipated and essentially lost from the energy budget, thereby inhibiting demersal production. The carrying capacity was removed and the benthic efficiency kept low to best approximate the distribution of benthic resources. In the future, it would be best to develop a similar size- and trait-based mechanistic model of the benthos to couple with the fish model (e.g. Blanchard et al. 2009).

\subsection{Conclusions}

We have created a dynamic and mechanistic global model of commercially important fishes that can be run coupled to global earth system models. It represents (i) basic life cycle dynamics, (ii) competitive and predatory interactions, and (iii) differences in life history, habitat, maximum size, and feeding preferences. As a result, it captures the main drivers and processes that structure marine communities at high trophic levels. Additionally, it is temporally dynamic making it capable of capturing trends forced by climate change, as well as non-linear tipping points and regime shifts. The model provides an improved global-scale understanding, quantification, and prediction of the ocean's capacity for fish biomass and yield. In this paper, we examined the bottom-up mechanisms of fish biomass and yield and found that not just the total system productivity, but the type of productivity (zooplankton vs. benthos) determines broad-scale spatial patterns in abundance and dominance of the commercially harvested fish. Though our model is simple in terms of only modeling three functional types of fishes, we think that it has great potential as a tool for global ecosystem studies and to project the effects of climate change on fishes and fisheries. 


\section{ACKNOWLEDGEMENTS}

We would like to thank Vicky Lam for the Sea Around Us data, Kelly Kearney for food web visualization, Jorge Sarmiento for helpful discussions, Hans van Someren Gréve for graphic design, and two anonymous reviewers for their suggestions that improved this paper. CMP was funded by the Nereus Program. KHA and PDvD were funded by the "Ocean Life" VKR center of excellence supported by the Villum foundation.

\section{CONTRIBUTORS}

CMP, CAS, and JRW developed the initial conceptualization of research. KHA further refined model development. KHA, CMP, CAS, and PDvD established the manuscript structure and key figures. CMP performed simulations/analyses and wrote the initial draft. All authors contributed to the interpretation of results and editing of the manuscript.

\section{DECLARATION OF INTEREST}

None.

\section{REFERENCES}

AFMA., 2015. Australian Fisheries Management Authority Annual Report, 2014-15. Australian Fisheries Management Authority, Canberra.

Andersen, K.H., Beyer, J.E., 2006. Andersen, K.H., Beyer, J.E., 2015. Size structure, not metabolic scaling rules, determines fisheries reference points. The American Naturalist 168, 5461.

Andersen, K.H., Beyer, J.E., 2015. Size structure, not metabolic scaling rules, determines fisheries reference points. Fish and Fisheries 16, 1-22. doi: 10.1111/faf.12042

Andersen, K.H., Pedersen, M., 2010. Damped trophic cascades driven by fishing in model marine ecosystems. Proceedings of the Royal Society B 277, 795-802.

doi:10.1098/rspb.2009.1512

Barange, M., Merino, G., Blanchard, J.L., Scholtens, J., Harle, J., Allison, E.H., Allen, J.I., Holt, J., Jennings, S., 2014. Impacts of climate change on marine ecosystem production in societies dependent on fisheries. Nature Climate Change 4, 211-216.

Benoit, E., Rochet, M.J., 2004. A continuous model of biomass size spectra governed by predation and the effects of fishing on them. Journal of Theoretical Biology 226, 9-21.

Blaxter, J.H.S., Hunter, J.R., 1982. The biology of the clupeoid fishes. Advances in Marine Biology 20, 1-223.

Blanchard, J.L., Jennings, S., Law, R., Castle, M.D., McCloghrie, P., Rochet, M.J., Benoît, E., 2009. How does abundance scale with body size in coupled size-structured food webs? Journal of Animal Ecology 78, 270-280. 
Blanchard, J.L., Jennings, S., Holmes, R., Harle, J., Merino, G., Allen, J.I., Holt, J., Dulvy, N.K., Barange, M., 2012. Potential consequences of climate change for primary production and fish production in large marine ecosystems. Philosophical Transactions of the Royal Society B: Biological Sciences 367, 2979-2989.

Boettiger, C., Lang, D.T., Wainwright, P.C., 2012. rfishbase: exploring, manipulating and visualizing FishBase data from R. Journal of Fish Biology 81, 2030-2039. doi:10.1111/j.10958649.2012.03464.x

Boyce, D.G, Tittensor, D.P., Worm, B., 2008. Effects of temperature on global patterns of tuna and billfish richness. Marine Ecology Progress Series 355, 267-276.

Branch, T.A., Watson, R., Fulton, E.A., Jennings, S., McGilliard, C.R., Pablico, G.T., Ricard, D., Tracey, S.R., 2010. The trophic fingerprint of marine fisheries. Nature 468, 431-435. doi:10.1038/nature09528.

Bulman, C., Althaus, F., He, X., Bax, N.J., Williams, A., 2001. Diets and trophic guilds of demersal fishes of the south-eastern Australian shelf. Marine Freshwater Research 52, 537-548.

Carozza, D.A., Bianchi, D., Galbraith, E.D., 2017. The ecological module of BOATS-1.0: a bioenergetically constrained model of marine upper trophic levels suitable for studies of fisheries and ocean biogeochemistry. Geosciences Model Development 9, 1545-1565.

Cheung, W.W.L., Close, C., Lam, V., Watson, R., Pauly, D., 2008. Application of macroecological theory to predict effects of climate change on global fisheries potential. Marine Ecology Progress Series 365, 187-197.

Cheung, W.W.L., Lam, V.W.Y., Sarmiento, J.L., Kearney, K., Watson, R., Zeller, D., Pauly, D., 2010. Large-scale redistribution of maximum fisheries catch potential in the global ocean under climate change. Global Change Biology 16, 24-35.

Christensen, V., Guénette, S., Heymans, J.J., Walters, C.J., Watson, R., Zeller, D., Pauly, D., 2003. Hundred-year decline of North Atlantic predatory fishes. Fish and Fisheries 4, 1-24.

Christensen, V., Coll, M., Buszowski, J., Cheung, W.W.L., Frölicher, T., Steenbeek, J., Stock, C.A., Watson, R.A., Walters, C.J., 2015. The global ocean is an ecosystem: simulating marine life and fisheries. Global Ecology and Biogeography 24, 507-517.

Clarke, A., Johnston, N.M., 1999. Scaling of metabolic rate with body mass and temperature in teleost fish. Journal of Animal Ecology 68, 893-905.

Cribari-Neto, F., Zeileis, A., 2010. Beta Regression in R. Journal of Statistical Software 34(2), 124. http://www.jstatsoft.org/v34/i02/. 
Cury, P., Bakun, A., Crawford, R.J.M., Jarre, A., Quiñones, R.A., Shannon, L.J., Verheye, H.M., 2000. Small pelagics in upwelling systems: patterns of interaction and structural changes in "wasp-waist"' ecosystems. ICES Journal of Marine Science 57, 603-618.

De Roos, A.M., Persson, L., McCauley, E., 2003. The influence of size-dependent life-history traits on the structure and dynamics of populations and communities. Ecology Letters 6, 473487.

De Roos, A.M., Schellekens, T., Van Kooten, T., Van De Wolfshaar, K., Claessen, D., Persson, L., 2008. Simplifying a physiologically structured population model to a stage-structured biomass model. Theoretical Population Biology 73, 47-62.

Dierssen, H.M., 2010. Perspectives on empirical approaches for ocean color remote sensing of chlorophyll in a changing climate. Proceedings of the National Academy of Sciences 107, 17073-17078.

Delworth, T.L., Rosati, A., Anderson, W., Adcroft, A.J., Balaji, V., Benson, R., Dixon, K., Griffies, S.M., Lee, H.C., Pacanowski, R.C., Vecchi, G.A., 2012. Simulated climate and climate change in the GFDL CM2.5 high-resolution coupled climate model. Journal of Climate 25, 27552781.

Deutsch, C., Ferrel, A., Seibel, B., Pörtner. H.-O., Huey, R.B., 2015. Climate change tightens a metabolic constraint on marine habitats. Science 348, 1132-1135.

Diehl, S., Feißel, M., 2000. Effects of enrichment on three-level food chains with omnivory. Am. Nat. 155, 200-218.

Dunne, J.P., John, J.G., Adcroft, A.J., Griffies, S.M., Hallberg, R.W., Shevliakova, E., Stouffer, R.J., Cooke, W., Dunne, K.A., Harrison, M.J., Krasting, J.P., Malyshev, S.L., Milly, P.C.D., Phillipps, P.J., Sentman, L.T., Samuels, B.L., Spelman, M.J., Winton, M., Wittenberg, A.T., and Zadeh, N., 2012. GFDL's ESM2 global coupled climate-carbon earth system models, Part I: Physical formulation and baseline simulation characteristics. Journal of Climate 25, 6646-6665. doi:10.1175/Jcli-D-11-00560.1.

Dunne, J.P., John, J.G., Shevliakova, E., Stouffer, R.J., Krasting, J.P., Malyshev, S.L., Milly, P. C.D., Sentman, L.T., Adcroft, A.J., Cooke, W., Dunne, K.A., Griffies, S.M., Hallberg, R.W., Harrison, M.J., Levy, H., Wittenberg, A.T., Phillips, P.J., and Zadeh, N., 2013. GFDL's ESM2 global coupled climate-carbon earth system models, Part II: Carbon system formulation and baseline simulation characteristics. Journal of Climate 26, 2247-2267. doi:10.1175/Jcli-D-1200150.1 .

Eppley, R.W., 1972. Temperature and phytoplankton growth in the sea. Fisheries Bulletin 70, 1063-1085.

FAO., 2016. The State of World Fisheries and Aquaculture 2016. Contributing to food security and nutrition for all. FAO, Rome. 
Flood, M., Stobutzki, I., Andrews, J., Ashby, C., Begg, G., Fletcher, R., Gardner, C., Georgeson, L., Hansen, S., Hartmann, K., Hone, P., Horvat, P., Maloney, L., McDonald, B., Moore, A., Roelofs, A., Sainsbury, K., Saunders, T., Smith, T., Stewardson, C., Stewart, J., Wise, B., 2014. Status of Key Australian Fish Stocks Reports 2014. Fisheries Research and Development Corporation, Canberra.

Frank, K.T., Petrie, B., Choi, J.S., Leggett, W.C., 2005. Trophic cascades in a formerly coddominated ecosystem. Science 308, 1621-1623.

Friedland, K.D., Stock, C., Drinkwater, K.F., Link, J.S., Leaf, R.T., Shank, B.V., Rose, J.M., Pilskaln, C.H., Fogarty, M.J., 2012. Pathways between primary production and fisheries yields of large marine ecosystems. PLoS One 10, e0133794.

Fuiman, L.A., Higgs, D.M., 1997. Ontogeny, growth, and the recruitment process. In: Chambers, R.C., Trippel, E.A. (Eds.), Early Life History and Recruitment in Fish Populations. Chapman \& Hall, London, pp. 225-250.

Galbraith, E.D., Carozza, D.A. and Bianchi, D., 2017. A coupled human-Earth model perspective on long-term trends in the global marine fishery. Nature Communications, doi:10.1038/ncomms 14884 .

Garcia, H., Locarini, R., Boyer, T., Antonov, J., 2006. World Ocean Atlas 2005. In: Levitus, S. (Ed.), Nutrients (phosphate, nitrate, silicate), NOAA Atlas NESDIS

63, vol. 4. US Government Printing Office, Washington, DC, pp. 396.

Garrison, L.P., Link, J.S., 2000. Dietary guild structure of the fish community in the Northeast United States continental shelf ecosystem. Marine Ecology Progress Series 202, 231-240.

Hansen, B.W., Bjornsen, P.K., Hansen, P.J., 1994. The size ratio between planktonic predators and their prey. Limnology and Oceanography 39, 395-402.

Harfoot, M.B.J., Newbold, T., Tittensor, D.P., Emmott, S., Hutton, J., Lyutsarev, V., Smith, M. J., Scharlemann, J.P.W., Purves, D. W., 2014. Emergent global patterns of ecosystem structure and function from a mechanistic general ecosystem model. PLoS Biology 12, e1001841.

Hartvig, M., Andersen, K.H., Beyer, J.E., 2011. Food web framework for size-structured populations. Journal of Theoretical Biology 272,113-122.

Hartvig, M., Andersen, K.H., 2013. Coexistence of structured populations with size-based prey selection. Theoretical Population Biology 89, 24-33.

Hastie, T.J., Tibshirani, R.J., 1990. Generalized additive models, volume 43 of Monographs on Statistics and Applied Probability. Chapman \& Hall, London, 352pp.

Holt, R.D., Polis, G.A. 1997. A theoretical framework for intraguild predation. Am. Nat. $149,745-764$. 
Jennings, S., Collingridge, K., 2015. Predicting consumer biomass, size-structure, production, catch potential, responses to fishing and associated uncertainties in the world's marine ecosystems. Marine Ecology Progress Series 410, 233-244.

Kaschner, K., Tittensor, D.P., Ready, J., Gerrodette, T., Worm, B., 2011. Current and future patterns of global marine mammal biodiversity. PLoS ONE 6, e19653. doi:10.1371/journal.pone.0019653

Key, R.M., Kozyr, A., Sabine, C.L., Lee, K., Wanninkhof, R., Bullister, J.L., Feely, R.A., Millero, F.J., Mordy, C., Peng, T.H., 2004. A global ocean carbon climatology: Results from Global Data Analysis Project (GLODAP). Global Biogeochemical Cycles 18, GB4031.

Killen, S.S., Glazier, D.S., Rezende, E.L., Clark, T.D., Atkinson, D., Willener, A.S.T., Halsey, L.G., 2016. Ecological influences and morphological correlates of resting and maximal metabolic rates across teleost fish species. The American Naturalist 187, 592-606.

Kitchell, J.F., Stewart, D.J., Weininger, D., 1977. Applications of a bioenergetics model to yellow perch (Perca flavescens) and walleye (Stizostedion vitreum vitreum). Journal of the Fisheries Research Board of Canada 34, 1922-1935.

Kroodsma, D.A, Mayorga, J., Hochberg, T., Miller, N.A., Boerder, K., Ferretti, F., Wilson, A., Bergman, B., White, T.D., Block, B.A., Woods, P., Sullivan, B., Costello, C., Worm, B., 2018. Tracking the global footprint of fisheries. Science 359, 904-908.

Laufkötter, C., Vogt, M., Gruber, N., Aita-Noguchi, M., Aumont, O., Bopp, L., Buitenhuis, E., Doney, S., Dunne, J., Hashioka, T., Hauck, J., 2015. Drivers and uncertainties of future global marine primary production in marine ecosystem models. Biogeosciences 12, 6955-6984.

Le Manach, F., Cisneros-Montemayor, A.M., Zeller, D., Pauly, D., 2015. Reconstructing catches of large pelagic fishes. In: Pauly, D., Zeller, D. (Eds), Catch reconstructions: concepts, methods and data sources. Sea Around Us, Vancouver.

http://www.seaaroundus.org/doc/Methods/CatchReconstructionMethod/Methods-Catch-tabJune-8-2015. (pdf on June 8 2015).

Lefort, S., Aumont, O., Bopp, L., Arsouze, T., Gehlen, M., Maury, O., 2015. Spatial and bodysize dependent response of marine pelagic communities to projected global climate change. Global Change Biology 21, 154-164. doi: 10.1111/gcb.12679

Lehodey, P., Senina, I., Murtugudde, R., 2008. A spatial ecosystem and populations dynamics model (SEAPODYM) - Modeling of tuna and tuna-like populations. Progress in Oceanography 78, 304-318.

Libralato, S., Coll, M., Tudela, S., Palomera, I., Pranovi, F., 2008. Novel index for quantification of ecosystem effects of fishing as removal of secondary production. Marine Ecology Progress Series 355, 107-129. 
Magurran, A.E., 1990, January. The adaptive significance of schooling as an anti-predator defense in fish. In: Annales Zoologici Fennici. Finnish Zoological Publishing Board, formed by the Finnish Academy of Sciences, Societas Scientiarum Fennica, Societas Biologica Fennica Vanamo and Societas pro Fauna et Flora Fennica, pp. 51-66.

Maureaud, A., Gascuel, D., Colléter, M., Palomares, M.L.D., Du Pontavice, H., Pauly, D., Cheung, W., 2017. Global change in the trophic functioning of marine food webs. PLoS ONE 12 , e0182826.

Maury, O., 2010. An overview of APECOSM, a spatialized mass balanced "Apex Predators ECOSystem Model" to study physiologically structured tuna population dynamics in their ecosystem. Progress in Oceanography 84, 113-117.

Mcowen, C.J., Cheung, W.W., Rykaczewski, R.R., Watson, R.A., Wood, L.J., 2015. Is fisheries production within large marine ecosystems determined by bottom-up or top-down forcing? Fish and Fisheries 16, 623-632.

Mylius, S.D., Klumpers, K., de Roos, A.M., Persson, L. 2001. Impact of intraguild predation and stage structure on simple communities along a productivity gradient. Am. Nat. 158, 259-276.

Palomares, M.L.D., Tran, L.D., Coghlan, A.R., Sheedy, J., Cheung, W., Lam, V., Pauly, D., 2015. Taxon distributions. In: Pauly, D., Zeller, D. (Eds), Catch reconstructions: concepts, methods and data sources. Sea Around Us, Vancouver. http://www.seaaroundus.org/doc/Methods/CatchReconstructionMethod/Methods-Catch-tabJune-8-2015. (pdf on June 8 2015).

Pauly, D., Christensen, V., 1995. Primary production required to sustain global fisheries. Nature 374, 255-257.

Pauly, D., Zeller, D., 2015. Reconstructing marine fisheries catch data. In: Pauly, D., Zeller, D. (Eds), Catch reconstructions: concepts, methods and data sources. Sea Around Us, Vancouver. http://www.seaaroundus.org/doc/Methods/CatchReconstructionMethod/Methods-Catch-tabJune-8-2015. (pdf on June 8 2015).

Perrin, N., 1995. About Berrigan and Charnov's life-history puzzle. Oikos 73, 137-139.

Pikitch, E.K., Rountos, K.J., Essington, T.E., Santora, C., Pauly, D., Watson, R., Sumaila, U.R., Boersma, P.D., Boyd, I.L., Conover, D.O. Cury, P., Heppel, S.S., Houde, E.D., Mangel, M., Plagányi, E., Sainsburt, K., Steneck, R.S., Geers, T.M., Gownaris, N., Munch, S.B., 2014. The global contribution of forage fish to marine fisheries and ecosystems. Fish and Fisheries 15, 4364.

Polis, G.A., Myers, C.A., Holt, R.D. 1989. The ecology and evolution of intraguild predation: potential competitors that eat each other. Annu. Rev. Ecol. Evol. Syst. 20, 297-330. 
R Core Team (2017). R: A language and environment for statistical computing. R Foundation for Statistical Computing, Vienna, Austria. https://www.R-project.org/.

Rall, B.C., Brose, U., Hartvig, M., Kalinkat, G., Schwarzmüller, F., Vucic-Pestic, O., Petchey, O.L., 2012. Universal temperature and body-mass scaling of feeding rates. Philosophical Transactions of the Royal Society B: Biological Sciences 367, 2923 LP-2934

Redfield A.C. 1934. On the proportions of organic derivations in sea water and their relation to the composition of plankton. In: Daniel, R.J. (Ed.), James Johnstone Memorial Volume. University Press of Liverpool, Liverpool, pp. 176-192.

Reglero, P., Tittensor, D.P., Álvarez-Berastegui, D., Aparicio-González, A., Worm, B., 2014. Worldwide distributions of tuna larvae: revisiting hypotheses on environmental requirements for spawning habitats. Marine Ecology Progress Series 501, 207-224.

Rosenberg, A.A., Fogarty, M.J., Cooper, A.B., Dickey-Collas, M., Fulton, E.A., Gutiérrez, N.L., Hyde, K.J.W., Kleisner, K.M., Kristiansen, T., Longo, C., Minte-Vera, C., Minto, C., Mosqueira, I., Osio, G.C., Ovando, D., Selig, E.R., Thorson, J.T., Ye, Y., 2014. Developing new approaches to global stock status assessment and fishery production potential of the seas. FAO, Rome.

Rosenheim, J.A. 2007. Intraguild Predation: New Theoretical and Empirical Perspectives. Ecology 88, 2679-2680.

Rowe, G.T., Demming, J.W., 1985. The role of bacteria in the turnover of organic carbon in deep-sea sediments. Journal of Marine Research 43, 925-950.

Rowe, G.T., Demming, J.W., 2011. An alternative view of the role of heterotrophic microbes in the cycling of organic matter in deep-sea sediments. Marine Biology Research 7, 629-636.

Ryther, J.H., 1969. Photosynthesis and fish production in the sea. Science 166, 72-76.

Schaefer, K.M., 2001. Reproductive biology of tunas. Fish Physiology 19, 225-270.

Schofield, O., Arnone, R.A., Bissett, W.P., Dickey, T.D., Davis, C.O., Finkel, Z., Oliver, M., Moline, M.A., 2004. Watercolors in the coastal zone: What can we see? Oceanography 17, 2431.

Sieburth, J.M., Smetacek, V., Lenz, J., 1978. Pelagic ecosystem structure: heterotrophic compartments of the plankton and their relationship to plankton size fractions. Limnology and Oceanography 23, 1256-1263.

Stock, C.A., Dunne, J.P., John, J.G., 2014. Global-scale carbon and energy flows through the marine planktonic food web: an analysis with a coupled physical-biological model. Progress in Oceanography 120, 1-28. doi:10.1016/j.pocean.2013.07.001. 
Stock, C.A., John, J.G., Rykaczewski, R.R., Asch, R.G., Cheung, W.W.L., Dunne, J.P., Friedland, K.D., Lam, V.W.Y., Sarmiento, J.L., Watson, R.A., 2017. Reconciling fisheries catch and ocean productivity. Proceedings of the National Academy of Sciences 114, E1441-E1449. doi:10.1073/pnas.1610238114.

Szuwalski, C.S., Burgess, M.G., Costello, C., Gaines, S.D., 2017. High fishery catches through trophic cascades in China. Proceedings of the National Academy of Sciences 114, 717-721.

van de Wolfshaar, K.E., de Roos, A.M., Persson, L., 2006. Size-dependent interactions inhibit coexistence in intraguild predation systems with life-history omnivory. American Naturalist 168, $62-75$.

van Denderen, D., Lindegren, M., MacKenzie, B.R., Watson, R.A., Andersen, K.H., 2018. Global patterns in marine predatory fish. Nature Ecology \& Evolution 2, 65-70. doi:10.1038/s41559-017-0388-z.

van der Lingen, C.D., Hutchings, L., Field, J.G., 2006. Comparative trophodynamics of anchovy Engraulis encrasicolus and sardine Sardinops sagax in the southern Benguela: are species alternations between small pelagic fish trophodynamically mediated? African Journal of Marine Science 28, 465-477.

Van Leeuwen, A., De Roos, A.M., Persson, L., 2008. How cod shapes its world. Journal of Sea Research 60, 89-104.

Van Oostende, N., Dussin, R., Stock, C. A., Barton, A. D., Curchitser, E., Dunne, J. P., \& Ward, B. B., 2018. Simulating the ocean's chlorophyll dynamic range from coastal upwelling to oligotrophy. Progress in Oceanography 168, 232-247.

von Bertalanffy, L., 1960. Fundamental aspects of normal and malignant growth. In: Nowinski, W. W. (Ed.), Fundamental aspects of normal and malignant growth. Elsevier, Amsterdam, pp. 137-259.

Watson, J.R., Stock, C.A., Sarmiento, J.L., 2015. Exploring the role of movement in determining the global distribution of marine biomass using a coupled hydrodynamic - Size-based ecosystem model. Progress in Oceanography 138, 521-532.

Watson, R.A., 2017. A database of global marine commercial, small-scale, illegal and unreported fisheries catch 1950-2014. Scientific Data 4, 170039.

Watson, R.A., Cheung, W.W., Anticamara, J.A, Sumaila, R.U., Zeller, D., Pauly, D., 2013. Global marine yield halved as fishing intensity redoubles. Fish and Fisheries 14, 493-503.

Wei, C.-L., Rowe, G.T., Escobar-Briones, E., Boetius, A., Soltwedel, T., Caley, M.J., Soliman, Y., Huettmann, F., Qu, F., Yu, Z., Pitcher, C.R., Haedrich, R.L., Wicksten, M.K., Rex, M.A., Baguley, J.G., Sharma, J., Danovaro, R., MacDonald, I.R., Nunnally, C.C., Deming, J.W., Montagna, P., Lévesque, M., Weslawski, J.M., Wlodarska-Kowalczuk, M., Ingole, B.S., Bett, 
B.J., Billett, D.S.M, Yool, A., Bluhm, B.A., Iken, K., Narayanaswamy, B.E., 2010. Global patterns and predictions of seafloor biomass using random forests. PLoS ONE 5, e15323. doi:10.1371/journal.pone.0015323

Werner, E.E. 1977. Species packing and niche complementarity in three sunfishes. The American Naturalist 111, 553-578. 
TABLES

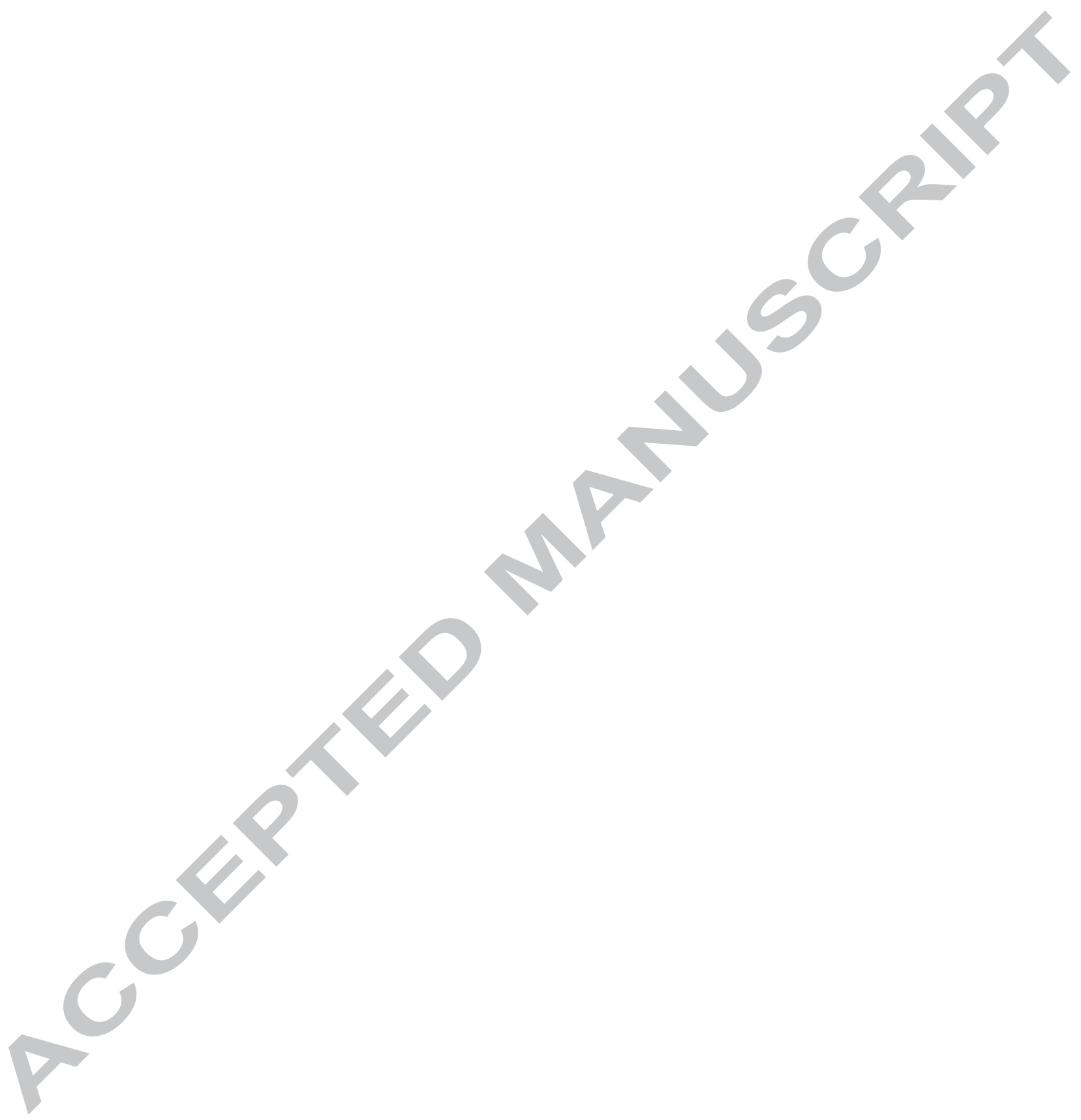




\begin{tabular}{|c|c|c|c|c|}
\hline Symbol & Description & Value & Units & Source \\
\hline \multicolumn{5}{|c|}{ Parameters } \\
\hline$a_{C}$ & maximum consumption intercept & 0.0548 & $\mathrm{~g}^{\mathrm{bc}-1} \mathrm{~d}^{-1}$ & Hartvig* \\
\hline$a_{E}$ & encounter intercept & 0.1918 & $m^{2} g^{\text {be- }-1} d^{-1}$ & Hartvig* \\
\hline$a_{M}$ & metabolism intercept & 0.011 & $\mathrm{~g}^{\mathrm{bm}-1} \mathrm{~d}^{-1}$ & Hartvig* \\
\hline$\alpha$ & assimilation efficiency & 0.7 & -- & Watson \\
\hline$b_{C}$ & maximum consumption slope & -0.25 & -- & Hartvig \\
\hline$b_{\mathrm{E}}$ & encounter slope & -0.20 & -- & Hartvig \\
\hline$b_{M}$ & metabolism slope & -0.175 & -- & Hartvig* \\
\hline ?? & $\begin{array}{l}\text { transfer efficiency from detritus to benthic } \\
\text { invertebrates }\end{array}$ & 0075 & -- & $\mathrm{RD}^{*}$ \\
\hline $\mathrm{dt}$ & time step & & $\mathrm{d}$ & \\
\hline$\varepsilon$ & reproductive efficiency & 0.01 & -- & $\mathrm{JC}$ \\
\hline$f$ & fishing mortality rate & 8.22E-04 & $\mathrm{d}^{-1}$ & $\mathrm{AB}$ \\
\hline $\mathrm{k}$ & temperature sensitivity of most rates & 0.063 & ${ }^{\circ} \mathrm{C}^{-1}$ & Stock \\
\hline $\mathrm{k}_{\mathrm{M}}$ & metabolism temperature sensitivity & 0.0855 & ${ }^{\circ} \mathrm{C}^{-1}$ & Stock* \\
\hline$\kappa$ & fraction of energy allocated to growth & $1,1,0.5$ & -- & \\
\hline $\mathrm{L}_{\mathrm{L}}$ & length of large fish size class individual & $\begin{array}{c}292.4- \\
2320.8 \\
\text { (mean } 824)\end{array}$ & $\mathrm{mm}$ & $\mathrm{w}_{\mathrm{L}}, \mathrm{AB}$ \\
\hline $\mathrm{L}_{\mathrm{M}}$ & length of medium fish size class individual & $\begin{array}{l}36.8-292.4 \\
(\text { mean } 104)\end{array}$ & $\mathrm{mm}$ & $\mathrm{w}_{\mathrm{M}}, \mathrm{AB}$ \\
\hline $\mathrm{L}_{\mathrm{S}}$ & length of small fish size class individual & $\begin{array}{c}4.6-36.8 \\
(\text { mean } 13)\end{array}$ & $\mathrm{mm}$ & $\mathrm{w}_{\mathrm{S}}, \mathrm{AB}$ \\
\hline$\mu_{\text {nat }}$ & natural mortality rate constant & $2.74 \mathrm{E}-04$ & $\mathrm{~d}^{-1}$ & \\
\hline $\mathrm{T}_{0}$ & metabolic rates reference temperature & 10 & ${ }^{\circ} \mathrm{C}$ & Hartvig \\
\hline$\theta$ & prey preference & Table 2 & & \\
\hline$\theta_{\mathrm{A}}$ & large fishes preference on medium forage fish & 0.5 & -- & calibration \\
\hline$\theta_{\mathrm{D}}$ & preference of large demersals on pelagic prey & 0.75 & -- & $\operatorname{vanD*}$ \\
\hline$\theta_{\mathrm{s}}$ & $\begin{array}{l}\text { medium fish preference on medium } \\
\text { zooplankton }\end{array}$ & 0.25 & -- & \\
\hline $\mathrm{w}_{\mathrm{L}}$ & weight of large fish size class individual & $\begin{array}{l}250-125000 \\
\text { (mean } \\
5600)\end{array}$ & $\mathrm{g}$ & \\
\hline $\mathrm{w}_{\mathrm{M}}$ & weight of medium fish size class individual & $\begin{array}{c}0.5-250 \\
(\text { mean } 11.2)\end{array}$ & g & \\
\hline
\end{tabular}




\begin{tabular}{|c|c|c|c|c|}
\hline $\mathrm{W}_{\mathrm{S}}$ & weight of small fish size class individual & $\begin{array}{c}0.001-0.5 \\
(\text { mean } 0.02)\end{array}$ & $\mathrm{g}$ & \\
\hline $\mathrm{Z}$ & $\begin{array}{l}\text { ratio of the initial to the final body size of } \\
\text { each fish size class }\end{array}$ & 0.002 & -- & $\begin{array}{l}\mathrm{W}_{\mathrm{L}}, \mathrm{w}_{\mathrm{M}} \\
\mathrm{W}_{\mathrm{S}}\end{array}$ \\
\hline \multicolumn{5}{|l|}{ Forcing } \\
\hline det_btm & flux of detrital matter to the ocean bottom & forcing & $\mathrm{g} \mathrm{m}^{-2} \mathrm{~d}^{-1}$ & COBALT \\
\hline $\lg z$ & $\begin{array}{l}\text { large zooplankton biomass integrated over the } \\
\text { top } 100 \mathrm{~m}\end{array}$ & forcing & & COBALT \\
\hline loss_lgz & $\begin{array}{l}\text { biomass of large zooplankton lost to higher } \\
\text { predators integrated over the top } 100 \mathrm{~m}\end{array}$ & forcing & $\mathrm{g} \mathrm{m}^{-2} \mathrm{~d}^{-1}$ & COBALT \\
\hline loss_mdz & $\begin{array}{l}\text { biomass of medium zooplankton lost to } \\
\text { higher predators integrated over the top } 100 \mathrm{~m}\end{array}$ & forcing & $\mathrm{g} \mathrm{m}^{-2} \mathrm{~d}^{-1}$ & COBALT \\
\hline $\mathrm{mdz}$ & $\begin{array}{l}\text { medium zooplankton biomass integrated over } \\
\text { the top } 100 \mathrm{~m}\end{array}$ & forcing & $\mathrm{g} \mathrm{m}^{-2}$ & COBALT \\
\hline $\mathrm{T}_{\mathrm{b}}$ & bottom temperature & forcing & ${ }^{\circ} \mathrm{C}$ & COBALT \\
\hline $\mathrm{T}_{\mathrm{p}}$ & mean temperature in the upper $100 \mathrm{~m}$ & forcing & ${ }^{\circ} \mathrm{C}$ & COBALT \\
\hline $\mathrm{Y}$ & prey biomass & $\begin{array}{l}\text { forcing, } \\
\text { simulated }\end{array}$ & $\mathrm{g} \mathrm{m}^{-2}$ & $\begin{array}{l}\text { COBALT, } \\
\text { eqs. } 1,2\end{array}$ \\
\hline \multicolumn{5}{|l|}{ Simulated } \\
\hline A & mass-specific search rate & simulated & $\mathrm{m}^{2} \mathrm{~g}^{-1} \mathrm{~d}^{-1}$ & eq. 4 \\
\hline B & biomass of fish or benthic invertebrates & simulated & $\mathrm{g} \mathrm{m}^{-2}$ & eqs. 1,2 \\
\hline $\mathrm{C}$ & mass-specific maximum consumption rate & simulated & $\mathrm{g} \mathrm{g}^{-1} \mathrm{~d}^{-1}$ & eq. 6 \\
\hline $\mathrm{E}$ & mass-specific encounter rate & simulated & $\mathrm{g} \mathrm{g}^{-1} \mathrm{~d}^{-1}$ & eq. 3 \\
\hline$\gamma$ & energy for growth & simulated & $\mathrm{g} \mathrm{g}^{-1} \mathrm{~d}^{-1}$ & eq. 10 \\
\hline $\mathrm{H}$ & biomass lost to fishing & simulated & $\mathrm{g} \mathrm{m}^{-2} \mathrm{~d}^{-1}$ & eq. 14 \\
\hline I & mass-specific consumption rate & simulated & $\mathrm{g} \mathrm{g}^{-1} \mathrm{~d}^{-1}$ & eq. 5 \\
\hline$\lambda$ & fraction of time spent in the pelagic & simulated & -- & eq. 15 \\
\hline M & biomass-specific basal metabolic rate & simulated & $\mathrm{g} \mathrm{g}^{-1} \mathrm{~d}^{-1}$ & eq. 9 \\
\hline$\mu_{\text {tot }}$ & total mortality rate & simulated & $d^{-1}$ & eq. 11 \\
\hline ? & $\begin{array}{l}\text { total energy available for growth and } \\
\text { reproduction }\end{array}$ & simulated & $\mathrm{g} \mathrm{g}^{-1} \mathrm{~d}^{-1}$ & eq. 8 \\
\hline $\mathrm{R}$ & biomass recruiting to the next size class & simulated & $\mathrm{g} \mathrm{m}^{-2} \mathrm{~d}^{-1}$ & eq. 13 \\
\hline$\rho$ & energy for reproduction & simulated & $\mathrm{g} \mathrm{g}^{-1} \mathrm{~d}^{-1}$ & eq. 12 \\
\hline $\mathrm{T}$ & habitat temperature & simulated & ${ }^{\circ} \mathrm{C}$ & eq. 16 \\
\hline$\psi$ & $\begin{array}{l}\text { biomass lost from predation by larger size } \\
\text { classes }\end{array}$ & simulated & $\mathrm{g} \mathrm{m}^{-2} \mathrm{~d}^{-1}$ & eq. 7 \\
\hline
\end{tabular}


Table 1. Model parameters, forcing, and key simulated variables. Means are geometric means. Parameter values are those used in the final simulation. The "forcing" designation indicates externally-imposed model forcing that are derived from the ESM2.6-COBALT (Section 2.1). These are the specific names output from COBALT. Note that the COBALT medium and large zooplankton fall into the meso and small fish size classes, respectively, of FEISTY (Figure 1). Simulated quantities are those derived from the model-governing equations, given a specified set of parameters and forcing. Note that these simulated variables are in addition to the core model state variables summarized in Figure 1. Parameter sources are provided: $\mathrm{AB}=$ Andersen \& Beyer 2015; Hartvig = Hartvig et al. 2011, Hartvig \& Andersen 2013; JC = Jennings \& Collingridge 2015; RD = Rowe \& Demming 1985, Rowe \& Demming 2011; Stock = Stock et al. 2014; Watson $=$ Watson et al. 2015; vanD = van Denderen et al 2018. Those marked with an asterisk began as the baseline value from this source, but were altered through model calibration (Appendix). 


\begin{tabular}{|c|c|c|c|c|c|c|c|c|c|}
\hline & Bent & MZ & $\mathbf{L Z}$ & SF & SP & SD & MF & MP & MD \\
\hline SF & & 1 & & & & & & & \\
\hline SP & & 1 & & & & & & & \\
\hline SD & & 1 & & & & & & & \\
\hline MF & & $\theta_{S}$ & 1 & 1 & 1 & 1 & & & \\
\hline MP & & $\theta_{S}$ & 1 & 1 & 1 & 1 & & & \\
\hline MD & 1 & & & & & & & & \\
\hline LP & & & & & & & $\theta_{A}$ & 1 & \\
\hline LD & 1 & & & & & & $\theta_{A} \cdot \theta_{D}$ & $\theta_{D}$ & 1 \\
\hline
\end{tabular}

Table 2. Feeding preferences with predators in the rows (labeled with leftmost column) and prey in the columns (labeled with top row). S: small, M: medium, L: large, Bent: benthic invertebrates, Z: zooplankton, F: forage fish, P: large pelagic fish, D: demersal fish. See Table 1 for $\theta$ values. 


\begin{tabular}{|c|c|c|c|c|}
\hline Functional Group & Description & $\mathbf{F}$ & $\mathbf{P}$ & D \\
\hline pelagicsm & Small Pelagics $(<30 \mathrm{~cm})$ & 1 & 0 & 0 \\
\hline pelagicmd & Medium Pelagics (30 - $90 \mathrm{~cm})$ & 0 & 1 & 0 \\
\hline pelagiclg & Large Pelagics $(\geq 90 \mathrm{~cm})$ & 0 & 1 & 0 \\
\hline demersalsm & Small Demersals $(<30 \mathrm{~cm})$ & 0 & 0 & 0 \\
\hline demersalmd & Medium Demersals (30 - $90 \mathrm{~cm})$ & 0 & 0 & 1 \\
\hline demersallg & Large Demersals $(\geq 90 \mathrm{~cm})$ & 0 & 0 & 1 \\
\hline bathypelagicsm & Small Bathypelagics (<30 cm) & 1 & 0 & 0 \\
\hline bathypelagicmd & Medium Bathypelagics (30 - $90 \mathrm{~cm})$ & 0 & 1 & 0 \\
\hline bathypelagiclg & Large Bathypelagics $(\geq 90 \mathrm{~cm})$ & 0 & 1 & \\
\hline bathydemersalsm & Small Bathydemersals $(<30 \mathrm{~cm})$ & 0 & 0 & 0 \\
\hline bathydemersalmd & Medium Bathydemersals $(30-90 \mathrm{~cm})$ & 0 & & 1 \\
\hline bathydemersallg & Large Bathydemersals ( $\geq 90 \mathrm{~cm})$ & & & 1 \\
\hline benthopelagicsm & Small Benthopelagics $(<30 \mathrm{~cm})$ & & 0 & 0 \\
\hline benthopelagicmd & Medium Benthopelagics (30 - $90 \mathrm{~cm})$ & 0 & 0 & 1 \\
\hline benthopelagiclg & Large Benthopelagics $(\geq 90 \mathrm{~cm})$ & 0 & 0 & 1 \\
\hline reef-associatedsm & Small Reef assoc fish $(<30 \mathrm{~cm})$ & 0 & 0 & 0 \\
\hline reef-associatedmd & Medium Reef assoc fish $(30-90 \mathrm{~cm})$ & 0 & 0 & 1 \\
\hline reef-associatedlg & Large Reef assoc fish ( $\geq 90 \mathrm{~cm})$ & 0 & 0 & 1 \\
\hline sharksm-md & Small to Medium Sharks $(<90 \mathrm{~cm})$ & 0 & 0.5 & 0.5 \\
\hline sharklg & Large Sharks $(\geq 90 \mathrm{~cm})$ & 0 & 0.5 & 0.5 \\
\hline raysm-md & Small to Medium Rays $(<90 \mathrm{~cm})$ & 0 & 0 & 1 \\
\hline raylg & Large Rays $(\geq 90 \mathrm{~cm})$ & 0 & 0 & 1 \\
\hline flatfishsm-md & Small to Medium Flatfishes $(<90 \mathrm{~cm})$ & 0 & 0 & 1 \\
\hline flatfishlg & Large Flatfishes $(\geq 90 \mathrm{~cm})$ & 0 & 0 & 1 \\
\hline
\end{tabular}

Table 3. The weighting of SAU functional groups in FEISTY functional types for catch comparisons by functional type. 


\begin{tabular}{lcc}
\hline & r & RMSE \\
\hline SAU All Fish & $\mathbf{0 . 5 4}$ & 0.38 \\
SAU F & 0.27 & 1.42 \\
SAU P & $\mathbf{0 . 6 2}$ & 0.81 \\
SAU D & $\mathbf{0 . 6 2}$ & 0.41 \\
SAU Frac Pelagic & $\mathbf{0 . 3 3}$ & 0.31 \\
vanD Frac Pelagic & $\mathbf{0 . 5 4}$ & 0.26 \\
Stock All Fish & $\mathbf{0 . 7 9}$ & 0.13 \\
\hline
\end{tabular}

Table 4. Statistical comparisons (Pearson's $r$ and root mean square error (RMSE)) to catch estimates (SAU and Stock model (Section 4.2.2)) and fraction of the catch that is large pelagic fish vs. demersal fish (SAU and vanD model (Section 4.2.3)). Bold numbers denote significance with $\mathrm{p} \leq 0.05$. 


\begin{tabular}{clcccc}
\hline & Model & $\log _{\mathbf{1 0}}($ Zl:Det $)$ & PelT & Frac $<200$ & $\log _{\mathbf{1 0}}(\mathbf{N P P})$ \\
\hline \multirow{2}{*}{$\mathrm{P} /(\mathrm{P}+\mathrm{D})$} & $\begin{array}{l}\text { Deviance } \\
\text { explained }\end{array}$ & 0.68 & 0.49 & 0.3 & 0.55 \\
& $\mathrm{R}^{2}$ & 0.51 & 0.31 & 0.24 & 0.37 \\
& $\begin{array}{l}\text { Deviance } \\
\mathrm{P} /(\mathrm{P}+\mathrm{F})\end{array}$ & & & & \\
& explained & 0.26 & 0.35 & 0.09 & 0.22 \\
& $\mathrm{R}^{2}$ & 0.19 & 0.35 & 0.05 & 0.18 \\
$\mathrm{~L} /(\mathrm{L}+\mathrm{M})$ & $\begin{array}{l}\text { Deviance } \\
\text { explained }\end{array}$ & 0.24 & 0.59 & 0.13 & 0.05 \\
& $\mathrm{R}^{2}$ & 0.20 & 0.60 & 0.11 & 0.02 \\
\hline
\end{tabular}

Table 5. Deviance explained and $\mathrm{R}^{2}$ of generalized additive models of the LME-scale fraction of large pelagic fish vs. demersal fish $(\mathrm{P} /(\mathrm{P}+\mathrm{D}))$, large pelagic fish vs. forage fish $(\mathrm{P} /(\mathrm{P}+\mathrm{F}))$, and large fishes to medium fishes $(\mathrm{L} /(\mathrm{L}+\mathrm{M}))$ as a function of the individual terms: the $\log _{10}$ transformed ratio of zooplankton losses to higher predators to seafloor detritus flux $\left(\log _{10}\right.$ Zl:Det), mean pelagic temperature in the top $100 \mathrm{~m}$ (PelT), the fraction of LME area $<200 \mathrm{~m}$ (Frac200), and the $\log _{10}$ transformed net primary production (NPP). 


\begin{tabular}{lcrrrc}
\hline Location & Abbrev. & Longitude & Latitude & Depth (m) & Domain \\
\hline Eastern Bering Sea & EBS & -164.5 & 56.5 & 79 & Shelf Sea \\
$\begin{array}{l}\text { Peruvian Upwelling } \\
\text { Hawaii Ocean }\end{array}$ & PUP & -79.5 & -12.5 & 4782 & Upwelling \\
\begin{tabular}{l} 
Timeseries \\
\hline
\end{tabular} & HOT & -157.5 & 22.5 & 4616 & Oligotrophic gyre \\
\hline
\end{tabular}

Table 6. Longitude, latitude, and depth of the Domain example locations. 


\begin{tabular}{lccc}
\hline & EBS & PUP & HOT \\
\hline TEeff $_{\text {ATL }}$ loc & $3.80 \mathrm{E}-03$ & $2.95 \mathrm{E}-03$ & $2.27 \mathrm{E}-05$ \\
TEeff $_{\text {LTL }}$ loc & 0.14 & 0.10 & 0.03 \\
TEeff $_{\text {HTL }}$ loc & $2.72 \mathrm{E}-02$ & $3.04 \mathrm{E}-02$ & $6.71 \mathrm{E}-04$ \\
TEeff $_{\text {HTL }}$ LME & $2.08 \mathrm{E}-02$ & $2.67 \mathrm{E}-02$ & $1.87 \mathrm{E}-03$ \\
Maureaud ECI & $2.46 \mathrm{E}-02$ & $5.40 \mathrm{E}-03$ & $3.40 \mathrm{E}-03$ \\
LME & EBS $(1)$ & Humb (13) & Haw (10)
\end{tabular}

Table 7. Modeled effective transfer efficiencies of all trophic levels from NPP to the large fishes (ATL), from NPP to the lower trophic levels (LTL), and from LTL to the highest trophic level (HTL) at the individual domain locations (loc; Table 6) and averaged for the corresponding LME (LME). For comparison is the ECI of Maureaud et al. (2017), which is equivalent to TEeff ${ }_{\text {HTL }}$. 
Figure 1. Model structure denoting the two zooplankton and three fish size, three functional types, three habitats, two prey categories, and feeding interactions (arrows). Dashed arrow denotes feeding only occurs in shelf regions with depth $<200 \mathrm{~m}$. The dotted line surrounds zooplankton biomass that is input from an ESM. Graphic design by Hans van Someren Gréve. [Color in print and online; Double column]

Figure 2. Distribution of $\log _{10}$ biomass $\left(\mathrm{g} \mathrm{m}^{-2}\right)$ of forage fish (left) and large pelagic fish (right). Coexistence in productive regions required metabolic scalings with size that were favorable for small fish and an assumption that predator avoidance in adult forage fish exceeded that of the juvenile stages of larger fish. Simulations with (A) $b_{M}=-0.25$ and $\theta_{A}=1.0$, (B) $b_{M}=-0.175$ and $\theta_{A}=1.0$, and (C) $b_{M}=-0.175$ and $\theta_{A}=0.5$. [Color in print and online; Double column]

Figure 3. Heatmap and clustering of $\pm 10 \%$ individual parameter changes from the set most commonly employed in the literature (Table A1). Response values are the percent difference in biomass, relative to the simulation with the full literature parameter set, of: Forage fish biomass (F), Large pelagic fish biomass (P), Demersal fish biomass (D), all biomass in low latitudes $\left(<30^{\circ} \mathrm{N}\right.$ or S, Low $)$, all biomass at higher latitudes $\left(>30^{\circ} \mathrm{N}\right.$ or S, High). The colorbar on the left shows the total magnitude (Mag) of all responses. For the slope of biomass-specific allometric relationships $\left(b_{\mathrm{M}}, b_{\mathrm{E}}, b_{\mathrm{C}}\right)$, which are generally negative, perturbations refer to the magnitude of the negative slope (i.e., $b_{M^{-}} 10$ results in a reduced weight sensitivity of metabolic costs, which leads to more forage fish because the metabolic penalty for being small is not as great as the unperturbed case). Parameters with an asterisk were adjusted in the model calibration (see Appendix). [Color in print and online; 1.5 column]

Figure 4. The mean fraction of large pelagics out of large pelagic fish and demersals with varying benthic efficiency, $\beta$, at the LME scale. [Color in print and online; Double column]

Figure 5. Distribution of all fish $\log _{10}$ biomass $\left(\mathrm{g} \mathrm{m}^{-2}\right)$ with different basal metabolism temperature sensitivities: $k_{M}$ equal to (A) $0.0405\left(\mathrm{Q}_{10}=1.50\right),(\mathrm{B}) 0.0855\left(\mathrm{Q}_{10}=2.35\right),(\mathrm{C}) 0.1305$ $\left(\mathrm{Q}_{10}=3.69\right)$. [Color in print and online; Single column]

Figure 6. Catch comparisons between model simulations (FEISTY) and global catch reconstructions (SAU) for (A) forage fish, (B) large pelagic fish, (C) demersals, and (D) all fishes combined. Dot color indicates mean pelagic (top $100 \mathrm{~m})$ temperature $\left({ }^{\circ} \mathrm{C}\right)$ of the LME. Dashed lines represent 1:1 (black), 2x difference (blue), 5x difference (red). [Color in print and online; 1.5 column]

Figure 7. Simulated global $\log _{10}$ biomass $\left(\mathrm{g} \mathrm{m}^{-2}\right)$ of (A) forage fish, (B) large pelagic fish, (C) demersals, and (D) all fishes combined. [Color in print and online; Double column]

Figure 8. Fraction of (A) large pelagic vs. demersal, (B) large pelagic vs. forage, and (C) large vs. medium fishes as a function of the ratio of zooplankton production lost to higher predation (ZLoss) to detritus flux to the seafloor (Det) by LME. Solid lines: predicted response, dashed lines: standard error. Dot color indicates mean pelagic (top $100 \mathrm{~m}$ ) temperature $\left({ }^{\circ} \mathrm{C}\right)$ of the LME. [Color in print and online; Single column] 
Figure 9. Mean biomasses (circles) and fluxes of biomass (lines) through the pelagic and benthic food webs at the three test locations in the Pacific: Eastern Bering Sea (EBS), Peruvian Upwelling (PUP), and Hawaii Ocean Timeseries (HOT). Reference circle sizes correspond to the biomasses $\left(\mathrm{g} \mathrm{m}^{-2}\right)$ and reference line widths correspond to the fluxes $\left(\mathrm{g} \mathrm{m}^{-2} \mathrm{~d}^{-1}\right)$ given. Pelagic terms are integrated over the top $100 \mathrm{~m}$ while the benthic terms are at the seafloor. Net primary productivity (NPP): grey, Medium and large zooplankton (MZ+LZ): yellow, Forage fish: red, Large pelagic fish: blue, Benthos: brown, Demersals: green. Note that NPP is depicted as a circle for visual ease, though it is a rate in units of $\mathrm{g} \mathrm{m}^{-2} \mathrm{~d}^{-1}$. [Color in print and online; 1.5 column] 


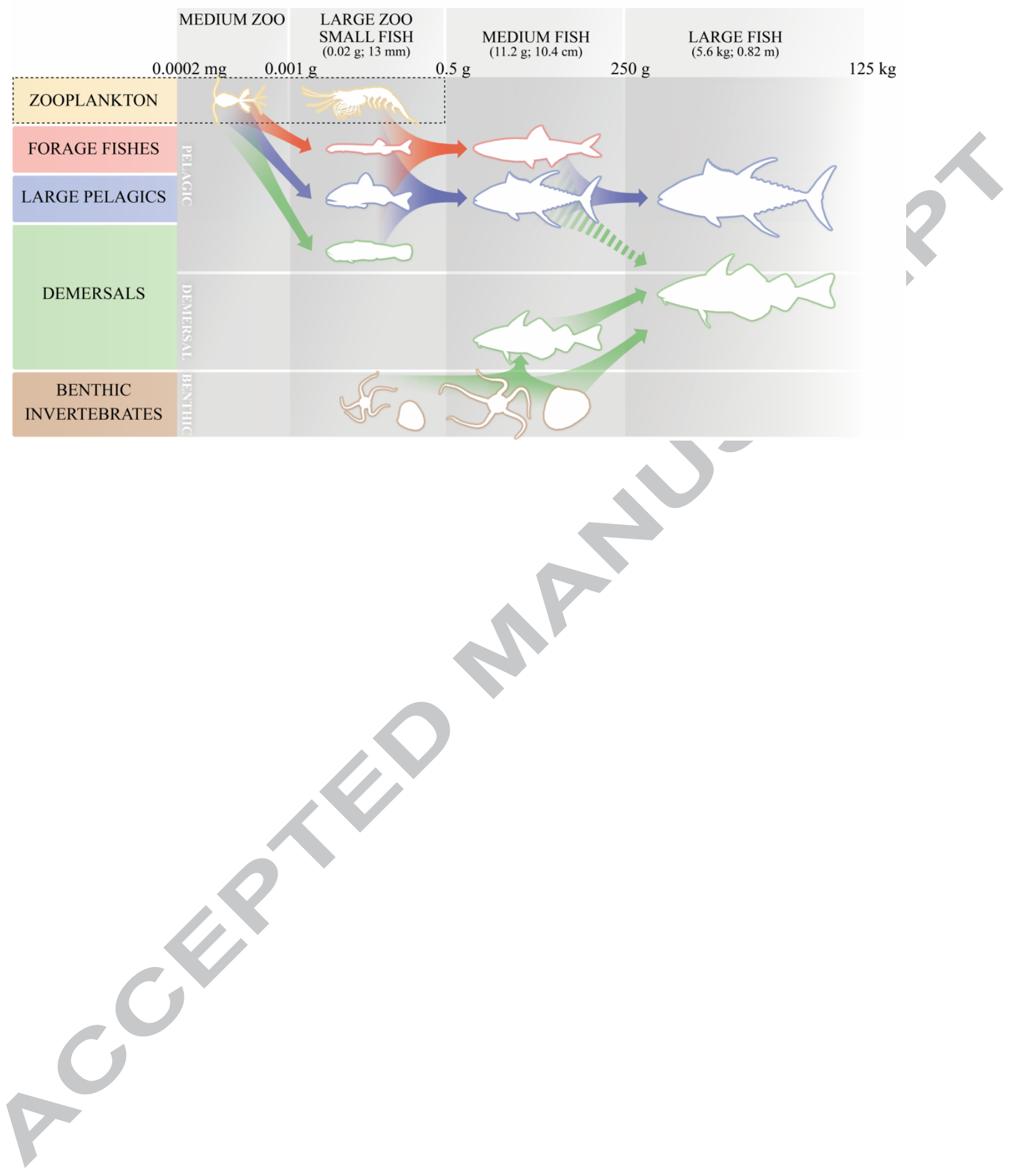



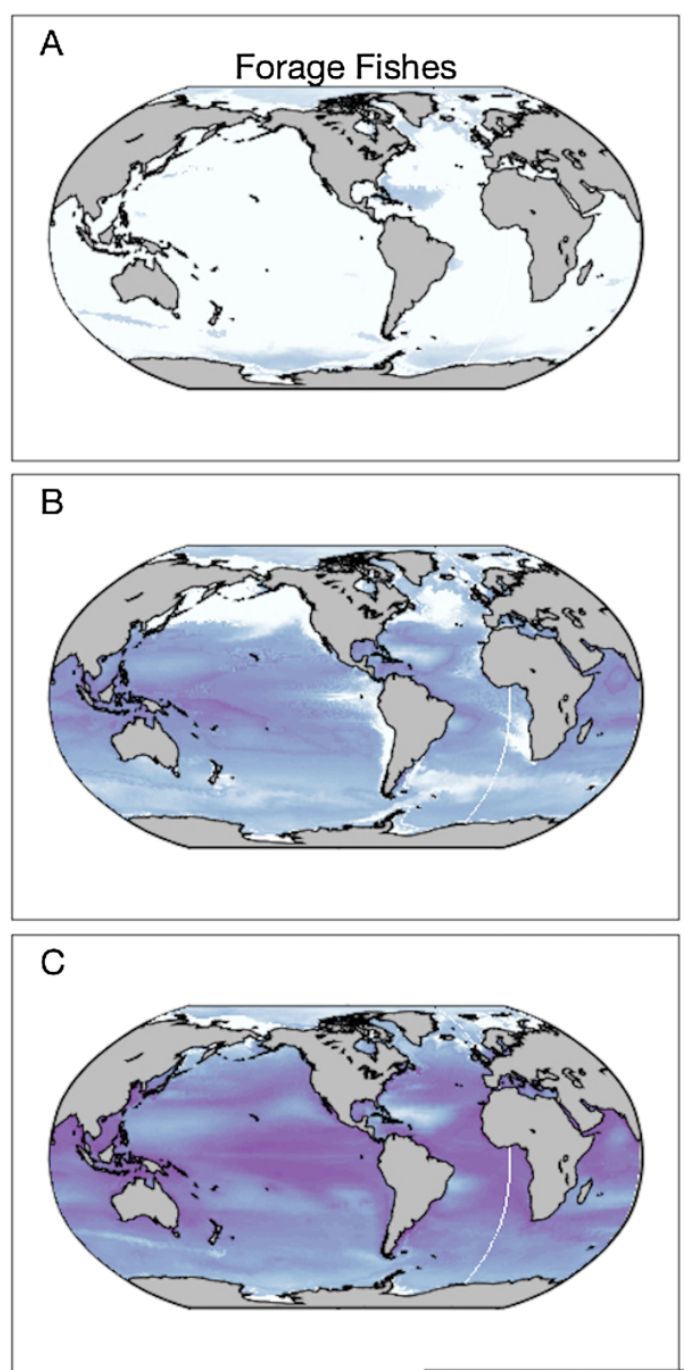
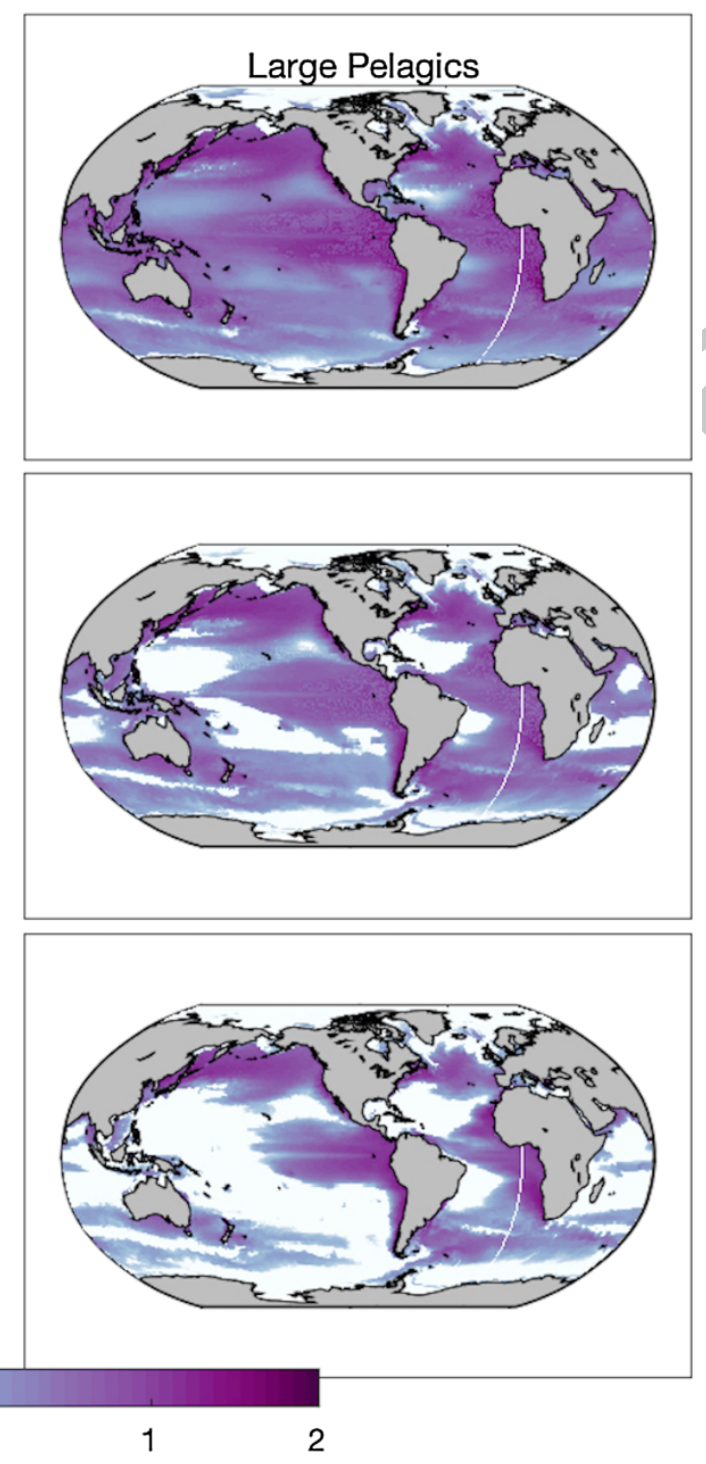


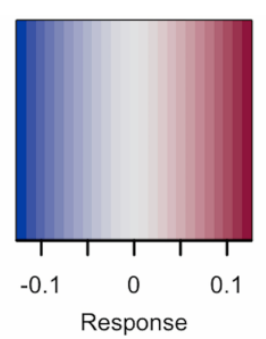

\section{Parameter sensitivity}

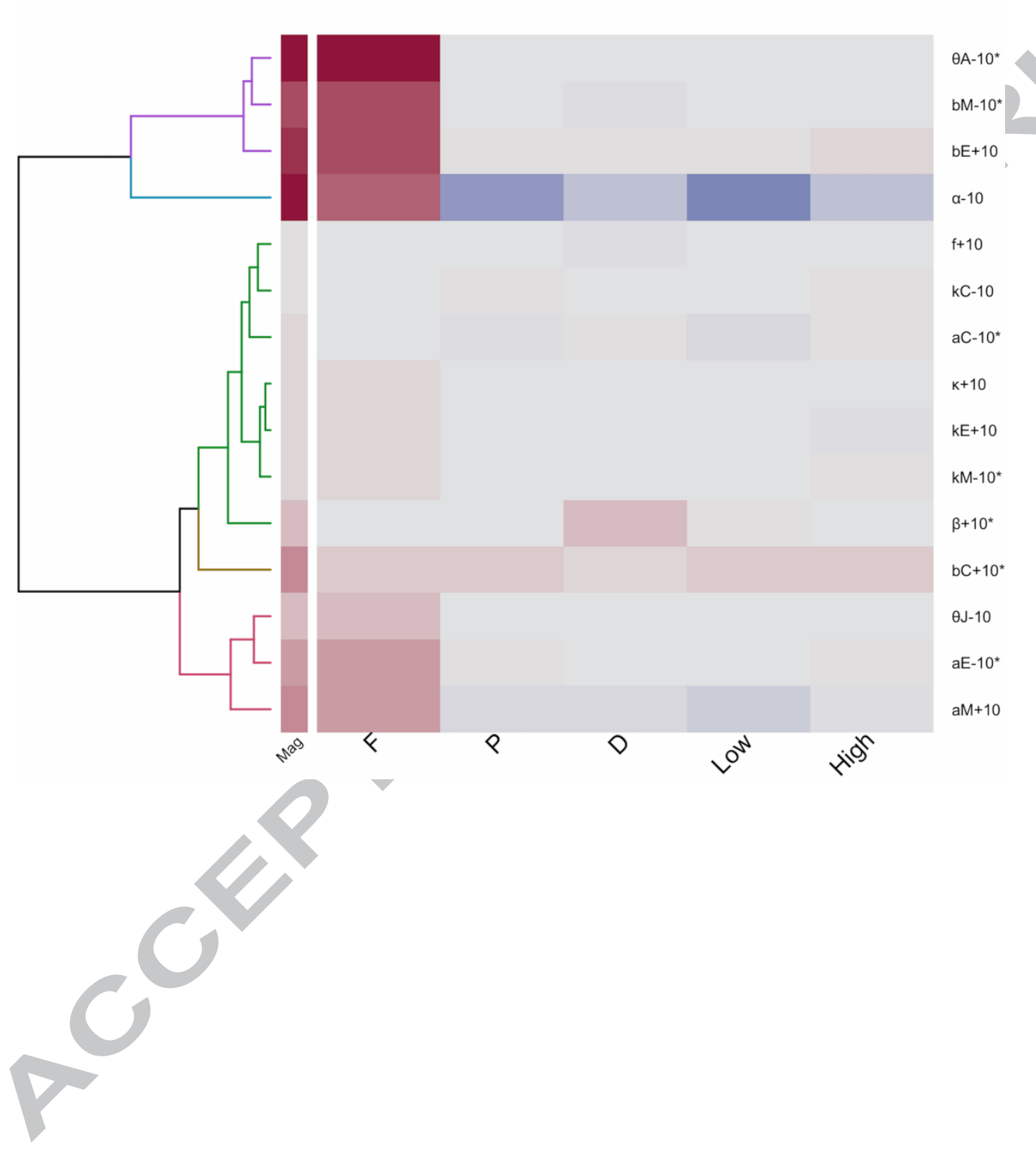



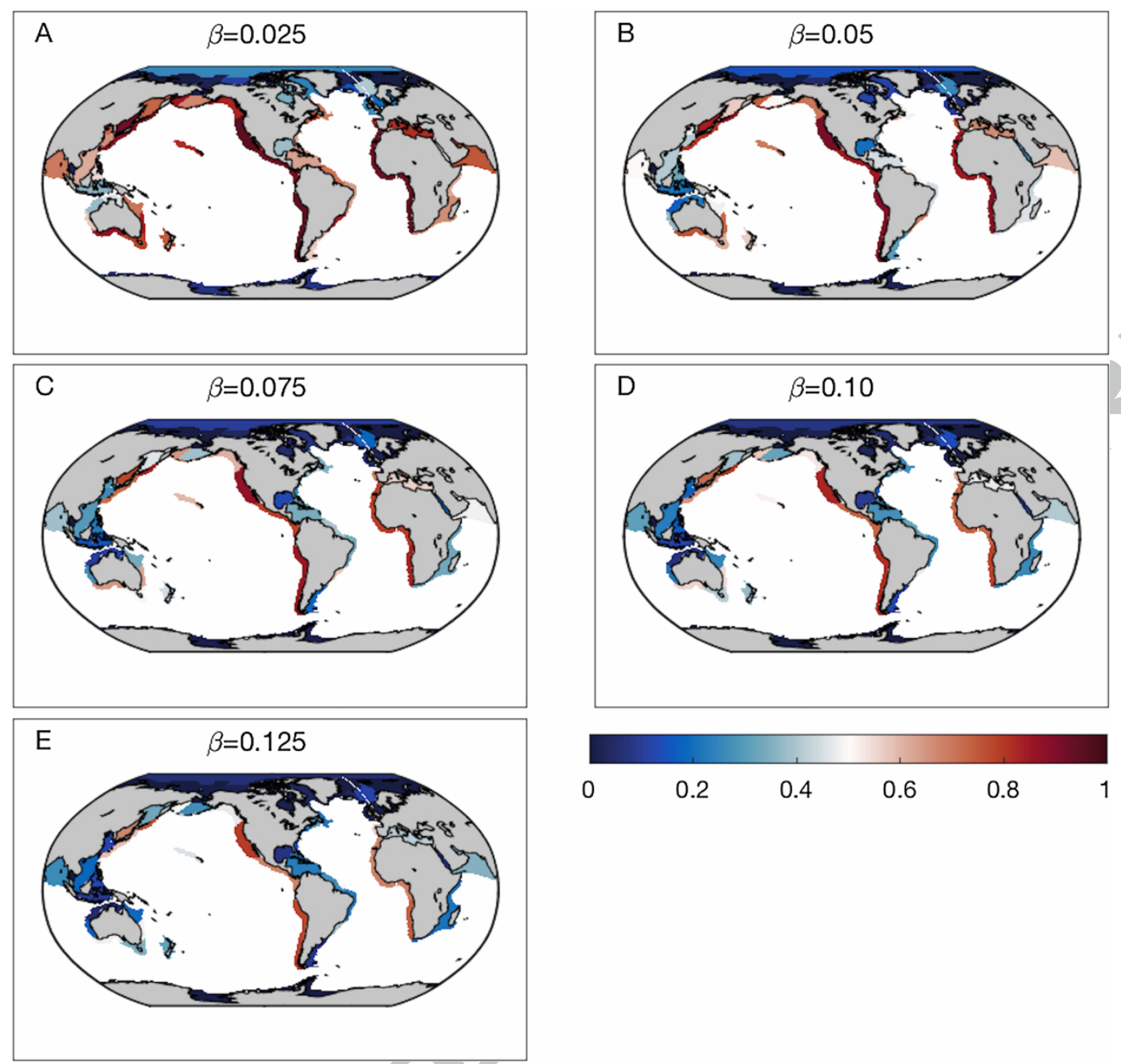

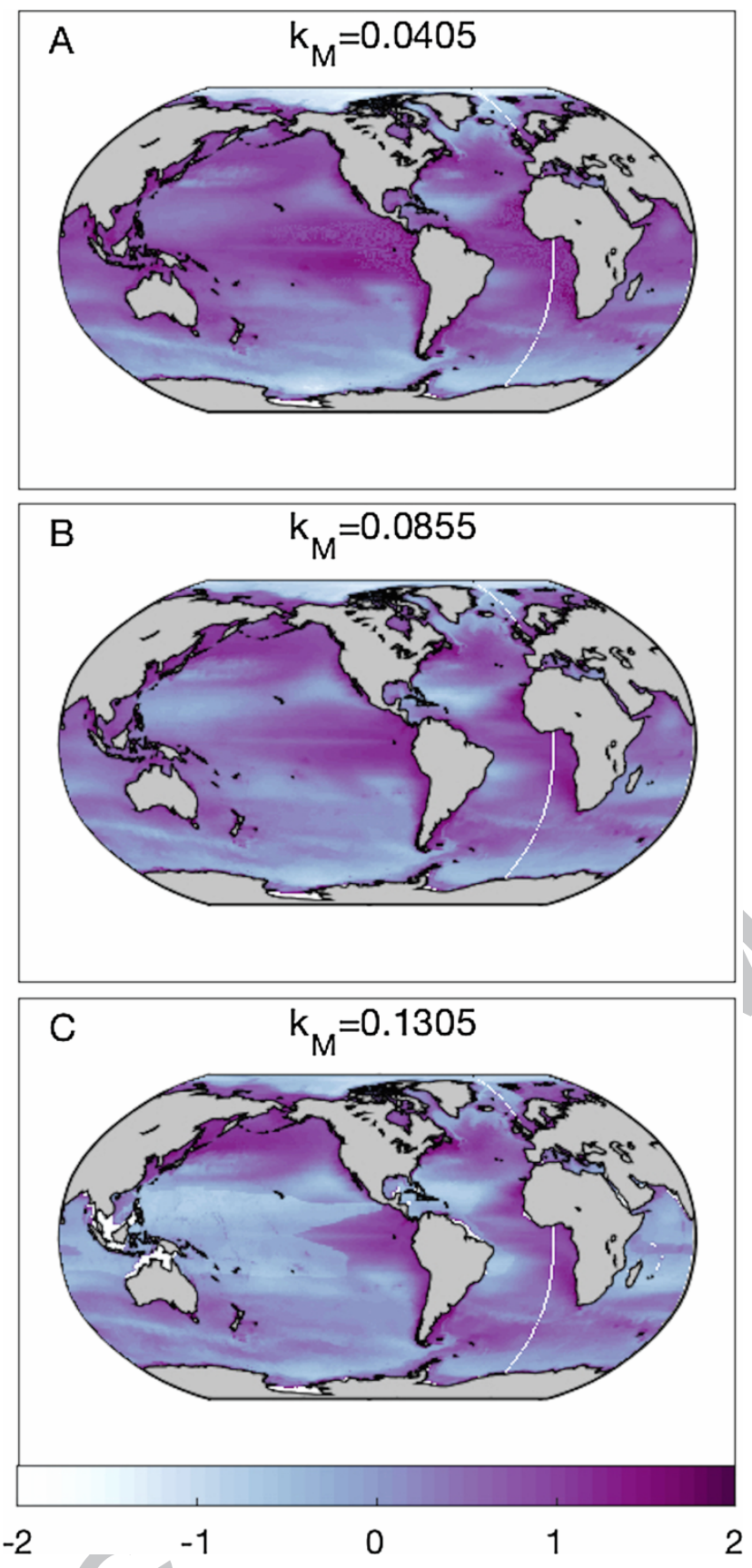

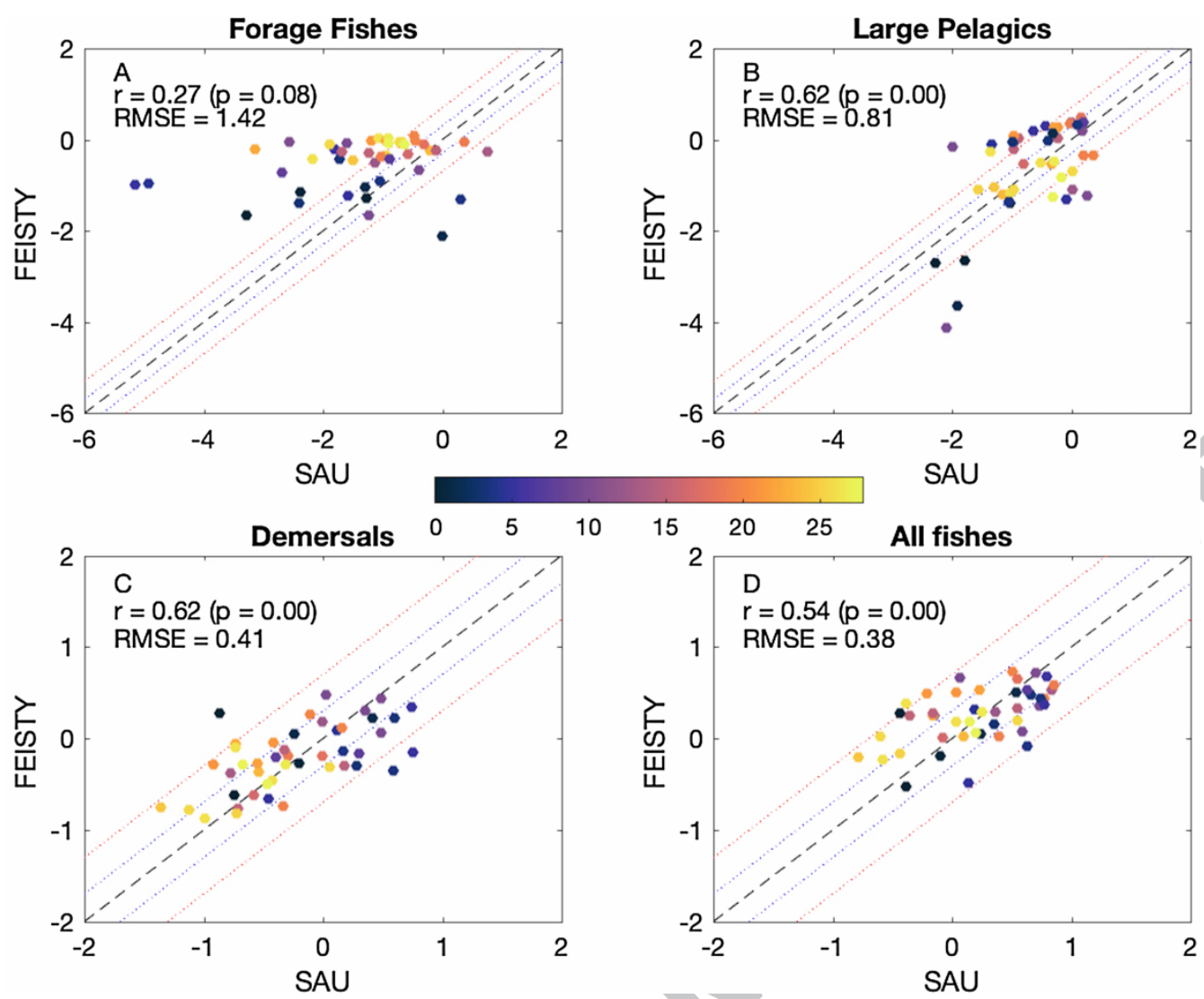

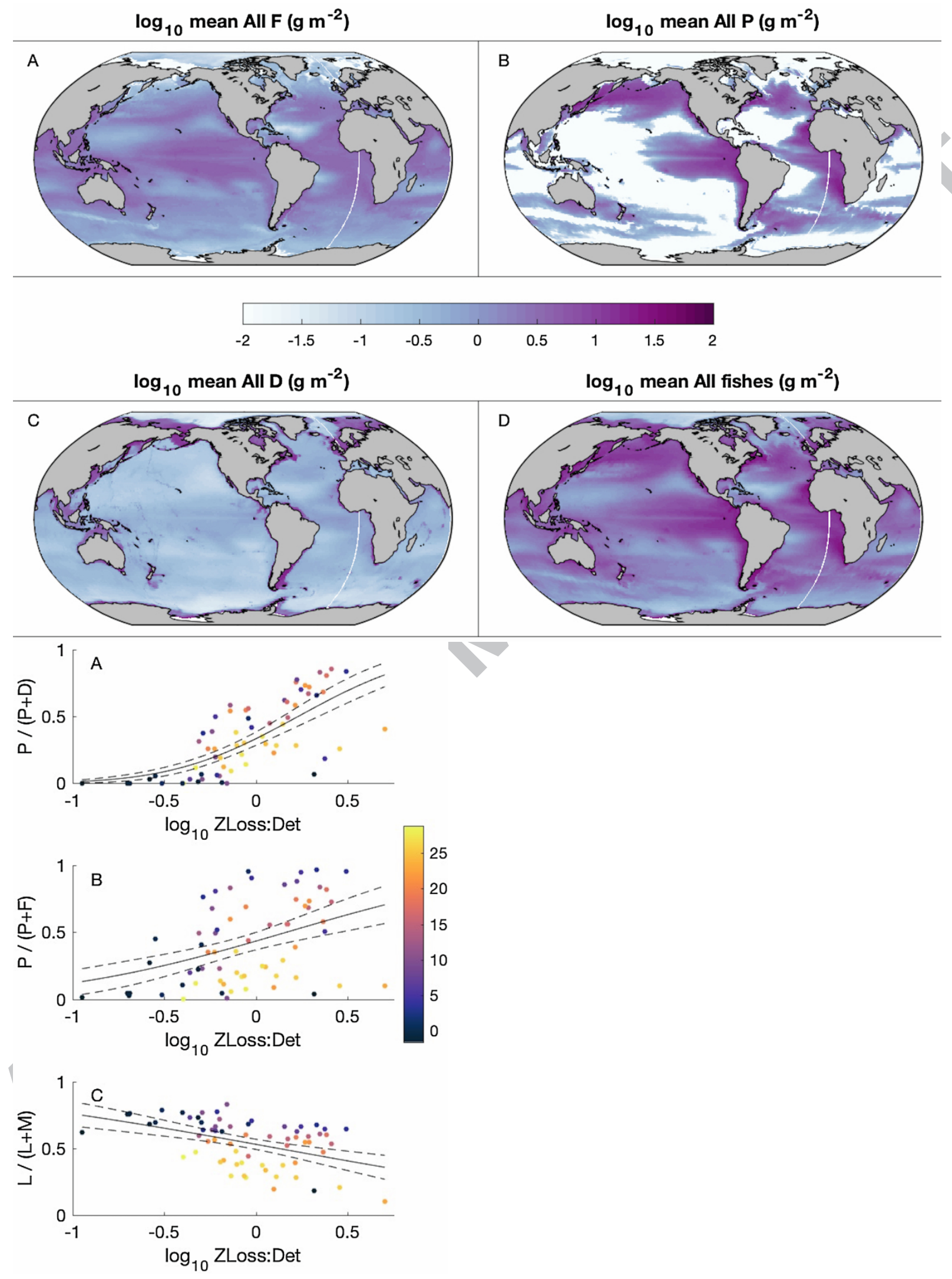


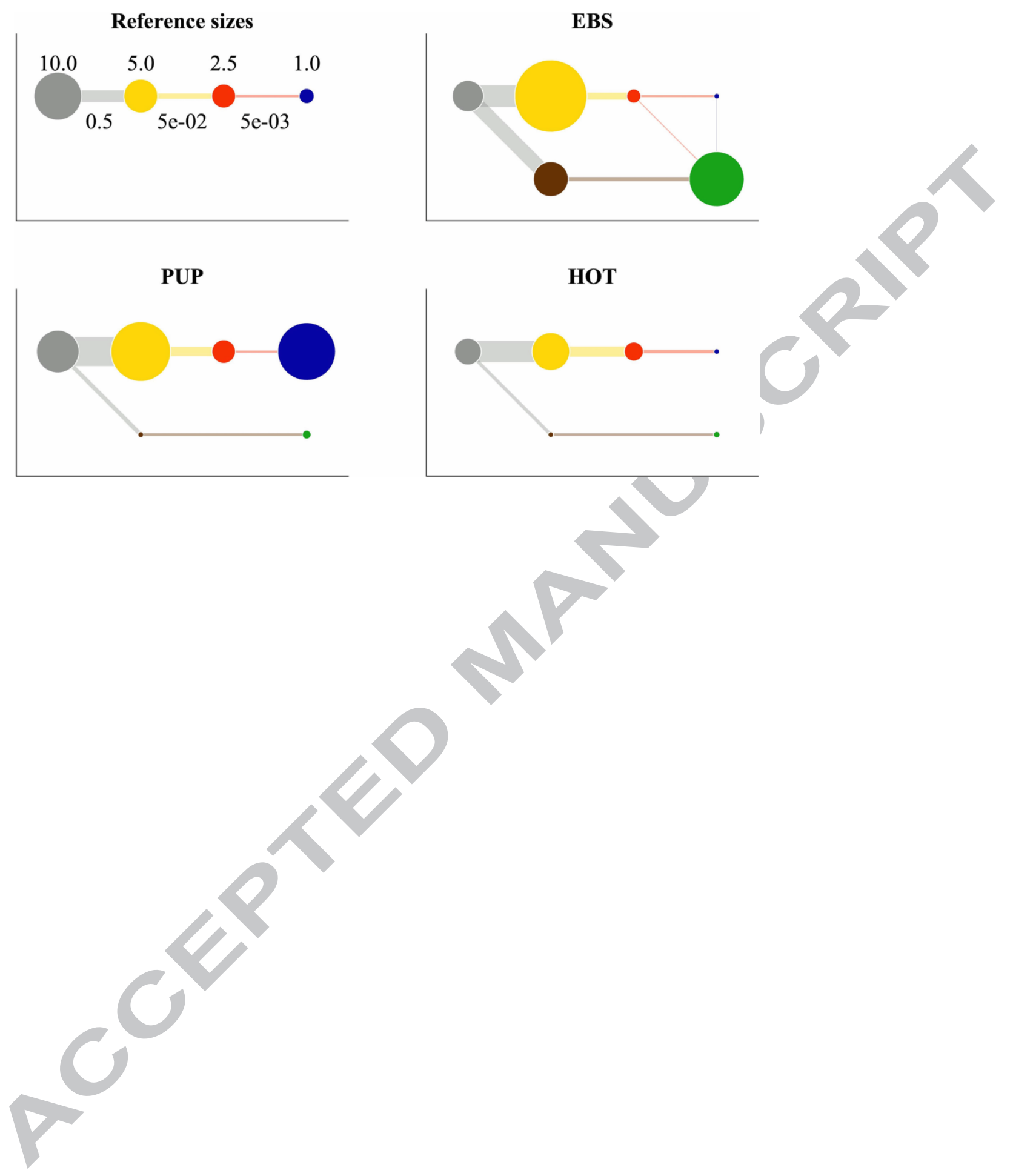


APPENDIX: Model calibration

Complete optimization across all parameters is not possible in a $3 \mathrm{D}$ global context, thus we focus on using seven of the parameters (denoted with asterisks) drawn from the clusters in Figure A1, but acknowledge that there may be other pathways to similar skill. We used the results of the parameter sensitivity to parameterize the model with two goals in mind: (1) coexistence between forage and large pelagic fishes in upwelling areas and (2) high correlations with observation-based catch estimates across functional types. As discussed in the main text, the primary misfit present in the baseline simulations was very low forage fish biomass. We thus first selected the parameter having the largest single effect $\left(\theta_{A}\right)$ and set this to its lower limit (0.5), giving adult forage fish a marked advantage over their juvenile adult counterparts. While this was essential for buoying forage fish biomass, it was not enough on its own. We thus added the possibility of decreasing the weight sensitivity of metabolism $\left(b_{M}\right)$. From the parameter sensitivity results, we selected parameters that had moderate or large effects on forage fish biomass: $a_{E}, b_{M}$, and $\theta_{A}$. The maximum consumption rate intercept $a_{C}$ was jointly varied with $a_{E}$ because of their integrated effect on consumption. We initially focused our calibration on three sites spanning large ecosystem contrasts (the Eastern Bering Sea, the Peruvian Upwelling, and the Hawaii Ocean Time series), before moving to full global calibration (see appendix A1 for details). Catch calibrations, particularly of large pelagic fish, demersal fish, and their fractions, were achieved through $b_{M}, k_{M}$, and ??, and are presented at the LME scale. We allowed each parameter to vary by as much as a factor of 2 from the mid-point values. 


\begin{tabular}{|c|c|c|c|}
\hline Symbol & Description & Value & Units \\
\hline$a_{C}$ & maximum consumption intercept & 50 & $\mathrm{~g}^{\mathrm{bc}-1} \mathrm{y}^{-1}$ \\
\hline$a_{E}$ & encounter intercept & 50 & $m^{2} g^{b e-1} y^{-1}$ \\
\hline$a_{M}$ & metabolism intercept & 4 & $\mathrm{~g}^{\mathrm{bm}-1} \mathrm{y}^{-1}$ \\
\hline$\alpha$ & assimilation efficiency & 0.7 & -- \\
\hline $\mathrm{b}_{\mathrm{C}}$ & maximum consumption slope & -0.21 & -- \\
\hline$b_{\mathrm{E}}$ & encounter slope & -0.21 & \\
\hline$b_{M}$ & metabolism slope & -0.21 & \\
\hline ?? & $\begin{array}{l}\text { transfer efficiency from detritus to benthic } \\
\text { invertebrates }\end{array}$ & 0.075 & \\
\hline$\varepsilon$ & reproductive efficiency & 0.01 & -- \\
\hline$f$ & fishing mortality rate & 0.3 & $y^{-1}$ \\
\hline $\mathrm{k}_{\mathrm{C}}$ & $\begin{array}{l}\text { maximum consumption rate temperature } \\
\text { sensitivity }\end{array}$ & 0.063 & ${ }^{\circ} \mathrm{C}^{-1}$ \\
\hline $\mathrm{k}_{\mathrm{E}}$ & encounter rate temperature sensitivity & 0.063 & ${ }^{\circ} \mathrm{C}^{-1}$ \\
\hline $\mathrm{k}_{\mathrm{M}}$ & metabolism temperature sensitivity & 0.063 & ${ }^{\circ} \mathrm{C}^{-1}$ \\
\hline$\kappa$ & fraction of energy allocated to growth & 0.5 & -- \\
\hline$\mu_{\text {nat }}$ & natural mortality rate constant & 0.1 & $y^{-1}$ \\
\hline$\theta_{\mathrm{A}}$ & large fishes preference on medium forage fish & 0.75 & -- \\
\hline$\theta_{\mathrm{D}}$ & preference of large demersals on pelagic prey & 0.75 & -- \\
\hline$\theta_{\mathrm{J}}$ & $\begin{array}{l}\text { medium large pelagic fish preference on large } \\
\text { zooplankton }\end{array}$ & 0.75 & -- \\
\hline$\theta_{\mathrm{S}}$ & $\begin{array}{l}\text { medium fish preference on medium } \\
\text { zooplankton }\end{array}$ & 0.25 & -- \\
\hline
\end{tabular}

Table A1. Parameter base values used in the parameter sensitivity test and varied in the model calibration by a factor of 2 . Most are mid-point values from the literature or those most often employed in size-based models. Note that the rate variables have units of per year, whereas Table 1 uses per day.

Intercepts of encounter rate and maximum consumption rate

Using the mid-point literature parameters, the intercepts of encounter rate and maximum consumption rate were first examined. To calibrate the feeding responses, the encounter rate intercept $\left(a_{E}\right)$ and the maximum consumption rate intercept $\left(a_{C}\right)$ were adjusted so that mean feeding levels were 0.5-0.8 of maximum consumption (C) (c.f. Hartvig et al. 2011, i.e. fish stomachs are rarely completely full or empty; Figure A3) and that mean gross growth efficiency (GGE; energy available for growth as a fraction of total energy consumed) was 0.1-0.6 and decreased with size (Blaxter \& Hunter 1982; Figure A4). For visual ease, $a_{E}$ and $a_{C}$ are presented as their values for annual rather than daily rates, i.e. $a_{E}=70\left(\mathrm{~m}^{2} \mathrm{~g}^{\mathrm{be}-1} \mathrm{y}^{-1}\right)=a_{E}=70 / 365\left(\mathrm{~m}^{2} \mathrm{~g}^{\mathrm{be}-1}\right.$ $\left.\mathrm{d}^{-1}\right)=0.1918\left(\mathrm{~m}^{2} \mathrm{~g}^{\mathrm{be}-1} \mathrm{~d}^{-1}\right.$; Table 1$)$. A lower intercept of maximum consumption rate was necessary to simulate forage fish coexistence in upwelling areas (Figures A1, A2). This lower intercept of $a_{C}=10\left(\mathrm{y}^{-1}\right)$ was also required for GGE to decrease with size (Figure A5). However, 
this maximum consumption rate led to feeding levels higher than the desired 0.8 (Figure A4). Lower feeding levels and increased forage fish biomass were next sought by varying the weight exponents of metabolism and maximum consumption rate using a slightly higher $a_{C}=20\left(\mathrm{y}^{-1}\right)$.
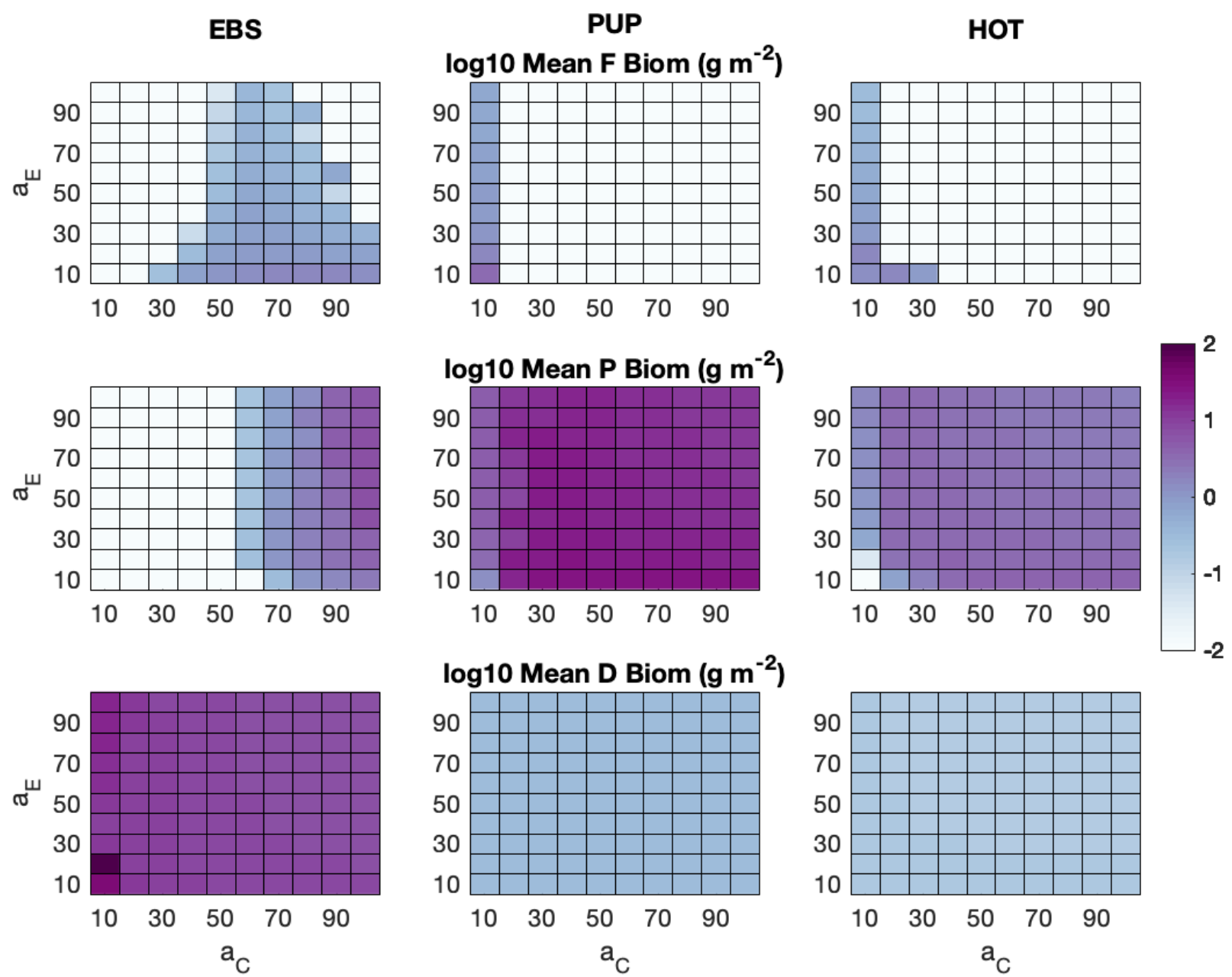

Figure A1. Mean $\log 10$ biomass of (Top) forage fish (F), (Middle) large pelagic fish (P), and (Bottom) demersal fish (D) at the 3 domain example locations: Eastern Bering Sea (EBS), Peruvian Upwelling (PUP), and Hawaii Ocean Time series (HOT). $\theta_{A}=0.5, b_{C}=b_{E}=b_{M}=-0.21$. 

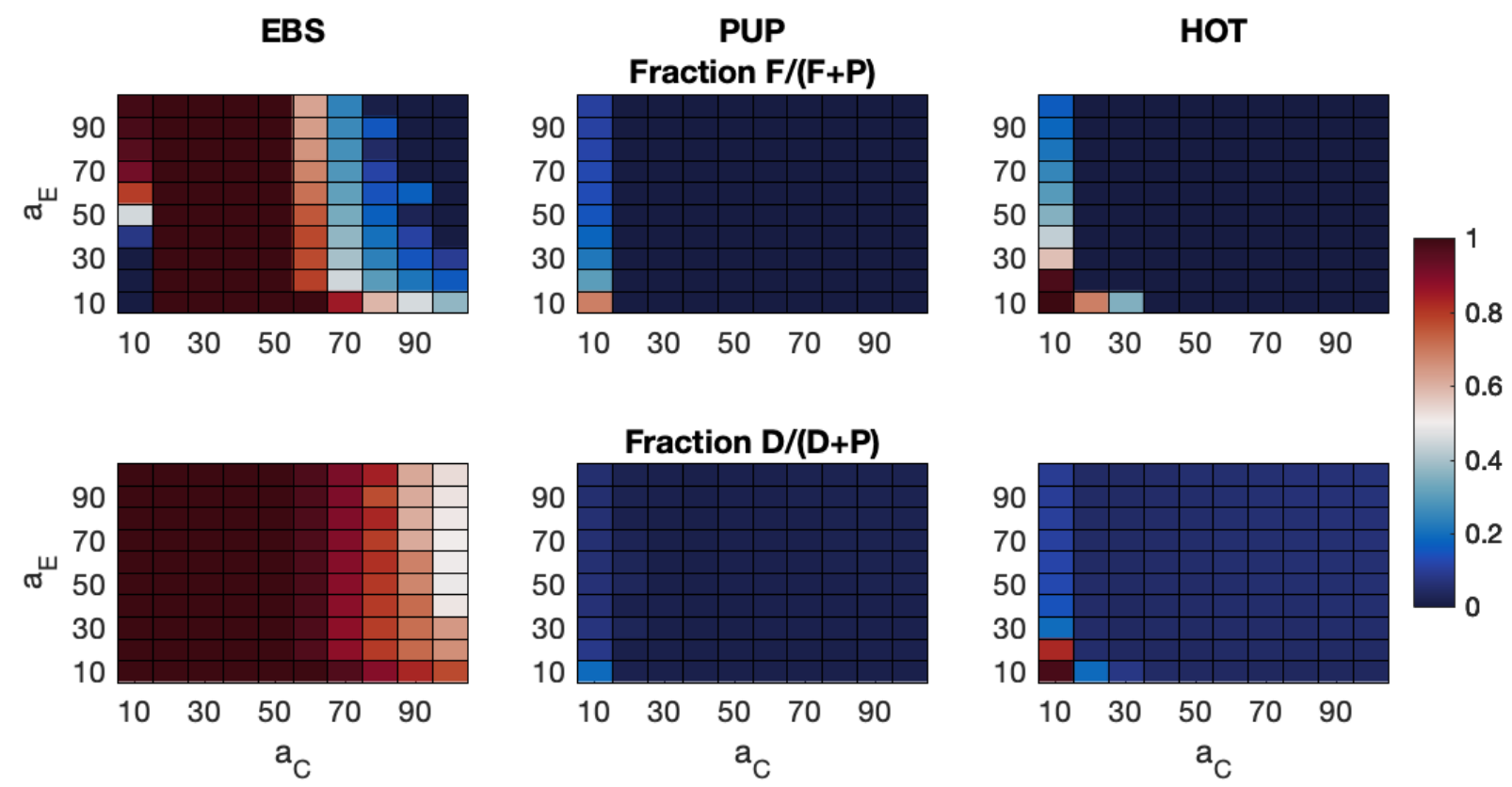

Figure A2. Fractions of (Top) forage fish (F) and (Bottom) demersal fish (D) in reference to large pelagic fish $(\mathrm{P})$ at the 3 domain example locations: Eastern Bering Sea (EBS), Peruvian Upwelling (PUP), and Hawaii Ocean Time series (HOT). $\theta_{\mathrm{A}}=0.5, \mathrm{~b}_{\mathrm{C}}=\mathrm{b}_{\mathrm{E}}=\mathrm{b}_{\mathrm{M}}=-0.21$. 
EBS
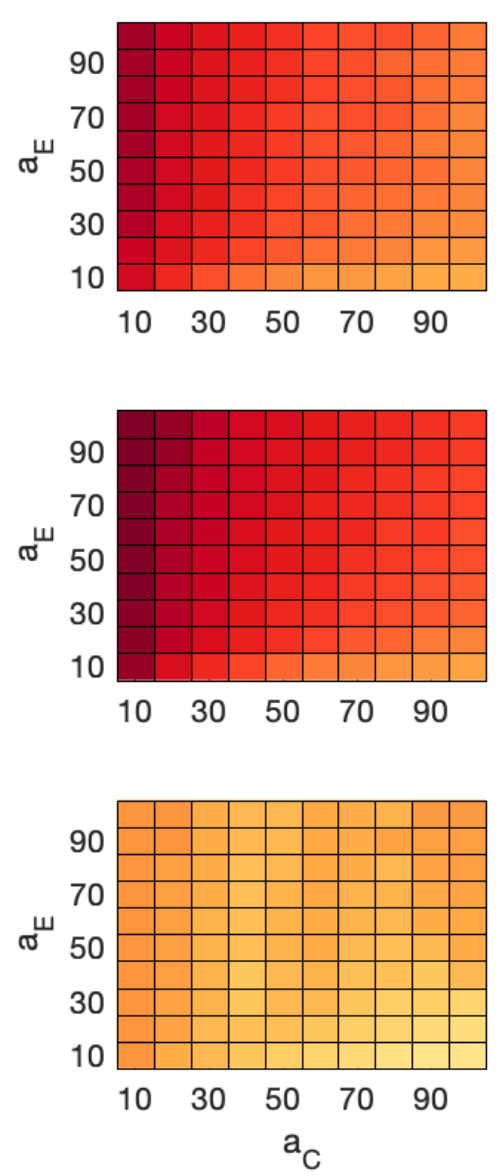

PUP

$S$ mean feeding level

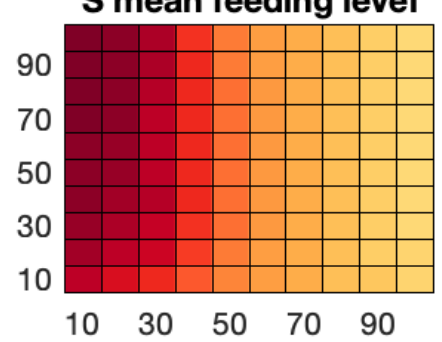

M mean feeding level

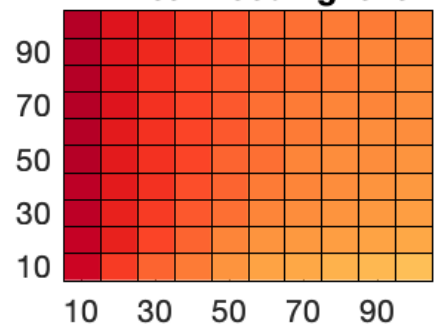

L mean feeding level

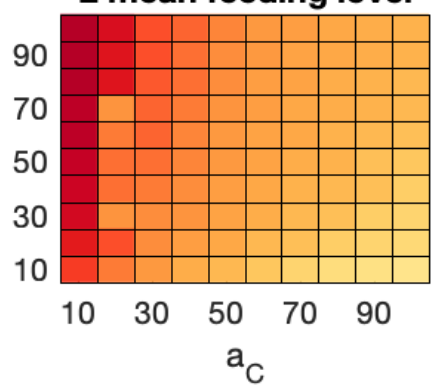

HOT
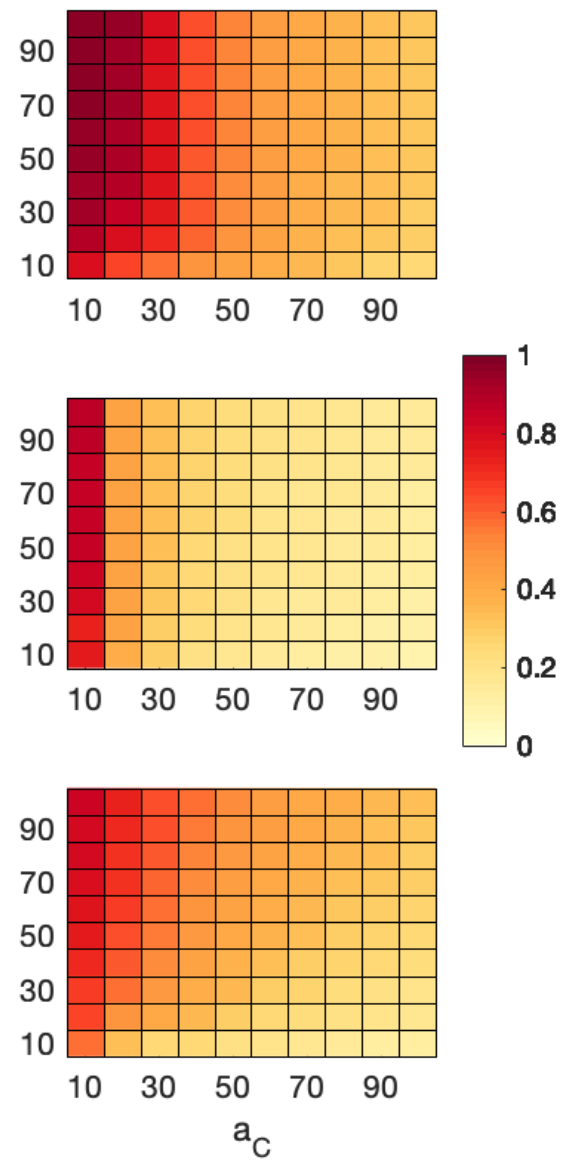

Figure A3. Feeding level (fraction of maximum consumption rate) of (Top) small (S), (Middle) medium (M), and (Bottom) large (L) fishes at the 3 domain example locations: Eastern Bering Sea (EBS), Peruvian Upwelling (PUP), and Hawaii Ocean Time series (HOT). $\theta_{\mathrm{A}}=0.5, \mathrm{~b}_{\mathrm{C}}=\mathrm{b}_{\mathrm{E}}=$ $\mathrm{b}_{\mathrm{M}}=-0.21$. 
EBS
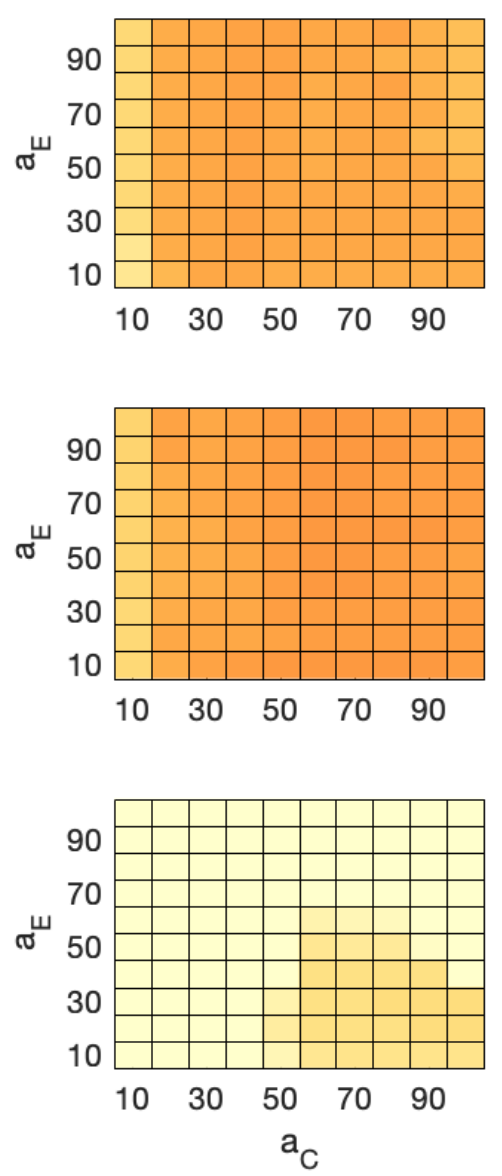

PUP $S$ mean gross growth efficiency

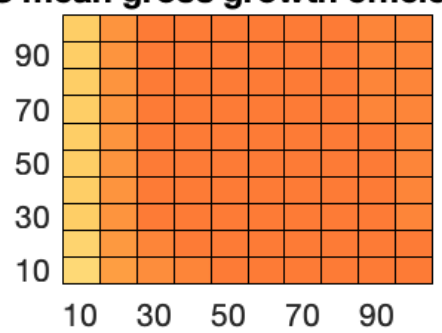

HOT
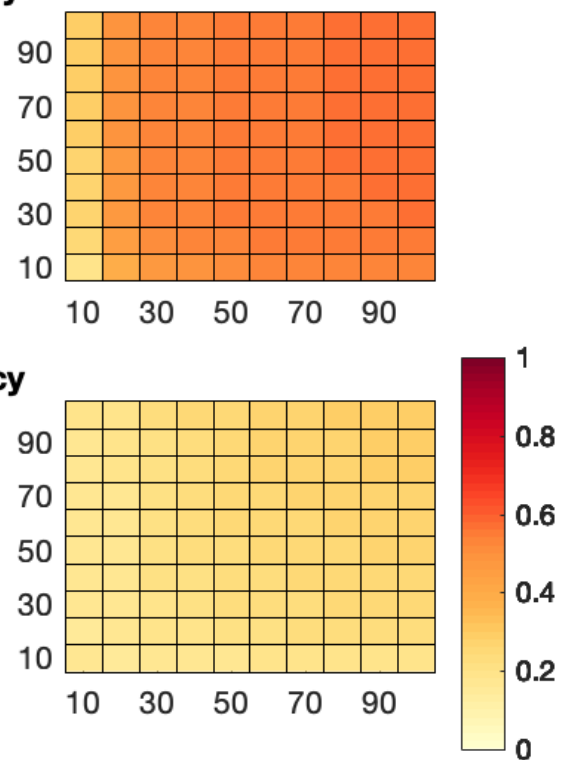

L mean gross growth efficiency
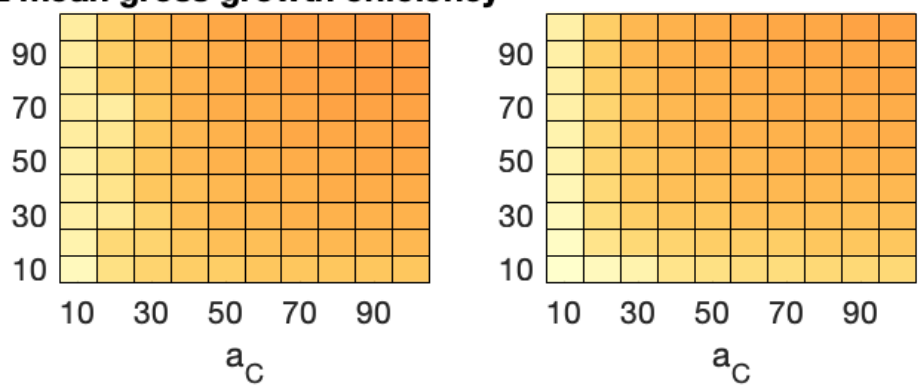

Figure A4. Gross growth efficiency of (Top) small (S), (Middle) medium (M), and (Bottom) large (L) fishes at the 3 domain example locations: Eastern Bering Sea (EBS), Peruvian Upwelling (PUP), and Hawaii Ocean Time series (HOT). $\theta_{\mathrm{A}}=0.5, \mathrm{~b}_{\mathrm{C}}=\mathrm{b}_{\mathrm{E}}=\mathrm{b}_{\mathrm{M}}=-0.21$. 
Weight exponents of metabolism and maximum consumption rate

The intercepts were changed to $a_{C}=20\left(\mathrm{y}^{-1}\right)$ and $a_{E}=70\left(\mathrm{y}^{-1}\right)$ to next examine the effects of the weight sensitivity of metabolism $\left(b_{M}\right)$ and maximum consumption rate $\left(b_{C}\right)$. For these simulations and all following, $b_{E}=-0.20$ following Hartvig et al. (2011) and Hartvig and Andersen (2013; Table 1). Coexistence could be achieved by lowering the metabolic rate sizesensitivity (less negative exponent) with respect to the maximum consumption rate sizesensitivity, particularly near a difference of 0.075 in the exponents (Figures A5, A6).

EBS
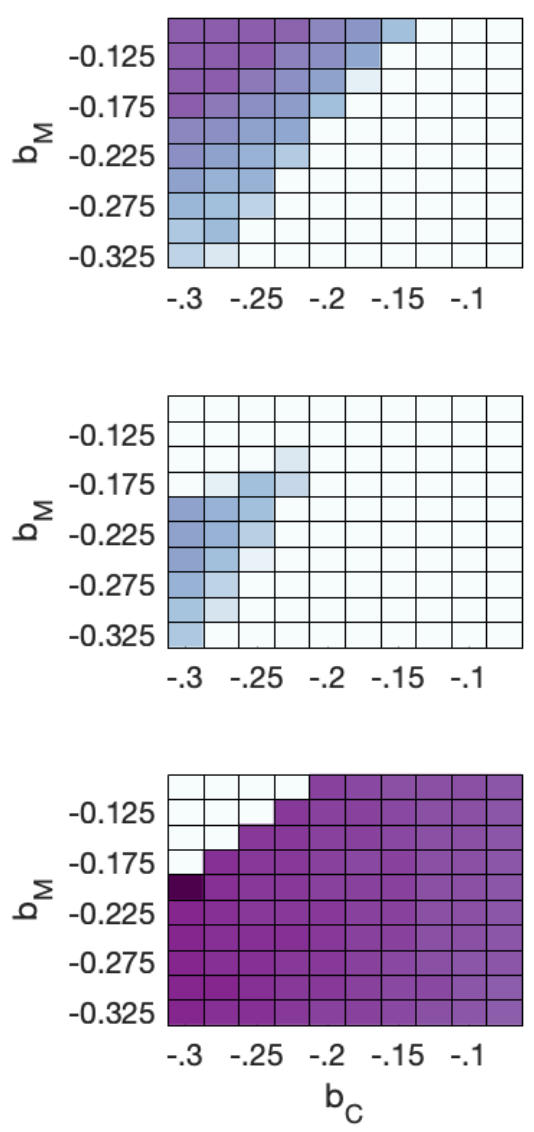

PUP

\section{$\log 10$ Mean F Biom $\left(\mathrm{g} \mathrm{m}^{-2}\right)$}

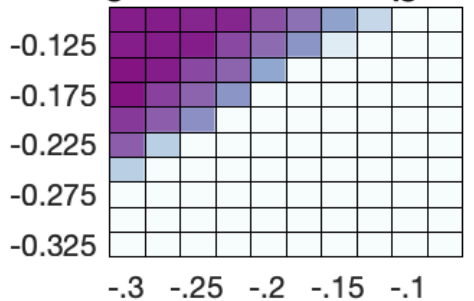

$\log 10$ Mean P Biom $\left(\mathrm{g} \mathrm{m}^{-2}\right)$
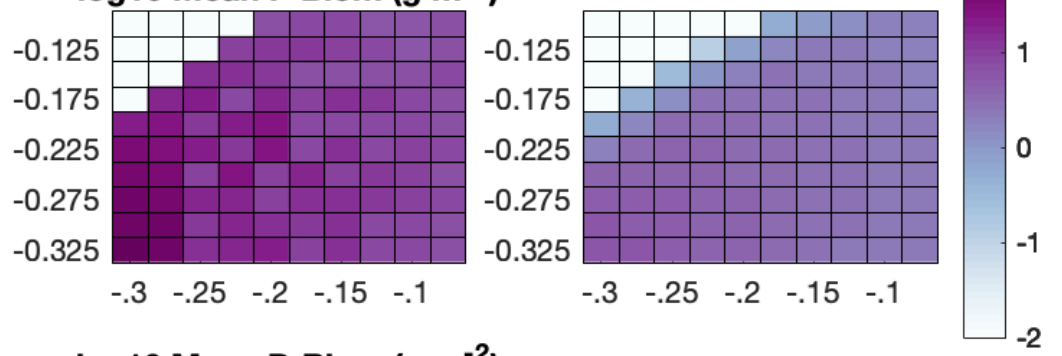

$\log 10$ Mean D Biom $\left(\mathrm{g} \mathrm{m}^{-2}\right)$

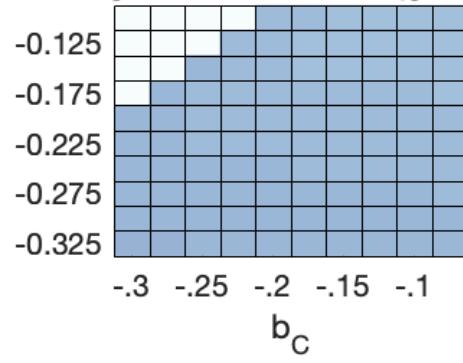

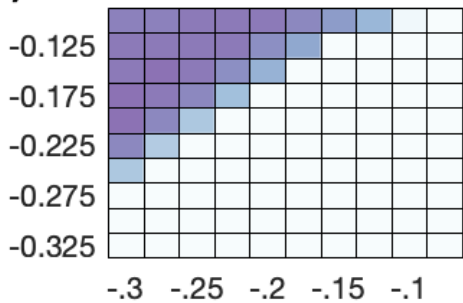

HOT

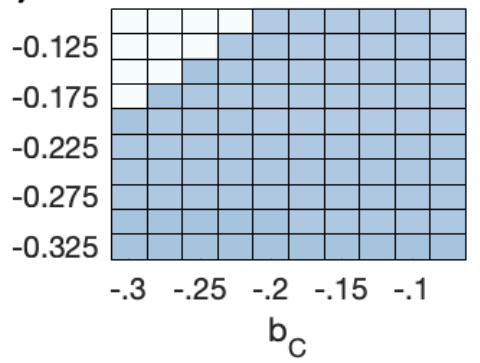

Figure A5. Mean $\log 10$ biomass of (Top) forage fish (F), (Middle) large pelagic fish (P), and (Bottom) demersal fish (D) at the 3 domain example locations: Eastern Bering Sea (EBS), Peruvian Upwelling (PUP), and Hawaii Ocean Time series (HOT). $\theta_{\mathrm{A}}=0.5, \mathrm{a}_{\mathrm{C}}=20, \mathrm{a}_{\mathrm{E}}=70, \mathrm{~b}_{\mathrm{E}}=$ -0.20 . 
EBS
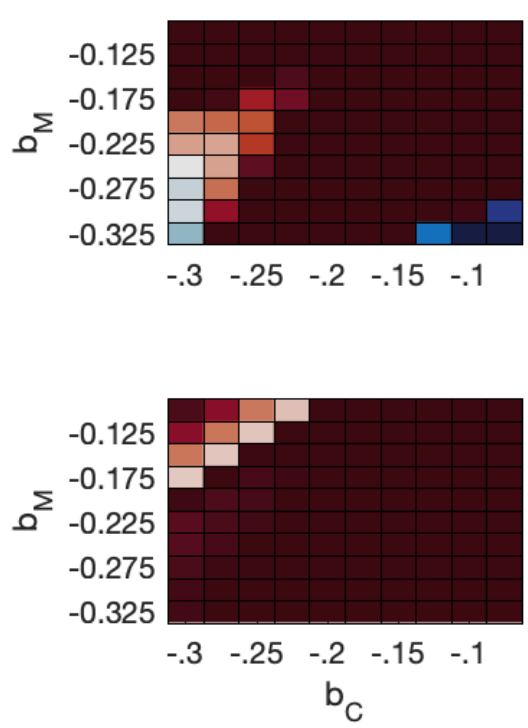

PUP

Fraction $F /(F+P)$

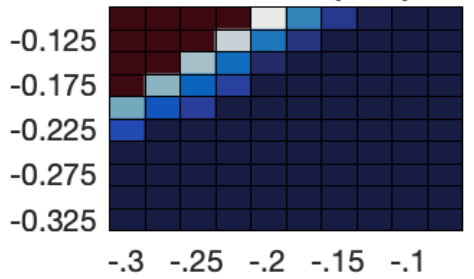

Fraction $D /(D+P)$

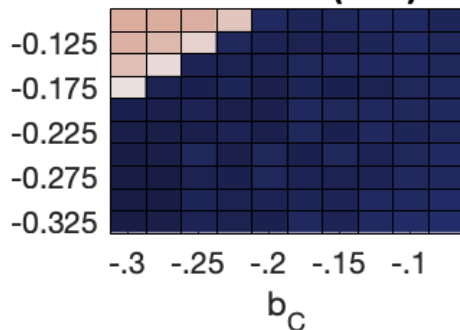

HOT

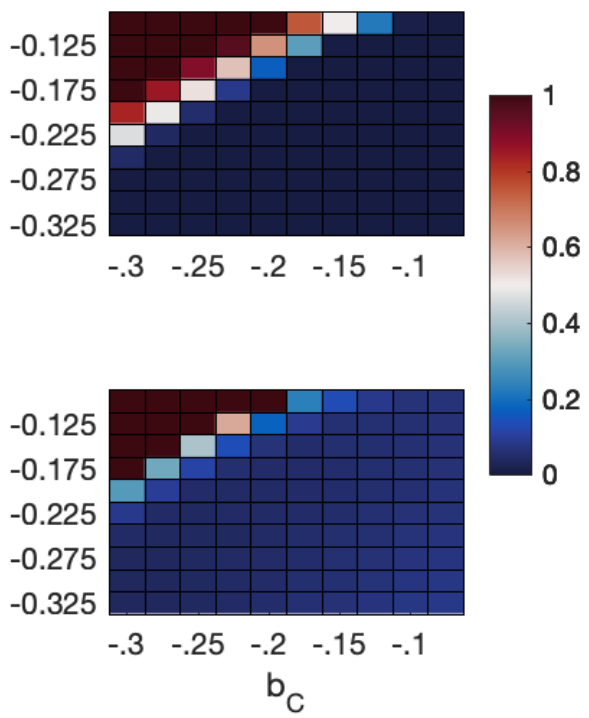

Figure A6. Fractions of (Top) forage fish (F) and (Bottom) demersal fish (D) in reference to large pelagic fish $(\mathrm{P})$ at the 3 domain example locations: Eastern Bering Sea (EBS), Peruvian Upwelling (PUP), and Hawaii Ocean Time series (HOT). $\theta_{\mathrm{A}}=0.5, \mathrm{a}_{\mathrm{C}}=20, \mathrm{a}_{\mathrm{E}}=70, \mathrm{~b}_{\mathrm{E}}=-0.20$.

\section{Weight exponent and temperature sensitivity of metabolism}

The maximum consumption rate exponent was set at $b_{C}=-0.25$ (Hartvig et al. 2011, Hartvig \& Andersen 2013; Table 1) to next examine the catch correlations using various weight $\left(b_{M}\right)$ and temperature sensitivities $\left(k_{M}\right)$ of metabolism. Catch correlations of forage fish, demersals, and all fish were rather insensitive, but large pelagic catch and the fraction of the catch that was large pelagics benefitted from stronger metabolic weight sensitivity (more negative exponents) and temperature-dependence that ranged from 0.07-0.09 (Figure A7). When the weight exponent and the temperature dependence of metabolism were at the higher values, large pelagic catch and the fraction of the catch that was large pelagics were underestimated in warm LMEs (Figures A8-11). To achieve both coexistence and high catch correlations, a metabolic rate exponent of $b_{M}=-0.175$ was selected. 

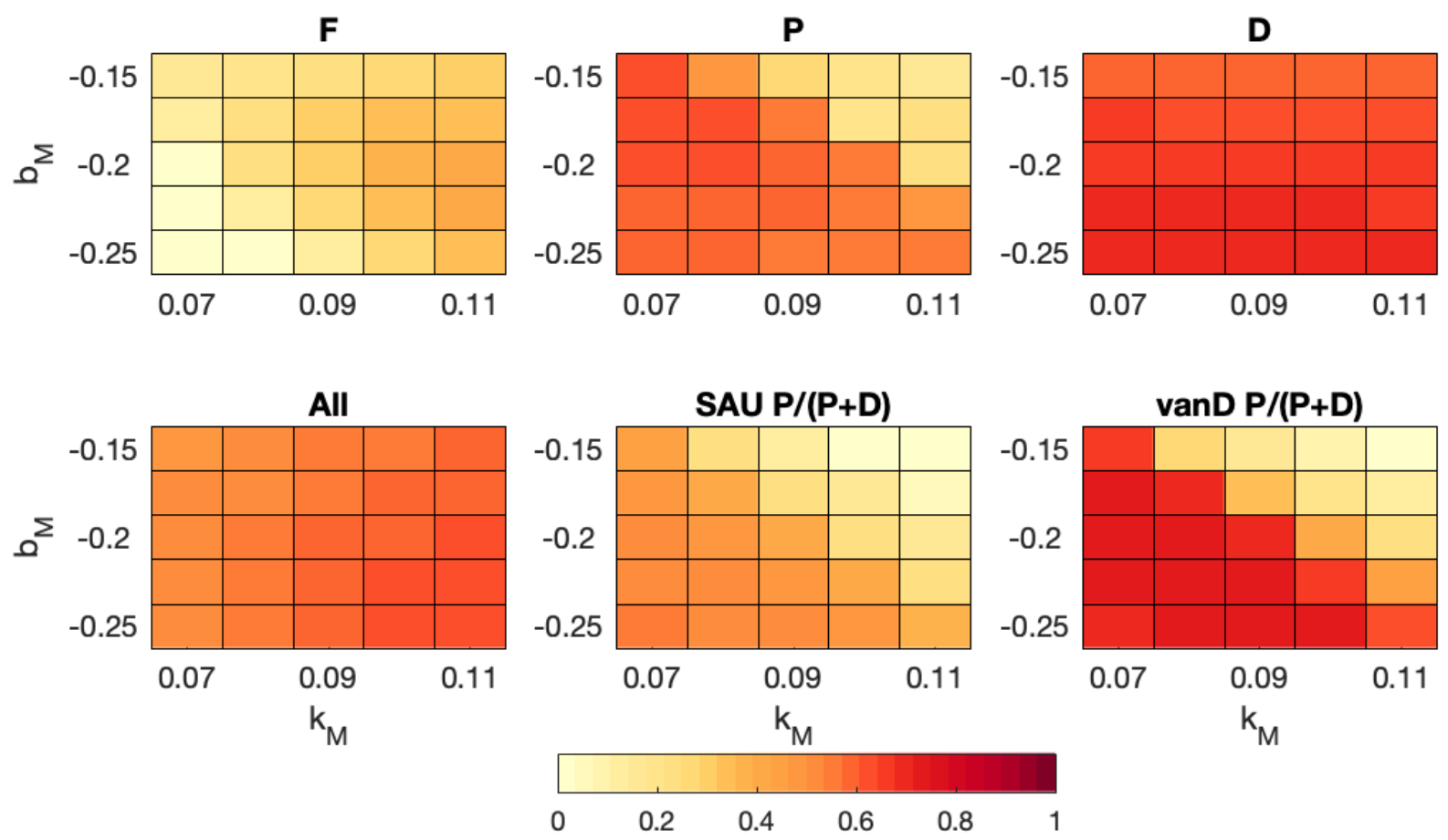

Figure A7. Correlation (r) with SAU catches and Van Denderen (vanD) fraction pelagics by LME. $\theta_{\mathrm{A}}=0.5, \mathrm{a}_{\mathrm{C}}=20, \mathrm{a}_{\mathrm{E}}=70, \mathrm{~b}_{\mathrm{E}}=-0.20, \mathrm{~b}_{\mathrm{C}}=-0.25$. 


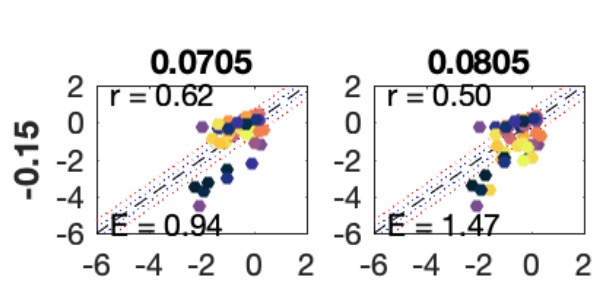

\section{Large Pelagics}
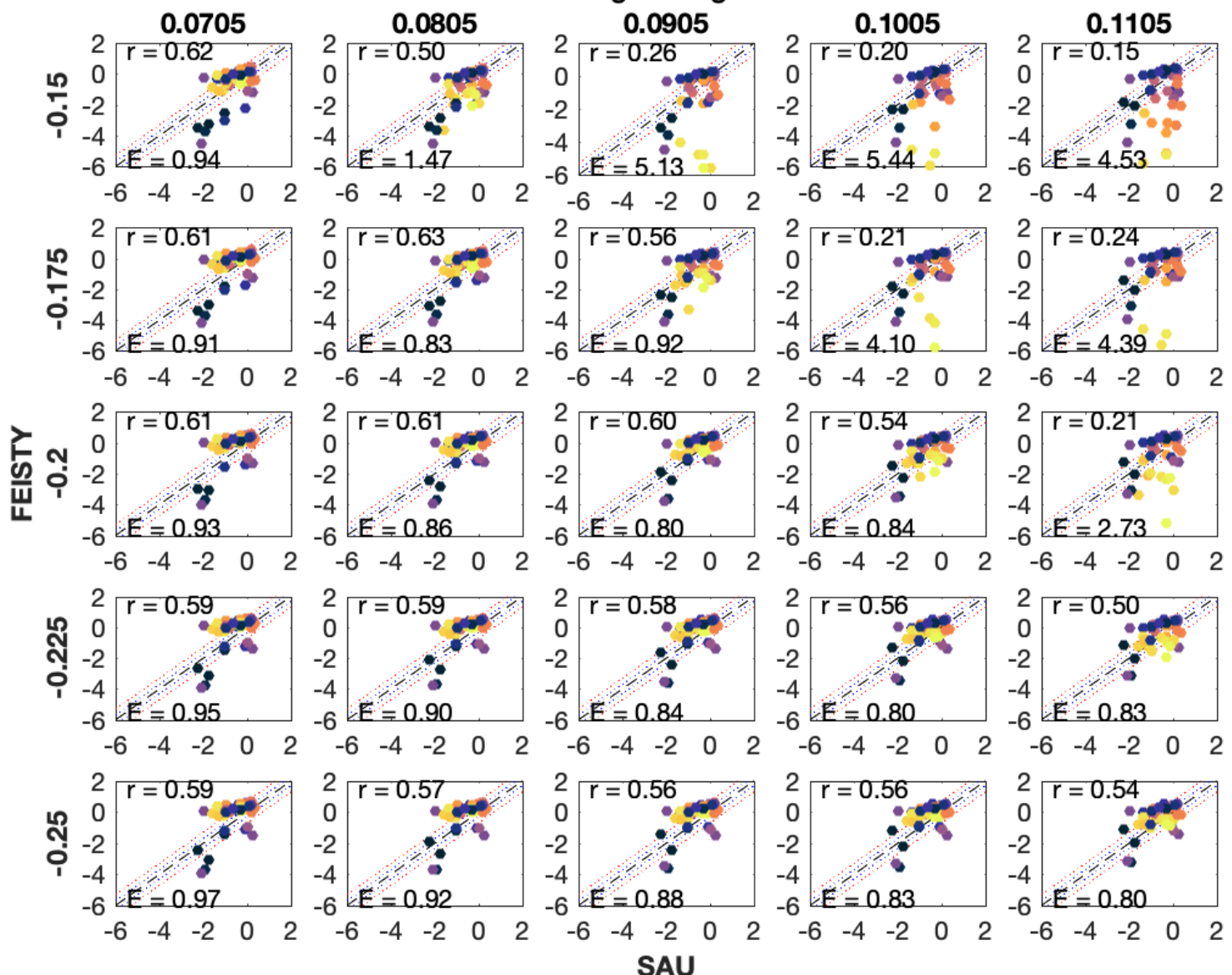

Figure A8. Comparison of FEISTY large pelagic fish catch with SAU catch by LME. The rows are different values of metabolic weight sensitivity $\left(b_{M}\right)$ and the columns are different values of metabolic temperature sensitivity $\left(k_{M}\right)$. Correlations (r) and root mean square error (E) are given. Dot color indicates mean pelagic (top $100 \mathrm{~m}$ ) temperature $\left({ }^{\circ} \mathrm{C}\right)$ of the LME. Dashed lines represent 1:1 (black), $2 x$ difference (blue), $5 x$ difference (red). $\theta_{A}=0.5, a_{C}=20, a_{E}=70, b_{E}=$ $-0.20, \mathrm{~b}_{\mathrm{C}}=-0.25$. 

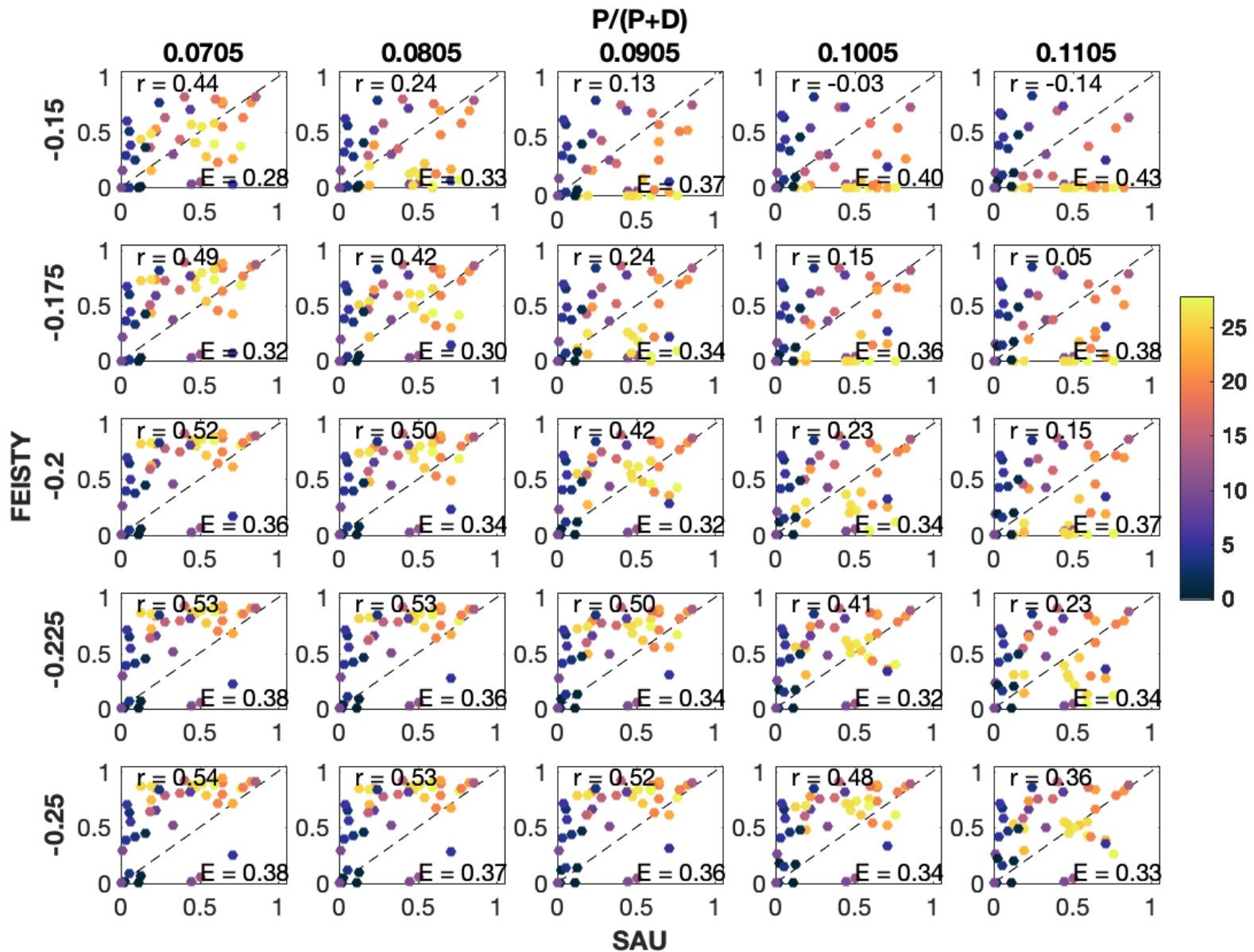

Figure A9. Comparison of FEISTY fraction of catch that is large pelagic fish with SAU catch by LME. The rows are different values of metabolic weight sensitivity $\left(b_{M}\right)$ and the columns are different values of metabolic temperature sensitivity $\left(k_{M}\right)$. Correlations $(\mathrm{r})$ and root mean square error (E) are given. Dot color indicates mean pelagic (top $100 \mathrm{~m})$ temperature $\left({ }^{\circ} \mathrm{C}\right)$ of the LME. Dashed lines represent 1:1 (black), $2 \mathrm{x}$ difference (blue), $5 \mathrm{x}$ difference (red). $\theta_{\mathrm{A}}=0.5, \mathrm{a}_{\mathrm{C}}=20, \mathrm{a}_{\mathrm{E}}$ $=70, \mathrm{~b}_{\mathrm{E}}=-0.20, \mathrm{~b}_{\mathrm{C}}=-0.25$. 

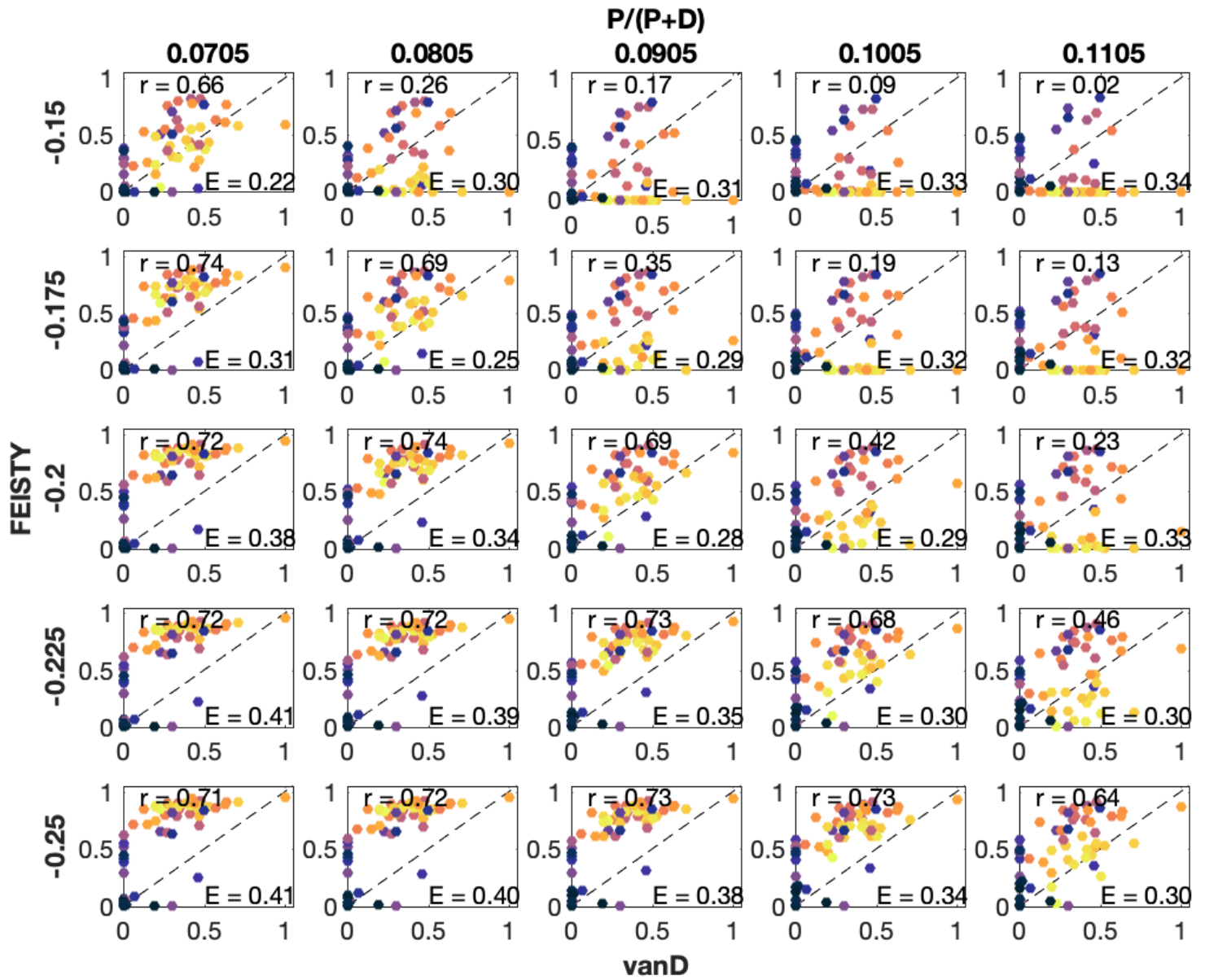

Figure A10. Comparison of FEISTY fraction of catch that is large pelagic fish with van Denderen model predictions by LME. The rows are different values of metabolic weight sensitivity $\left(b_{M}\right)$ and the columns are different values of metabolic temperature sensitivity $\left(k_{M}\right)$. Correlations (r) and root mean square error (E) are given. Dot color indicates mean pelagic (top $100 \mathrm{~m}$ ) temperature $\left({ }^{\circ} \mathrm{C}\right)$ of the LME. Dashed lines represent 1:1 (black), 2x difference (blue), 5x difference (red). $\theta_{\mathrm{A}}=0.5, \mathrm{a}_{\mathrm{C}}=20, \mathrm{a}_{\mathrm{E}}=70, \mathrm{~b}_{\mathrm{E}}=-0.20, \mathrm{~b}_{\mathrm{C}}=-0.25$. 
Temperature sensitivity of metabolism and benthic efficiency

The temperature sensitivity of metabolism, in combination with the benthic efficiency (??), was further tuned with the demersal catch and fraction of catch that was large pelagics rather than demersals. Lower temperature sensitivity and higher benthic efficiency was helpful in this vein, with catch being less sensitive to benthic efficiency (Figure A11). Higher values of $k_{M}$ led to underestimation of large pelagic catch in warm LMEs (Figure A12), while lower values of ?? led to underestimation of demersal catch in cold LMEs (Figure A13). The final parameters selected were $k_{M}=0.0855$ and $? ?=0.075$.
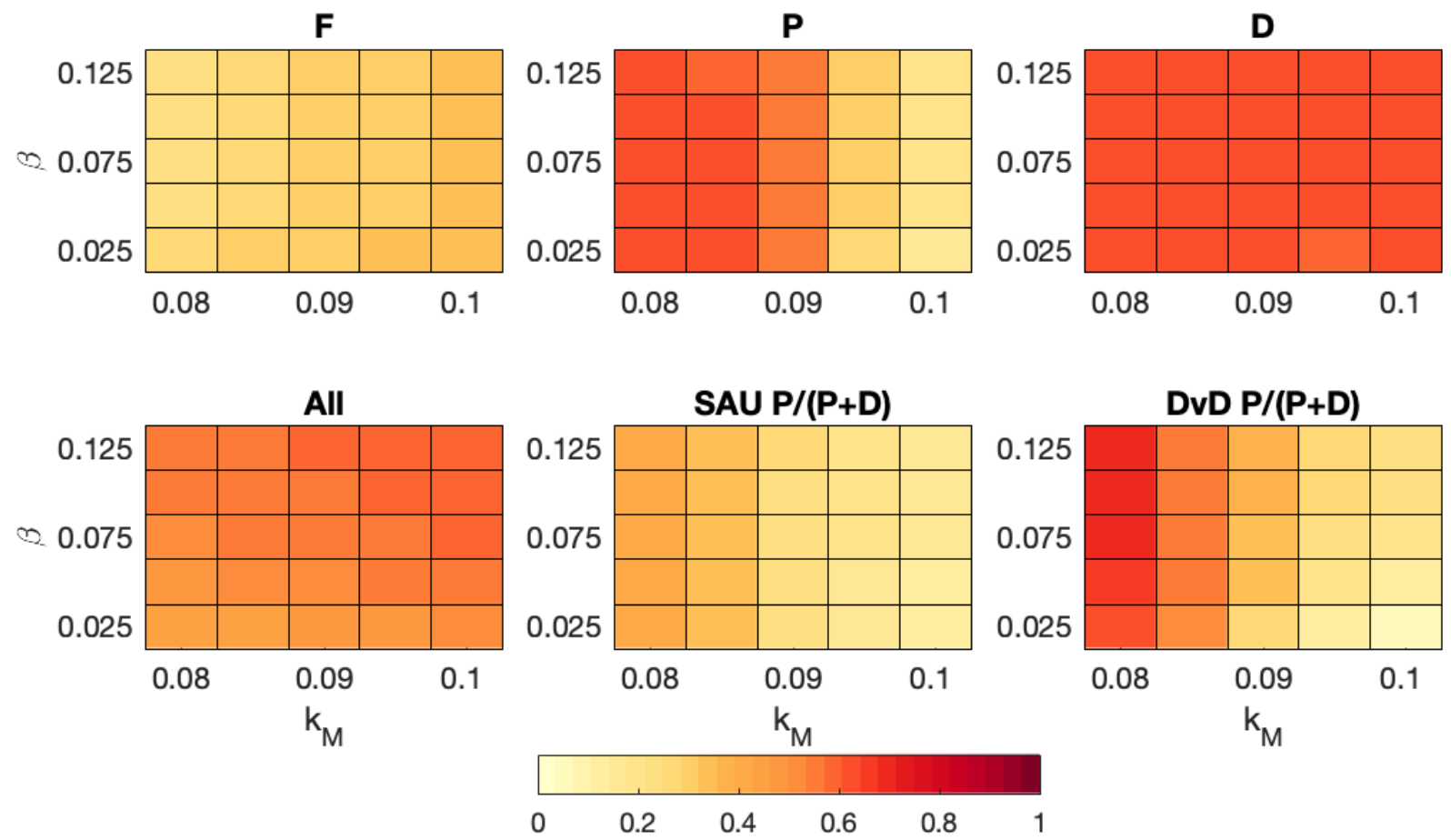

Figure A11. Correlation (r) with SAU catches and Van Denderen (vanD) fraction pelagics by LME. $\theta_{\mathrm{A}}=0.5, \mathrm{a}_{\mathrm{C}}=20, \mathrm{a}_{\mathrm{E}}=70, \mathrm{~b}_{\mathrm{E}}=-0.20, \mathrm{~b}_{\mathrm{C}}=-0.25, \mathrm{~b}_{\mathrm{M}}=-0.175$. 


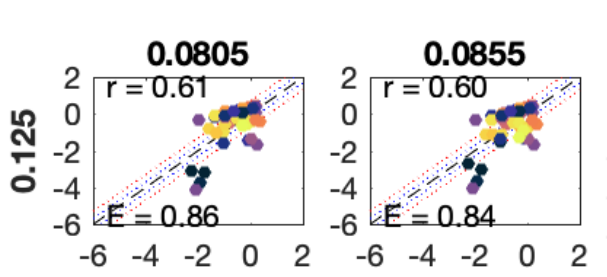

Large Pelagics
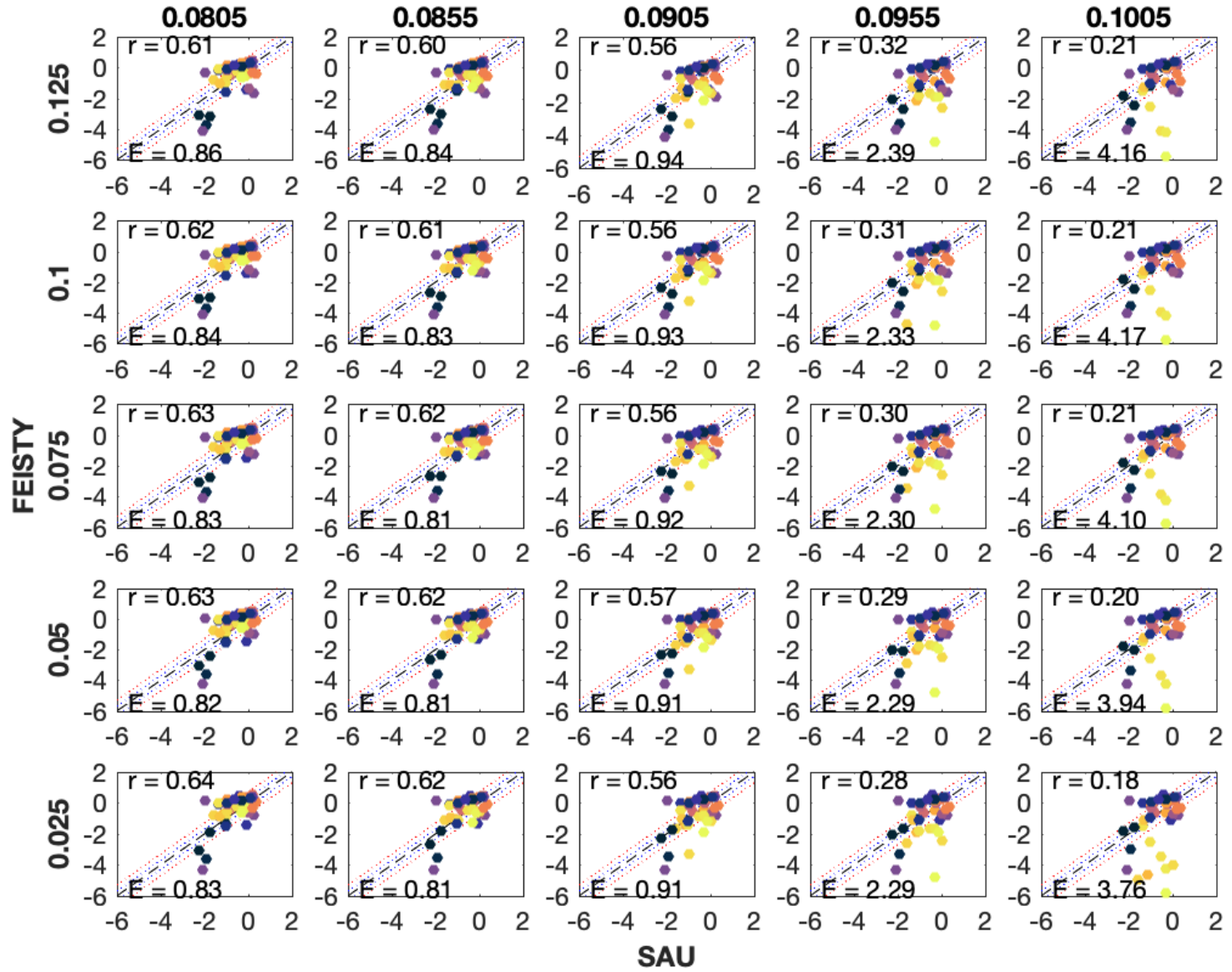

Figure A12. Comparison of FEISTY large pelagic fish catch with SAU catch by LME. The rows are different values of benthic efficiency (?) and the columns are different values of metabolic temperature sensitivity $\left(k_{M}\right)$. Correlations (r) and root mean square error (E) are given. Dot color indicates mean pelagic (top $100 \mathrm{~m}$ ) temperature $\left({ }^{\circ} \mathrm{C}\right.$ ) of the LME. Dashed lines represent 1:1 (black), $2 x$ difference (blue), $5 x$ difference (red). $\theta_{A}=0.5, a_{C}=20, a_{E}=70, b_{E}=-0.20, b_{C}=$ $-0.25, b_{M}=-0.175$. 

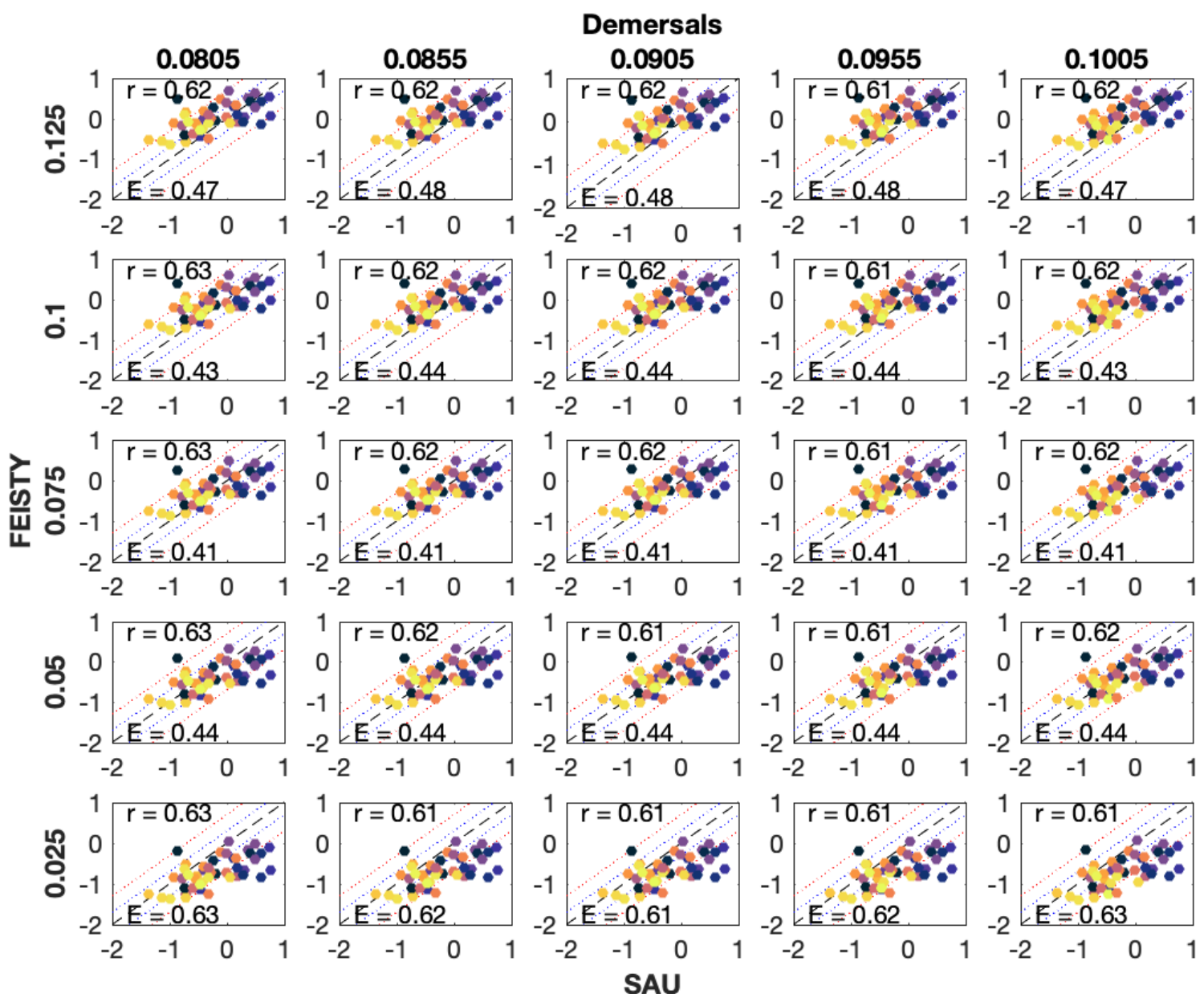

Figure A13. Comparison of FEISTY demersal fish catch with SAU catch by LME. The rows are different values of benthic efficiency (??) and the columns are different values of metabolic temperature sensitivity $\left(k_{M}\right)$. Correlations (r) and root mean square error (E) are given. Dot color indicates mean pelagic (top $100 \mathrm{~m}$ ) temperature $\left({ }^{\circ} \mathrm{C}\right.$ ) of the LME. Dashed lines represent 1:1 (black), $2 x$ difference (blue), $5 x$ difference (red). $\theta_{A}=0.5, a_{C}=20, a_{E}=70, b_{E}=-0.20, b_{C}=-$ $0.25, b_{\mathrm{M}}=-0.175$. 
Bottom-up drivers of global patterns of demersal, forage, and pelagic fishes Colleen M. Petrik ${ }^{1,}, \dagger$, Charles A. Stock ${ }^{2}$, Ken H. Andersen ${ }^{3}$, P. Daniël van Denderen 3 , James R. Watson 4

${ }^{1}$ Program in Atmospheric and Oceanic Sciences, Princeton University, Princeton, NJ 08540

2 NOAA, Geophysical Fluid Dynamics Laboratory, Princeton, NJ 08540

${ }^{3}$ Centre for Ocean Life, DTU Aqua, Technical University of Denmark, Lyngby, Denmark

${ }^{4}$ College of Earth, Ocean and Atmospheric Sciences, Oregon State University, Corvallis, OR 97331

*contact email: cpetrik@tamu.edu

†Present address: Department of Oceanography, Texas A\&M University, MS 3146, College Station, TX 77840

\section{HIGHLIGHTS}

- Global, spatially explicit, mechanistic model of forage, pelagic, and demersal fish

- Includes life cycle transitions, trophic interactions, and allometry of rates

- Captures cross-ecosystem differences in fish assemblages and productivity

- Dominance of large pelagics vs. demersals linked to the zooplankton to benthos ratio

- Can be coupled to earth system models for climate change projections 